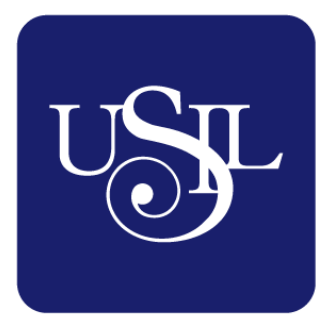

UNIVERSIDAD

SAN IGNACIO

DE LOYOLA

\author{
ESCUELA DE POSTGRADO \\ Maestría en Educación con mención en \\ Docencia en Educación Superior
}

\title{
ESTRATEGIA METODOLÓGICA PARA DESARROLLAR EL APRENDIZAJE AUTORREGULADO EN LOS ESTUDIANTES DEL PRIMER CICLO DE LA CARRERA DE ADMINISTRACIÓN EN UNA UNIVERSIDAD PRIVADA DE LIMA
}

Tesis para optar el grado de Maestro en Educación con mención en Docencia en Educación Superior

MÓNICA MARIBEL GARCÍA ÁLVAREZ

Asesor:

Félix Fernando Goñi Cruz

Lima - Perú

2020 


\section{Dedicatoria}

Dedico esta investigación a Dios, mi familia, mis amigos y a los maestros comprometidos con la excelencia en la educación, que he conocido a lo largo de mi vida, pues son ellos los que motivaron esta investigación y me inspiran a no desistir en esta hermosa vocación que es enseñar. Esta vocación nos escogió a nosotros. 


\section{Agradecimiento}

A Dios, porque siempre logra sorprenderme.

A mis padres, Zoila Álvarez y César Chillitupa, gracias por su amor incondicional, su ejemplo y dedicación.

A mis hermanos, Patricia, Sadith, Luis César y José Vicente, gracias por estar presentes, por sus oraciones, por procurar siempre lo mejor para mí y apoyarme en cada nuevo reto que emprendo.

A Luigi, gracias por su paciencia infinita, sus palabras de ánimo, sus oraciones, su compañía cada día y por enseñarme a disfrutar la vida con amor, esperenza y fe, más cerca a nuestro prójimo y a Dios.

A mis amigos, en especial a Frank De la Torre, gracias por hacer de esta maestría una experiencia extraordinaria. A mi asesor de tesis, el doctor Felix Goñi, por su valioso apoyo en todo el proceso de la maestría. 
Dedicatoria

Agradecimiento

Índice de tablas

Índice de figuras

Introducción

Planteamiento del problema de la investigación

Descripción del problema. $\quad 1$

Formulación del problema. $\quad 3$

Preguntas científicas. 3

Objetivos de la investigación 4

Objetivo principal. $\quad 4$

Objetivos específicos. 4

Enfoque, tipo y diseño de la investigación $\quad 4$

Métodos teóricos, empíricos y estadísticos de la investigación 5

Población, muestra, muestreo y unidad de análisis $\quad 8$

Técnicas e instrumentos para el trabajo de campo $\quad 8$

Categorías y subcategorías apriorísticas $\quad 9$

$\begin{array}{ll}\text { Justificación de la investigación } & 11\end{array}$

$\begin{array}{ll}\text { Capítulo I } & 12\end{array}$

Marco teórico, conceptual y referencial 12

$\begin{array}{ll}\text { Antecedentes de la investigación } & 12\end{array}$

$\begin{array}{lr}\text { Antecedentes internacionales. } & 12\end{array}$

$\begin{array}{ll}\text { Antecedentes nacionales. } & 14\end{array}$

Fundamentos teóricos del aprendizaje autorregulado 16 
La fundamentación de la propuesta de Vygotsky.

Zona de desarrollo próximo.

Aprendizaje autorregulado - El modelo de Pintrich.

Características de los estudiantes que autorregulan su aprendizaje.

La enseñanza del aprendizaje autorregulado.

Definiciones conceptuales de las subcategorías de aprendizaje autorregulado.

Cognición.

Motivación / Afecto.

Contexto del aprendizaje.

Fundamentos teóricos sobre la categoría estrategia metodológica

Importancia de las estrategias metodológicas.

Definiciones conceptuales de las subcategorías de estrategia metodológica.

Planificación estratégica.

Capacidad didáctica.

Recursos educativos.

Capítulo II

Diagnóstico o trabajo de campo

Características del campo de estudio

Análisis e interpretación de los hallazgos por técnicas e instrumentos

Presentación de resultados por técnicas de investigación

Encuesta realizada a los estudiantes.

Entrevista a los docentes.

Observación de clase. 
$\begin{array}{ll}\text { Capítulo III } & 66\end{array}$

Modelación y validación de la propuesta $\quad 66$

$\begin{array}{ll}\text { Propósito } & 66\end{array}$

$\begin{array}{ll}\text { Justificación } & 66\end{array}$

$\begin{array}{ll}\text { Fundamentación teórico-científica } & 67\end{array}$

$\begin{array}{ll}\text { Fundamentación socioeducativa. } & 67\end{array}$

$\begin{array}{lr}\text { Fundamentación psicopedagógica. } & 68\end{array}$

$\begin{array}{ll}\text { Fundamentación curricular. } & 75\end{array}$

$\begin{array}{ll}\text { Diseño de la propuesta } & 77\end{array}$

Desarrollo o implementación de la propuesta $\quad 81$

$\begin{array}{ll}\text { Validación de la propuesta } & 96\end{array}$

$\begin{array}{ll}\text { Conclusiones } & 100\end{array}$

$\begin{array}{ll}\text { Recomendaciones } & 102\end{array}$

$\begin{array}{ll}\text { Referencias } & 104\end{array}$

$\begin{array}{ll}\text { Anexos } & 115\end{array}$ 


\section{Índice de tablas}

Tabla 1. Resultados de la validación de instrumentos por juicio de expertos. 9

$\begin{array}{ll}\text { Tabla 2. Competencias, contenidos y capacidades. } & 77\end{array}$

Tabla 3. Especialistas de la validación de la propuesta. 96

Tabla 4. Validación interna por juicio de expertos. 96

Tabla 5. Validación externa por juicio de expertos. 98

$\begin{array}{ll}\text { Tabla 6. Escala de valoración. } & 98\end{array}$

Tabla 7. Validación interna y externa. 99 


\section{Índice de figuras}

Figura 1. Categorías emergentes y apriorísticas. $\quad 52$

Figura 2. Importancia de la educación emocional en docentes y estudiantes. 58

Figura 3. Desarrollo del pensamiento crítico y analítico. 59

Figura 4. Deficiencias en el desarrollo profesional de los docentes. $\quad 61$

Figura 5. Importancia de la investigación en el proceso de enseñanza-aprendizaje. $\quad 62$

Figura 6. Desarrollo de habilidades blandas en los docentes y estudiantes. 63

Figura 7. Previsión, planificación y activación. Adaptado de Panadero y Tapia (2014). 82

Figura 8. Análisis de la Tarea. Elaboración propia (2020). 83

Figura 9. Creencias Auto-motivadoras. Elaboración propia (2020). 85

Figura 10. Ejecución. Adaptado de Panadero y Tapia (2014). 86

Figura 11. Monitoreo. Elaboración propia (2020). $\quad 87$

Figura 12. Auto-control metacognitivo. Elaboración propia (2020). $\quad 88$

Figura 13. Auto-control motivacional. Elaboración propia (2020). $\quad 89$

Figura 14. Evaluación. Adaptado de Panadero y Tapia (2014). 90

Figura 15. Auto-reflexión. Elaboración propia (2020). 91

Figura 16. Auto-reacción. Elaboración propia (2020). 91

Figura 17. Validación interna y externa por jueces especialistas. 99 


\section{Resumen}

La investigación tiene por objetivo proponer una estrategia metodológica para desarrollar el aprendizaje autorregulado en estudiantes del primer ciclo de la carrera de Administración de una universidad privada de Lima. Esta investigación se circunscribe en los paradigmas sociocrítico e interpretativo, con un enfoque cualitativo, se clasifica como una investigación educacional de tipo aplicado, de diseño no experimental y de corte transversal descriptivo. La muestra estuvo conformada por 38 estudiantes y dos docentes. Las técnicas aplicadas fueron la entrevista, la encuesta y la observación, y como instrumentos, se usaron la guía de entrevista, el cuestionario y la guía de observación, con el fin de evaluar cómo se emplea el aprendizaje autorregulado. En el trabajo de campo, se identificó que la mayoría de los estudiantes y docentes desconocen las estrategias de autorregulación, además de otros problemas, como carencia de educación emocional, limitado desarrollo del pensamiento crítico y analítico, insuficiente desarrollo de habilidades blandas, escasa investigación en el proceso de enseñanza-aprendizaje y deficiente desarrollo profesional de los docentes. En la sistematización de las categorías apriorísticas se tomaron en cuenta las teorías de Pintrich para el aprendizaje autorregulado, y las teorías de Moya para la estrategia metodológica. Se concluye la investigación con la modelación de una estrategia metodológica, en la cual se propone que los docentes desarrollen las sesiones de clase incluyendo procesos y estrategias de autorregulación, en tres fases: planificación, ejecución y evaluación.

Palabras clave: estrategia metodológica, aprendizaje autorregulado, motivación, contexto del aprendizaje, docente mediador. 


\begin{abstract}
The research objective is to propose a methodological strategy to develop self-regulated learning in first-year students of Administration in a private university of Lima. This research is circumscribed to interpretative and socio-critic paradigms, it has a qualitative approach, it is classified as an educational research of applied type and its design is non-experimental, crosssectional and descriptive. The sample of study was 38 students and 2 teachers. The techniques applied were interview, survey and observation; and interview guides, questionnaires and observation guides were used as instruments to evaluate how self-regulated learning was used. During the fieldwork it was identified that the majority of students and teachers ignore selfregulation strategies, besides other problems as lack of emotional education, limited development of critic and analytic thinking, insufficient development of soft skills, scarcity of research about teaching-learning processes and deficient professional development of teachers. In the systematization of the aprioristic categories, theories of Pintrich were considered for selfregulated learning, and theories of Moya, for methodological strategy. The research concludes with the modeling of a methodological strategy in which it is proposed that the teachers develop class sessions including processes and strategies of self-regulation in three phases: planification, execution and evaluation.
\end{abstract}

Keywords: methodological strategy, self-regulated learning, motivation, learning context, mediator teacher. 


\section{Introducción}

\section{Planteamiento del problema de la investigación}

\section{Descripción del problema.}

En las universidades, se puede encontrar una gran diversidad de estudiantes, por ejemplo, aquellos que no cuentan con el apoyo necesario, por provenir de familias con poca o ninguna experiencia en la educación superior, lo cual favorece su deserción. También, están los estudiantes que trabajan y estudian, tanto en el pregrado como en los programas dirigidos a adultos con experiencia laboral, cuya mayoría persigue el sueño de una carrera universitaria que les permita mejorar su condición laboral o emprender un negocio propio. Estos grupos de estudiantes generalmente no cuentan con una autorregulación educativa, entendida como el uso de recursos propios para planear, controlar y analizar el cumplimiento de sus actividades académicas (Schunk y Zimmerman, 1995).

Nuestro sistema educativo ha permitido que muchos estudiantes ingresen a la universidad sin contar con conocimientos básicos ni con herramientas y técnicas necesarias para desarrollarse y tener éxito en sus estudios. Asimismo, muchos de ellos desconocen sus emociones y sus estrategias de aprendizaje, y no han desarrollado la capacidad de cuestionar, planificar, analizar y evaluar sus acciones en el proceso de enseñanza-aprendizaje, o en resumen, no han logrado "gobernarse a sí mismos” (Monereo, 2001) para lograr su desarrollo personal y profesional.

Además, también se observa el fenómeno de la masificación de universidades con fines de lucro, cuya misión suele estar centrada en el desarrollo de competencias y habilidades demandadas por el mercado laboral, que sin embargo deja de lado aspectos muy importantes, como la formación de valores ciudadanos, pensamiento crítico, creatividad e innovación. Si esta realidad se mantiene, nos estaremos alejando cada vez más de la razón de ser de las 
instituciones universitarias, que es educar a las personas, formarlas integralmente con conocimientos, habilidades, valores, creatividad y vocación de servicio (Portocarrero, 2014).

En las universidades, esta tendencia originada principalmente por iniciativa de la inversión privada ha sido calificada como una de menor calidad y acusada de ser la responsable de la incorporación de estudiantes con menor capacidad cognitiva (Yamada, Castro, Bacigalupo, y Velarde, 2013), lo cual ha producido, en consecuencia, un mayor nivel de subempleo en los egresados (Lavado, Martínez y Yamada, 2014).

Se necesita una nueva cultura del aprendizaje (Monereo y Pozo 2001), que incluya la creación de un sistema formativo en el que el estudiante sea el protagonista regulador de su propio proceso de aprendizaje, asistido por la mediación del maestro y la cooperación de otros profesionales. Lograr un aprendizaje de calidad será posible si se basa en el estudiante y su manera de percibir y gestionar su proceso autorregulado de aprender a aprender para desarrollarse integralmente (Biggs, 2005).

De acuerdo con Reimers (2015), la buena educación considera tres dimensiones: capacidades cognitivas, las cuales incluyen conocimiento básico, discernimiento crítico y pensar de manera creativa e innovadora; capacidad de conocerse y gobernarse, que implica la reflexión de la propia experiencia, regulación de emociones, determinación de metas, perseverancia para alcanzarlas y disposición ante la vida; y competencias de relacionamiento, que implica habilidades de liderazgo y habilidades sociales. También, al hablar de América Latina, Reimers señala que las currículas están muy orientadas a los niveles más básicos de la dimensión cognitiva (conocimiento), y afirma además que si bien las mejores currículas consideran la capacidad de procesar conocimientos, no incluyen innovación y creatividad, ni muestran evidencias acerca de las competencias sociales y de autorregulación.

En vista de la realidad en nuestra región, es necesario que se trabaje para lograr un verdadero cambio en el sistema educativo, en beneficio de los estudiantes, de los docentes y de 
la sociedad en general. Es tiempo de que los estudiantes reciban una buena educación que considere las dimensiones antes mencionadas, para formarse de manera integral, como individuos capaces, responsables y dispuestos a ser protagonistas en su sociedad. Estamos hablando de su formación para la vida, de aprender a reconocerse, valorarse y gobernarse a sí mismos, de ser capaces de gestionar y autorregular su propio aprendizaje y de desarrollar capacidades y competencias que la sociedad necesita en este momento.

\section{Formulación del problema.}

¿Cómo desarrollar el aprendizaje autorregulado en los estudiantes del primer ciclo de la carrera de Administración en una universidad privada de Lima?

De este problema general, se derivan los problemas específicos que se mencionan a continuación:

\section{Preguntas científicas.}

¿Cuál es el estado actual del desarrollo del aprendizaje autorregulado en los estudiantes del primer ciclo de la carrera de Administración en una universidad privada de Lima?

¿Cuáles son los fundamentos teóricos y metodológicos que sustentan la estrategia metodológica para desarrollar el aprendizaje autorregulado en los estudiantes del primer ciclo de la carrera de Administración en una universidad privada de Lima?

¿Qué criterios teóricos y metodológicos se deben tener en cuenta en la modelación de una estrategia metodológica para desarrollar el aprendizaje autorregulado en los estudiantes del primer ciclo de la carrera de Administración en una universidad privada de Lima?

¿Cómo validar la propuesta de estrategia metodológica para desarrollar el aprendizaje autorregulado en los estudiantes del primer ciclo de la carrera de Administración en una universidad privada de Lima? 


\section{Objetivos de la investigación}

\section{Objetivo principal.}

Proponer una estrategia metodológica para desarrollar el aprendizaje autorregulado en los estudiantes del primer ciclo de la carrera de Administración en una universidad privada de Lima.

\section{Objetivos específicos.}

Diagnosticar el estado actual del desarrollo del aprendizaje autorregulado en los estudiantes del primer ciclo de la carrera de Administración en una universidad privada de Lima.

Fundamentar teórica y metodológicamente la estrategia metodológica para desarrollar el aprendizaje autorregulado en los estudiantes del primer ciclo de la carrera de Administración en una universidad privada de Lima.

Determinar los criterios teóricos y metodológicos que se deben tener en cuenta en la modelación de una estrategia metodológica para desarrollar el aprendizaje autorregulado en los estudiantes del primer ciclo de la carrera de Administración en una universidad privada de Lima.

Validar por juicio de expertos la propuesta de estrategia metodológica para desarrollar el aprendizaje autorregulado en los estudiantes del primer ciclo de la carrera de Administración en una universidad privada de Lima.

\section{Enfoque, tipo y diseño de la investigación}

La investigación se circunscribe en los paradigmas sociocrítico e interpretativo. Según Rodríguez (2005), el paradigma sociocrítico se caracteriza por “su orientación hacia la solución de problemas prácticos, su marcado acento en el cambio social y el carácter participativo de los procesos de investigación" (p. 15); y el interpretativo, por "privilegiar como objeto de estudio al mundo subjetivo, abordar los hechos y fenómenos en sus ambientes naturales de 
manifestación y considerar al proceso del conocimiento como un proceso comprensivo y holístico" (p. 13).

Asimismo, la investigación tiene un enfoque cualitativo de carácter interpretativo. De acuerdo con Cook y Reichardt (1986), “del método cualitativo se afirma que postula una concepción global fenomenológica, inductiva, estructuralista, subjetiva, orientada al proceso y propia de la antropología social...” (p. 28).

De acuerdo con su finalidad, se clasifica como una investigación educacional y de tipo aplicado. Según Abero, Berardi, Capocasale, García y Rojas (2015), la investigación educacional:

Es un proceso de indagación de carácter científico y por lo tanto sistemático, que tiene claramente definido un problema de investigación. Este tiene que plantearse en torno a preguntas definidoras de objetivos consistentes con un marco teórico disciplinar (transversalmente vinculado a un paradigma o enfoque teórico desde la propia Investigación Educativa). (p. 40).

Además, Padrón (2006) señala que: “La investigación aplicada constituye un enlace importante entre ciencia (o Academia) y sociedad. Es el punto en el que los conocimientos son revertidos a las áreas de demanda ubicada en el entorno" (p. 5).

El diseño que se empleó en esta investigación es no experimental, de corte transversal descriptivo; al respecto, Martínez y Rodríguez (2005) señalan que las investigaciones descriptivas "se limitan a describir determinadas características del grupo de elementos estudiados, sin realizar comparaciones con otros grupos, se circunscriben a examinar una población definida, describiéndola a través de la medición de diversas características” (p.14).

\section{Métodos teóricos, empíricos y estadísticos de la investigación}

Los métodos teóricos que se emplearon durante la investigación fueron los siguientes: analíticosintético, histórico-lógico, inductivo-deductivo, análisis documental y modelación. 
De acuerdo con Rodríguez y Pérez (2017), el análisis es un procedimiento lógico, mediante el cual es posible disgregar mentalmente el todo en sus componentes, con el fin de observarlos; mientras que la síntesis es lo inverso, y se trata de unir mentalmente los componentes del todo, los cuales han sido analizados, para revelar que existen relaciones y propiedades entre las partes de la realidad. Este método fue utilizado durante el proceso de análisis de los documentos y los resultados que se obtuvieron luego de la aplicación de los instrumentos; ello permitió una visión más profunda de las ideas, conceptos y estrategias que se fueron desarrollando en la fundamentación teórica y en la modelación de la propuesta.

Rodríguez y Pérez (2017) indican, acerca del método histórico-lógico, lo siguiente: “Lo histórico se refiere al estudio del objeto en su trayectoria real a través de su historia, con sus condicionamientos sociales, económicos y políticos en los diferentes periodos. Lo lógico interpreta lo histórico e infiere conclusiones" (p. 189). En esta investigación, este método fue empleado para determinar los antecedentes históricos que se relacionan con el aprendizaje autorregulado y las estrategias metodológicas que se han propuesto y diseñado hasta la fecha.

Según Rodríguez y Pérez (2017), en el método inductivo-deductivo, la inducción y la deducción se complementan, la inducción permite generalizar a partir de hechos comunes en varios casos y de tales generalizaciones se logran deducir conclusiones lógicas, que gracias a la inducción se convierten en generalizaciones reforzadas, por lo que podemos afirmar que constituyen una unidad dialéctica. Este método se utilizó para determinar las inferencias lógicas, fijando un sistema de planteamientos teóricos de carácter concluyente, con el propósito de realizar la teorización de las categorías apriorísticas y subcategorías, y de optimizar las bases epistemológica y metodológica de esta investigación.

El método de análisis documental, de acuerdo con Castillo (2005), "es un conjunto de operaciones encaminadas a representar un documento y su contenido bajo una forma diferente de su forma original, con la finalidad posibilitar su recuperación posterior e identificarlo" ( $\mathrm{p}$. 
1). En la investigación, este método fue útil para consultar y analizar los documentos y literatura científica que sirvieron como base para la fundamentación y el diseño de la propuesta metodológica.

Respecto al método de la modelación, Rodríguez y Pérez (2017) explican que en él "se crean modelos para investigar la realidad. El modelo debe tener cierta analogía estructural y funcional con el objeto de investigación" (p. 192). Este método fue empleado en la propuesta metodológica, de acuerdo a los fundamentos teóricos y metodológicos, que se materializó en el diseño de una estrategia metodológica para el desarrollo del aprendizaje autorregulado de los estudiantes.

\section{Métodos empíricos.}

En relación con los métodos empíricos, según Rodríguez y Pérez (2017), “Empírico significa referente a la experiencia. Se refiere al uso de los sentidos, tanto en la observación de los objetos y fenómenos como en la experimentación o manipulación física de ellos” (p. 182). Los métodos empíricos empleados en la investigación fueron: observación, encuesta y entrevista.

El método de la observación, según Cerezal y Fiallo (2005), “es una percepción directa, atenta, racional, planificada, de los fenómenos relacionados con los objetivos de la investigación, en sus condiciones naturales y habituales, con vista a encontrar una explicación del fenómeno en estudio" (p. 63).

En cuanto al método de la entrevista, Cerezal y Fiallo (2005) señalan que "los objetivos principales de la entrevista son obtener información confiable sobre hechos y opiniones, además de enriquecer, completar o constatar la información obtenida por el empleo de otros métodos de investigación" (p. 106).

Asimismo, el método de la encuesta, de acuerdo con Cerezal y Fiallo (2005), se aplica de manera muy sencilla y permite obtener gran cantidad de información en poco tiempo, teniendo en cuenta que es posible contar con una muestra amplia de la población. 


\section{Métodos matemático-estadísticos.}

De acuerdo con Reynaga (1996), el método estadístico incluye la recolección de datos y su procesamiento, presentación, descripción y análisis. En esta investigación se aplicaron métodos matemático-estadísticos para el procesamiento y sistematización de la información recabada de los cuestionarios en el trabajo de campo; para ello, se emplearon como herramientas las hojas de cálculo de Microsoft Excel y el paquete estadístico SPSS.

\section{Población, muestra, muestreo y unidad de análisis}

La población estuvo conformada por todos los estudiantes y profesores del primer ciclo de la carrera de Administración de una universidad privada de Lima, de los cuales se consideró una muestra inicial de 38 estudiantes y dos profesores.

El muestreo fue de tipo no probabilístico, porque la elección de los estudiantes y docentes para las entrevistas de la investigación fue de acuerdo al criterio del investigador.

Las unidades de análisis se detallan de la siguiente manera: estudiantes del primer ciclo de la carrera de Administración de una universidad privada, docentes de la carrera de Administración, documentos y literatura especializada.

\section{Técnicas e instrumentos para el trabajo de campo}

En el trabajo de campo se emplearon las técnicas de observación, encuesta y entrevista.

Se observaron las sesiones de clase de estudiantes del primer ciclo, con la finalidad de comprobar su nivel de aprendizaje autorregulado y la forma en que los docentes aplican este tipo de aprendizaje. El instrumento que se empleó fue una guía de observación de clase de quince ítems, elaborados a partir de trece indicadores.

Asimismo, se aplicó una encuesta a los estudiantes, con el fin de conocer y evaluar sus niveles de autorregulación en sus procesos de aprendizaje y las estrategias que los docentes emplean. Para ello, se elaboró un cuestionario de catorce preguntas con opciones múltiples de respuesta, a partir de trece indicadores, 
También se realizaron entrevistas a los docentes, las cuales permitieron conocer y evaluar sus niveles de conocimientos en temas relacionados a la autorregulación del aprendizaje y al uso de estrategias en las sesiones de clases. En este caso, se elaboró una guía de entrevista con once preguntas, a partir de trece indicadores.

\section{Validación de los instrumentos.}

Se recurrió al método de juicio de expertos para validar los instrumentos de recolección de datos. Para ello, se remitieron a los expertos los instrumentos de recolección de datos, la matriz de categorización y fichas de validación, para su evaluación y observaciones acerca de la relevancia, pertinencia y construcción gramatical de los items de cada instrumento. A continuación, se detalla el resultado de la validación de instrumentos.

\section{Tabla 1}

Resultados de la validación de instrumentos por juicio de expertos

Opinión sobre instrumentos

\begin{tabular}{lcccc}
\hline \multicolumn{1}{c}{ Expertos } & Especialidad & $\begin{array}{c}\text { Guía de } \\
\text { observación }\end{array}$ & $\begin{array}{c}\text { Guía de } \\
\text { entrevista }\end{array}$ & Cuestionario \\
\hline Mg. Hernán Flores Valdiviezo & Metodológica & Aplicable & Aplicable & Aplicable \\
Dr. José Muñoz Salazar & Metodológica & Aplicable & Aplicable & Aplicable \\
Mg. María Teresa Herrera Montoya & Temática & Aplicable & Aplicable & Aplicable \\
\hline
\end{tabular}

Fuente: Elaboración propia (2020).

\section{Categorías y subcategorías apriorísticas}

Seguidamente, se exponen las categorías y subcategorías apriorísticas:

\section{Categoría problema: aprendizaje autorregulado.}

Según Pintrich (2000), la autorregulación es un proceso activo, mediante el cual los estudiantes establecen metas para sus aprendizajes y logran supervisar, regular y controlar su cognición, motivación y conducta, dirigidos por sus metas y por las características de su entorno.

\section{Subcategorías.}

En esta categoría se consideraron las subcategorías: cognición, motivación y contexto del aprendizaje. La cognición es la capacidad que permite el procesamiento de la información; entre 
las estrategias cognitivas tenemos las estrategias de elaboración, organización, repaso y pensamiento crítico (Pintrich, 2000). La motivación es el proceso que nos orienta hacia nuestros objetivos o metas; la activación y planificación motivacional implican adoptar metas y activar creencias motivacionales (Pintrich, 2000). El contexto consiste en todas las características de la clase, las cuales incluyen clima emocional, percepción de las reglas en el aula, métodos de enseñanza, características del ambiente físico de aprendizaje, percepciones de la tarea (análisis, control y evaluación), características de las evaluaciones y demandas de los docentes (Pintrich, 2000).

\section{Categoría propuesta: estrategia metodológica.}

De acuerdo con Moya (2018), la estrategia metodológica es la planificación de una serie de acciones a corto, mediano y largo plazo, que permite modificar la dirección del proceso de enseñanza-aprendizaje, teniendo como base los procedimientos, métodos y recursos didácticos, con el fin de alcanzar los objetivos concretos en un periodo de tiempo determinado. Asimismo, las acciones involucran capacidades didácticas, intencionalidad, resolución de problemas, definición de conceptos y recopilación de información valiosa.

\section{Subcategorías.}

Se consideraron las subcategorías planificación estratégica, capacidad didáctica y recursos educativos. La planificación estratégica es una serie de procesos anticipados, generalizados y sistemáticos que determinan acciones encaminadas a desarrollar equilibrada y coherentemente los procesos de enseñanza-aprendizaje, y fija objetivos, políticas, propósitos y estrategias rectoras que atienden las necesidades y demandas de los estudiantes (Moya, 2018).

La capacidad didáctica es definida como la destreza de los docentes para desarrollar contenidos de manera comprensible por los estudiantes y para organizarlos de forma adecuada como parte de una guía integral, teniendo en cuenta el contexto y las dificultades de aprendizaje y problemas que podrían presentarse (Moya, 2018). 
Los recursos educativos son todos aquellos instrumentos de soporte, implementos, materiales y apoyos didácticos (libros, guías, materiales impresos y no impresos, videos, esquemas, diapositivas, herramientas digitales, imágenes, etc.) seleccionados con el propósito de lograr una mayor vinculación con los estudiantes y facilitar su aprendizaje (Moya, 2018).

\section{Justificación de la investigación}

\section{Teórica.}

La investigación tiene como finalidad proponer una solución a un problema relacionado con la práctica pedagógica, que es el aprendizaje autorregulado de los estudiantes. Los referentes teóricos y metodológicos sobre las categorías apriorísticas fueron sistematizadas desde las contribuciones de Vigotsky, Pintrich, Zimmerman y Moya. Además, se ha desarrollado un modelo que puede servir como referencia para futuros estudios sobre la autorregulación, teniendo en cuenta los limitados avances en la región respecto al tema.

\section{Metodológica.}

La metodología que se propone en esta investigación tiene como objetivo el desarrollo del aprendizaje autorregulado en los estudiantes; así, se espera que sea de utilidad en la práctica pedagógica de los docentes. Además, los instrumentos usados en la investigación cuentan con la validación mediante juicio de expertos, lo cual posibilita su aplicación en otros estudios.

\section{Práctica.}

El diseño de la propuesta es creativo, funcional y está enfocado en mejorar la práctica pedagógica mediante el uso de estrategias de autorregulación en las sesiones de clase, lo cual permitirá que los estudiantes se conviertan en protagonistas de su aprendizaje, y los docentes, en mediadores. Es importante resaltar que el aprendizaje autorregulado está relacionado con aprender a aprender, aprender de manera permanente y otros conceptos y prácticas necesarias en el desarrollo integral de estudiantes y docentes, lo cual refuerza la relevancia de la propuesta. 


\section{Capítulo I}

\section{Marco teórico, conceptual y referencial}

\section{Antecedentes de la investigación}

\section{Antecedentes internacionales.}

Daura (2017) elaboró un artículo en el que identifica las estrategias didácticas y personalizadas que los profesores utilizan en el aula y que favorecen el desarrollo de la autorregulación de sus estudiantes. El trabajo tuvo un diseño de investigación mixto, predominantemente cualitativo, y se aplicó el método inductivo-deductivo. Se conformó una muestra compuesta por 75 docentes, cuyas clases fueron observadas de manera no participativa. Se llegó a concluir lo siguiente: la autorregulación es una capacidad que todos los estudiantes universitarios deben desarrollar con el fin de ajustarse a las exigencias de la educación superior y de su futuro profesional, y es una capacidad que puede desarrollarse, para lo cual se exige un rol activo de los docentes y estudiantes en el proceso de enseñanza-aprendizaje. Ante esto, la propuesta fue personalizar la educación mediante estrategias que contribuyeran al desarrollo de las potencialidades de los estudiantes, para que fueran capaces de aprender a aprender a lo largo de toda su vida.

González-Moreno (2017) realizó una investigación cuyo objetivo fue la autorregulación del aprendizaje de conceptos científicos. La muestra fue de 28 estudiantes universitarios. El método consistió en estudiar la autorregulación en actividades de aprendizaje, mediante la medición de las líneas de base de cada estudiante, la implementación de talleres teóricoprácticos y las evaluaciones. Se concluyó que la enseñanza que se orienta y es intencionada tiene efectos positivos en la autorregulación del aprendizaje de conceptos científicos. Además, la comunicación y la interacción de docentes y estudiantes beneficiaron el proceso de enseñanza-aprendizaje y permitieron que los estudiantes clarificaran sus ideas y las 
reelaboraran. Finalmente, los estudiantes consiguieron una relación positiva, activa y creativa con el aprendizaje, dentro y fuera del aula.

Cruz, Cortés y Álvarez (2017) realizaron una investigación aplicada sobre el modelo de autorregulación de Paul R. Pintrich, adaptado por Virginia Aguilar Davis y su impacto en el aprendizaje matemático. La muestra estuvo integrada por 75 estudiantes de primer grado de la licenciatura de Educación preescolar. La investigación fue de tipo aplicado, con alcance descriptivo y enfoque mixto. En la fase de diagnóstico se aplicaron encuestas y el instrumento utilizado fue una escala Likert de autorreporte. En la fase de investigación, el propósito fue la identificación de las escalas y subescalas de la fase de diagnóstico. Al finalizar, también se realizaron encuestas para evaluar el impacto de las estrategias implementadas. Se concluyó que el estudio del modelo educativo y del aprendizaje matemático ayuda a identificar la importancia de los esquemas para clasificar y analizar los diferentes procesos involucrados en el aprendizaje autorregulado, con el fin de mejorar las decisiones que se toman en la construcción de aprendizajes matemáticos. Además, la investigación demostró que los estudiantes de Educación que autorregulan sus intereses educativos se encuentran en mejores condiciones de enseñar y promover el aprendizaje matemático en sus futuros estudiantes.

Díaz, Pérez, González-Pienda y Núñez (2017) realizaron una investigación con el objetivo de estudiar el efecto de una preparación en aprendizaje autorregulado, mediante la plataforma virtual Moodle con y sin el apoyo de los docentes, en la autorregulación del aprendizaje y la autoeficacia autorreguladora. El trabajo fue cuasi-experimental y los instrumentos de medida fueron un inventario de auto eficacia en autorregulación del aprendizaje, un inventario de procesos de autorregulación del aprendizaje y una escala sobre el manejo de estrategias de autorregulación del aprendizaje. Participaron 118 estudiantes del primer año de tres carreras universitarias. Se concluyó que la preparación mediante el uso de la plataforma virtual Moodle tuvo un efecto favorable en el proceso de autorregulación del 
aprendizaje. Además, se evidenció que los estudiantes optimizaban su autorregulación si la instrucción se orientaba hacia ese objetivo. Aunque los protocolos determinados por el docente tuvieron ciertas restricciones, se pudo comprobar que la instrucción para la autorregulación ejecutada con su apoyo mejoró la autoeficacia autorreguladora del estudiante, de allí la importancia de la relación profesor-estudiante y lo ventajosas que resultaron las plataformas virtuales con el apoyo de los docentes.

Villanueva Espinosa (2016) realizó un estudio de enfoque interpretativo, para identificar cómo se maneja la autorregulación en los estudiantes, a partir de la indagación sobre los motivos y creencias que se encuentras detrás de sus acciones. En su tesis, se realizaron entrevistas semipresenciales a ocho estudiantes, la mayoría de los cuales se encontraban en la etapa final de sus estudios universitarios. También, se utilizaron estrategias inductivas y deductivas, y se incorporaron variantes a través del uso de las TIC. Los resultados evidenciaron las diferentes ideas de los estudiantes respecto a su aprendizaje y las diversas estrategias de autorregulación que emplearon. Este estudio permitió confirmar que la autorregulación debe tener en cuenta que existen contextos determinados y muy diversos que definen su actividad. Asimismo, el estudio se enfocó en la comprensión del concepto individual y particular de la autorregulación, la cual no puede ser generalizada en todos los estudiantes de nivel universitario.

\section{Antecedentes nacionales.}

Agüero (2018) hizo una investigación para analizar la relación existente entre las habilidades académicas y la autorregulación del aprendizaje. La muestra fue de 120 estudiantes del primer ciclo, el estudio fue cuantitativo y la problemática de la investigación fue analizada en función de variables como estrategias motivacionales de aprendizaje y metas de estudio. Se planteó la investigación correlacional con un diseño transversal, recolectando los datos para las variables de estudio en un solo tiempo. Los procedimientos utilizados fueron los autoinformes de los estudiantes, que tuvieron como base las fichas técnicas de habilidades académicas y 
autorregulación del aprendizaje. Se concluyó que existe relación entre las habilidades académicas, la autorregulación del aprendizaje, el esfuerzo diario en la realización de la tarea de la autorregulación del aprendizaje y el control y verificación del aprendizaje en la autorregulación. Ante estos resultados, se recomendó promover investigaciones sobre las habilidades académicas y la autorregulación del aprendizaje, diseñar y aplicar programas de desarrollo de las habilidades académicas relacionadas a la motivación, técnicas de estudio y aprendizaje, y sensibilizar a los estudiantes respecto a los beneficios de un programa de autorregulación.

Vicuña y Sanjinés (2018) realizaron una investigación enfocada en verificar el vínculo entre las habilidades de pensamiento y el aprendizaje autorregulado, en estudiantes de la facultad de Educación de una universidad pública de Lima, a través de una muestra de 284 estudiantes. La investigación tuvo un diseño no experimental de tipo correlacional. A los estudiantes de la muestra se les aplicó el cuestionario de habilidades de pensamiento de Alberto Acevedo y Marcela Carrera y el cuestionario de autorregulación para el aprendizaje de Juan Carlos Torre. Se concluyó que las habilidades de pensamiento se relacionan de forma directa y significativa con el aprendizaje autorregulado en los estudiantes, y que las dimensiones de las habilidades de pensamiento están estrechamente vinculadas con las dimensiones de aprendizaje autorregulado.

Camargo (2018), en su investigación, tuvo como objetivo establecer la relación entre el aprendizaje autorregulado y las estrategias de aprendizaje. La muestra fue conformada por 105 estudiantes del tercer año de una facultad de Educación de una universidad de Lima. El estudio fue descriptivo correlacional y los instrumentos que se emplearon fueron escalas de estrategias de aprendizaje y un inventario de autorregulación de aprendizaje, ambos instrumentos válidos y confiables en el Perú. En la comprobación de las hipótesis, se utilizó el coeficiente Pearson, y en el análisis de concordancia de los datos a la curva normal, se empleó la prueba de 
Kolmogorov Smirnov. Los resultados del estudio determinaron una correlación positiva entre el aprendizaje autorregulado y las estrategias de aprendizaje.

Vargas Díaz (2017) elaboró una tesis cuyo objetivo fue determinar la relación que existe entre el aprendizaje autorregulado y los procesos cognitivos. La investigación se realizó con una muestra de 97 estudiantes del primer ciclo de la facultad de Ciencias Económicas y Administrativas de una universidad de la ciudad de Huacho. El diseño de la investigación fue no experimental de tipo descriptivo correlacional, y los instrumentos fueron cuestionarios elaborados con la escala Likert. Se concluyó que el aprendizaje autorregulado presenta una correlación positiva con el desarrollo de procesos cognitivos de memoria, percepción y atención.

Alegre (2014) realizó un estudio para observar la relación entre la autoeficacia académica, la autorregulación del aprendizaje y el rendimiento académico en estudiantes universitarios. Se evaluó a 284 estudiantes, mediante el Cuestionario de Autoeficacia Académica General, validado por Torre (2006). El método correspondió a una investigación sustantiva de diseño correlacional. La muestra se obtuvo por un procedimiento no probabilístico e incidental. Las conclusiones de la investigación mostraron correlaciones positivas y significativas entre autorregulación y rendimiento académico, autoeficacia académica y rendimiento académico, y autorregulación y autoeficacia.

\section{Fundamentos teóricos del aprendizaje autorregulado}

Si bien la autorregulación es un proceso complejo de definir (Boekaters, Pintrich y Zeidner, 2000), existen diferentes aproximaciones que la explican, entre ellos, el modelo de Zimmerman (2000), quien retoma la propuesta de Bandura (1986) y propone que la autorregulación se refiere a la autogeneración de pensamientos, sentimientos y acciones que son planificados y adaptados para la consecución de metas personales, que ocurre en la interacción de tres ámbitos: 
personal, comportamental y ambiental, y que se estructura en tres fases cíclicas: planificación, desempeño y reflexión. Pintrich (2000) introduce una cuarta fase de monitorización.

Según Pintrich (2000), la autorregulación es un proceso activo mediante el cual los estudiantes establecen metas para sus aprendizajes y logran supervisar, regular y controlar su cognición, motivación y conducta, dirigidos por sus metas y por las características de su entorno.

Además, de acuerdo con Boekaerts, Pintrich y Zeidner (2000) y Pintrich (2004), el aprendizaje autorregulado considera factores afectivos, motivacionales y cognitivos, pero también incluye componentes sociales y contextuales. Entonces, el aprendizaje autorregulado también se define como un proceso de pensamientos, sentimientos y acciones sistémicos, autogenerados y orientados al logro de metas propias, en el que los estudiantes tienen un rol activo.

Chaves, Trujillo y López (2016) señalan: “...la persona realiza acciones de observación sobre su actuación en la autorregulación y en el aprendizaje, también observa su motivación, su eficacia y los logros que alcanza con sus acciones" (p. 68). Como se puede ver, se trata de un proceso que implica la observación sobre las propias acciones y motivaciones orientadas al logro de metas, y que incorpora además el concepto de eficacia.

Aunque la perspectiva del aprendizaje autorregulado ha tenido una gran dependencia de las teorías tradicionales sobre la cognición y la motivación, se debe reconocer que su aporte es mucho más amplio y dinámico, pues ha permitido una mayor comprensión de los procesos del aprendizaje y sus diferencias contextuales (Norabuena, 2011).

Según Zimmerman y Schunk (1997), para que el aprendizaje se pueda considerar como autorregulado, se deben tener en cuenta ciertas características, tales como: el empleo de estrategias de aprendizaje, la autoeficacia en la ejecución y el compromiso para el logro de las 
metas. El fin primordial de la autorregulación es que los estudiantes mejoren su aprendizaje y que procuren la calidad del mismo, y que ello dependa de su voluntad.

En relación con el aprendizaje autorregulado, Chaves et al. (2016) explican: “...es un proceso cíclico en el que la persona determina sus objetivos de aprendizaje, planifica las estrategias correspondientes a estos objetivos y pone en práctica las estrategias planificadas" (p. 68). Nuevamente, se observa que se trata de un proceso o una serie de pasos dirigidos, desde el uso de estrategias y la planificación, hasta el logro de objetivos.

El aprendizaje autorregulado también se define como una manera de hacer uso de los recursos que se poseen, para planificar, controlar, reflexionar y evaluar la propia ejecución en las diversas actividades de aprendizaje (Schunk y Zimmerman, 1995).

Por ello, la autorregulación del aprendizaje ha adquirido mayor relevancia en la literatura especializada, teniendo en cuenta los importantes aportes de las investigaciones acerca de cómo los estudiantes tienen una participación más activa en su proceso de aprendizaje cuando son capaces de monitorear, regular y evaluar sus procesos, para alcanzar sus metas académicas (Schunk y Mullen, 2012).

Además, la autorregulación del aprendizaje está relacionada con formas de aprendizaje autónomo y eficaz, que involucran el desempeño estratégico, el proceso de metacognición y la motivación intrínseca (Perry, 2002). Del mismo modo, se puede afirmar que el aprendizaje autorregulado influye directamente en la motivación y las emociones del estudiante. Así, si el estudiante cuenta con los métodos y las herramientas para aprender, su rendimiento académico mejorará, y como consecuencia, se reforzarán sus emociones positivas y su motivación.

Monterroso (2015) menciona lo siguiente, respecto al aprendizaje autorregulado: La autorregulación debe ser entendida como la capacidad de la persona para dirigir su propia conducta. Un estudiante autorregulado tiene capacidad para formular o asumir metas, proyectar su actuación, observarla críticamente, y evaluarla a la luz de varios 
criterios. Le permitirá valorar su eficacia para conseguir las metas; y reaccionar, dependiendo del grado de correspondencia entre las demandas de las metas que se ha fijado y la actuación que efectivamente ha alcanzado. (p. 22).

Por consiguiente, que el aprendizaje autorregulado consiste en la capacidad de los estudiantes para observar su propio aprendizaje como un proceso en el que se identifican objetivos y estrategias, desde la planificación hasta la evaluación del rendimiento, y en el que realizan los cambios y ajustes necesarios, sin perder de vista sus metas. El aprendizaje autorregulado es una actividad que los estudiantes realizan de forma autónoma, ya que mediante él son protagonistas de su aprendizaje, conscientes de sus fortalezas y debilidades, y capaces de monitorear, regular y evaluar sus propias actividades y progresos para mejorar su rendimiento y alcanzar metas académicas. En la actualidad, el aprendizaje es considerado un proceso dinámico, significativo, constructivo y autorregulado.

\section{El aprendizaje autorregulado desde el enfoque sociocultural de Vygotsky}

\section{La fundamentación de la propuesta de Vygotsky.}

Vygotsky transformó la forma de pensar de la psicología de su tiempo, con su propuesta de la inteligencia estrechamente relacionada con el entorno social y cultural en el que el individuo se relaciona y desarrolla. En aquella época, la psicología se hallaba dividida en dos corrientes opuestas: la psicología fisiológica, en la que los fenómenos psicológicos eran relacionados con mecanismos fisiológicos elementales; y la psicología descriptiva, en la cual las representaciones superiores de modo consciente eran analizadas como representaciones subjetivas de la mente (Harry, 2003).

Por otro lado, Sesento (2017) comenta:

Vigotsky destaca esta forma de pensar, con una formación dialéctica y marxista, pero no dogmática del mundo, pensaba que una psicología científica correspondía dar recuento de las creaciones de la cultura; era ineludible enclavar una extensión 
"histórica" en el núcleo mismo de la psicología y concebir la conciencia desde su naturaleza y su organización. (p. 2).

Para Molon (1995), el trabajo de Vygotsky estaba profundamente influenciado por las ideas y pensamientos de Marx, Engels y Pierre Janet, Hegel y su dialéctica, Darwin y su evolucionismo, y otros grandes pensadores, a partir de los cuales, creó las bases de su propio entendimiento de la psicología como una ciencia del individuo histórico y no del individuo abstracto, y estableció que los procesos psicológicos superiores se originan y se desarrollan socialmente mediante tres tipos de mediadores: las relaciones interpersonales, las actividades individuales y los signos e instrumentos, que el desarrollo de habilidades y funciones específicas ocurren gracias al surgimiento del trabajo, dado que mediante este, el hombre transforma tanto la naturaleza, para satisfacer sus propias necesidades, como a sí mismo, y que de acuerdo a la unidad que existe entre cuerpo y alma, el hombre es un ser total.

Según Vygotsky (1978), las funciones psicológicas superiores son exclusivas del hombre, poseen un origen social y se identifican por la intencionalidad de las acciones mediadas, las cuales son el resultado de la interrelación entre los componentes biológicos y culturales que han evolucionado a lo largo de la historia. Sobre este punto, Raynaudo y Peralta (2017) sostienen: "La mera maduración no alcanza para desarrollar las funciones psicológicas superiores, ya que estas se generan a partir de la interacción social, con la incorporación de las pautas culturales y sociales" (p. 5).

Vygotsky (1978) citado por Raynaudo y Peralta (2017), señala:

Las sucesivas internalizaciones y externalizaciones habilitarían el desarrollo de procesos psicológicos superiores más avanzados y culturalmente mediados que se diferencian cualitativamente de los anteriores. Se percibe el desarrollo como un complejo proceso dialéctico y no una mera acumulación de cambios. Las funciones 
psicológicas superiores representan nuevos sistemas psicológicos que no se contraponen a los procesos elementales. (p. 5).

Además, Lucci (2006) indica que es necesario recordar que el cerebro forma parte de la constitución de las funciones psicológicas superiores y no solo es un soporte de ellas, y que las funciones elementales no se excluyen con el surgimiento de las superiores. En la teoría vygotskiana, se considera que la adaptación del funcionamiento cerebral tiene bases filogenéticas (relacionadas con la evolución de la humanidad), ontogenéticas (relacionadas con la evolución individual) y sociogenéticas (pues la adaptación ocurre gracias a la interacción con el entorno físico y social). De este modo, las funciones psicológicas superiores que se originan en la vida sociocultural del individuo requieren de la actividad cerebral para existir.

De acuerdo con Vygotsky, la internalización de las funciones psicológicas determina el desarrollo mental; dicha internalización no consiste únicamente en transferir una actividad exterior a un plano interior, sino también en el proceso de formación de lo interno. Asimismo, tal proceso no sigue un camino ajeno al desarrollo cultural, pues lo que se interioriza son las formas histórica y culturalmente organizadas de interactuar con el medio (Lucci, 2006).

Sesento (2017) señala: "Por internalización se concibe al proceso que envuelve la evolución de fenómenos sociales en fenómenos psicológicos, a través del uso de herramientas y signos" (p. 3). Este uso de herramientas y signos se desarrolla en el niño, hasta ver la aparición progresiva del lenguaje como instrumento del pensamiento. Entonces, la internalización implica la conversión del lenguaje social del niño en etapa preescolar en un lenguaje de empleo intelectual, es decir, en pensamiento. A medida que ocurre este progreso, el individuo desarrolla su independencia de los objetos de la realidad, lo cual es el inicio para las representaciones mentales en su forma abstracta. En la etapa final de la internalización, cuando el niño logra formar generalidades a partir de un concepto, se transforma la utilización del lenguaje. 
Es decir, la internalización es un proceso psíquico, mediante el cual el individuo desarrolla su plano interior a partir de la información y el entorno que lo rodea. Este desarrollo es progresivo e involucra la práctica social, desde el uso de herramientas y signos, hasta llegar al uso del lenguaje.

El individuo se relaciona con el ambiente a través de la mediación, pues desde su posición como sujeto de conocimiento, no puede acceder directamente a los objetos sino a través de símbolos que interpretan la realidad. Esto es posible a través de la palabra, de los signos y de los instrumentos relacionados con el entorno cultural (Rego, 1998).

La mediación es una de las ideas primordiales de la psicología sociohistórica, y Oliveira (1993) la define como el "proceso de intervención de un elemento intermediario en una relación" (p. 26).

Asimismo, Sesento (2017) comenta lo siguiente: "En este proceso de internalización, son esenciales los efectos de mediación, los cuales son establecidos, por el medio sociocultural. El más significativo de ellos es el lenguaje oral, escrito y el pensamiento” (p. 3).

Por ello, se considera que el lenguaje es el mediador principal en el origen y en el desarrollo de funciones psicológicas superiores. El lenguaje, formado por un sistema de símbolos desarrollado durante la historia social de la humanidad, organiza los signos en estructuras complejas que permiten, entre otras funciones, nombrar objetos, establecer relaciones entre ellos y destacar sus calidades. Vygotsky afirmaba que la adquisición del lenguaje es el logro más importante del desarrollo cognitivo, pues simboliza la evolución de las funciones superiores, y que cuando este sirve como herramienta psicológica para regular el comportamiento, se logra cambiar la percepción de manera radical, lo cual permite la formación de nuevas memorias y procesos de pensamiento (Lucci, 2006).

A partir del surgimiento del lenguaje, se pueden identificar dos grandes cambios: la relación con objetos externos (no presentes), que permite analizar, abstraer y generalizar sus 
particularidades, eventos y situaciones, y su función comunicativa, o en otras palabras, "la preservación, transmisión y asimilación de informaciones y experiencias acumuladas por la humanidad a lo largo de la historia” (Rego, 1998, p. 54).

De esta forma, el lenguaje integra el sistema de mediación simbólica que sirve como herramienta de comunicación, autorregulación y planificación, y, por su función comunicativa, determina la manera en que el individuo se apropia de su entorno, puesto que en la comunicación suceden los diálogos, negociaciones y nuevas formulaciones de conceptos, significados e informaciones (Lucci, 2006).

Sobre el lenguaje, Sesento (2017) sostiene que: “También (Vygotsky) investigó acerca de la importancia del lenguaje, señalando que las palabras empiezan siendo emocionales, pasan luego a distinguir objetos concretos, y toman por último su significado abstracto" (p. 2).

Según Vygotsky, el lenguaje logra concretizar y constituir los significados producidos en el proceso social e histórico, y cuando las personas los interiorizan, pueden acceder a ellos como base para significar sus experiencias. Los significados resultantes serán aquellos que compondrán su conciencia y que serán mediadores en sus formas de pensar, sentir y actuar. Asimismo, ciñéndose al origen del individuo (ontogénesis), Vygotsky sostiene que ocurren dos saltos cualitativos en su desarrollo: cuando el individuo adquiere el lenguaje oral y cuando adquiere el lenguaje escrito (Lucci, 2006).

En conclusión, las funciones psicológicas superiores tienen su origen en la vida sociocultural, en la que el individuo desarrolla su plano interior mediante el uso de herramientas y signos, hasta llegar al lenguaje, el cual permite que las emociones puedan transformarse en palabras. Así, el individuo percibe lo concreto y construye lo abstracto en su interior, dentro de un proceso sociohistórico en el que se identifican la internalización, la mediación y el lenguaje. 


\section{Zona de desarrollo próximo.}

El concepto de zona de desarrollo próximo (ZDP) tiene carácter científico, es decir, no se produce espontáneamente a partir de generalizaciones de experiencias cotidianas, sino que se adquiere mediante instrucción sistémica. Por ejemplo, en la escuela se aprenden conceptos y categorías que luego se utilizan para organizar las experiencias y reflexionar sobre ellas, más allá de lo que se percibe mediante los sentidos. Aquí surge una relación compleja entre conceptos científicos y conceptos espontáneos que permite que el pensamiento se reestructure y se movilice de lo sencillo a lo complejo (Rodríguez, 2015).

Vygotsky (1988) define la Zona de Desarrollo Próximo como:

La distancia entre el nivel de desarrollo, determinado por la capacidad del sujeto para resolver independientemente un problema, y el nivel de desarrollo potencial, determinado a través de la resolución de un problema, bajo la guía de un adulto o en la colaboración con otro compañero más capaz. (p. 133).

Además, Sesento (2017) comenta: "La importancia de la llamada Zona de Desarrollo Próximo (ZDP) es indudable entre el sitio real y el adelantamiento del niño, y ha de ser apreciada por todos los educadores, sin concernir el nivel educativo del estudiante" (p. 7).

En realidad, Vygotsky vincula la zona de desarrollo próximo con otros elementos fundamentales de su teoría, como la mediación, el desarrollo cultural, la afectividad, la imitación y la influencia del maestro. Entonces, la ZDP es un proceso en el que se puede identificar a dos participantes proactivos: el que aprende y el que colabora, mediante el uso de medios o mediaciones diversas para que se produzca el aprendizaje (Ruíz, 2015).

La motivación principal de Vygotsky era aproximarse, de la forma más real posible, a la formulación de una teoría de la interacción entre naturaleza, cultura, herencia y medio ambiente (Yasnitsky y van der Veer, 2015). 
La interacción en la zona de desarrollo próximo, según Vygotsky, se orienta al conocimiento del mundo y a la forma en que este se hace posible, teniendo como contexto la interacción de los seres humanos, en lo cotidiano o en procesos específicos y organizados para la enseñanza, y abarca más allá de la adquisición de conocimientos, pues considera el desarrollo de la persona en ese proceso. Durante la constitución de conocimientos y el advenimiento de su desarrollo, se logra penetrar en el papel del otro (más experimentado). El más experto es el que aporta y organiza los elementos que serán de ayuda para promover el conocimiento del mundo y su desarrollo (Labarrere, 2016).

El interés de Vygotsky estaba orientado a proveer un anclaje metodológico práctico a sus ideas sobre desarrollo. Sobre este punto, Zavershneva (2014) señala que la psicología vigotskiana requiere de teorías de nivel medio como puentes entre la teoría y metodología generales y la práctica social. Lo que menciona la autora es muy importante por estar relacionado con encontrar el significado práctico de la construcción, es decir, todo aquello (acciones, instrumentos y condiciones) que logra materializar los aspectos que se señalan en la teoría.

En resumen, el concepto de ZDP identifica a dos participantes activos, el que aprende y el que ayuda al que aprende. Además, abre la posibilidad de investigar y diseñar metodologías formativas para el desarrollo de los estudiantes en el proceso de enseñanza-aprendizaje, en relación con el medio ambiente, la cultura y la sociedad. La intención principal de la teoría de Vygotsky era explicar que es posible conocer el mundo, de lo sencillo a lo complejo, a partir de la socialización.

\section{Aprendizaje autorregulado - El modelo de Pintrich.}

Pintrich (2000) se basó en una perspectiva sociocognitiva del aprendizaje para analizar y clasificar los distintos procesos del aprendizaje autorregulado. En este modelo, los procesos reguladores se organizan en cuatro fases: planificación, autoobservación, control y evaluación. 
Además, las actividades de autorregulación se enmarcan en cuatro áreas: la cognitiva, la motivacional-afectiva, la comportamental y la contextual.

Para Pintrich, las cuatro fases que atraviesa el estudiante a medida que desarrolla la tarea no están ordenadas jerárquicamente, sino que se presentan de manera dinámica y simultánea, y generan una interacción compuesta entre sus diferentes elementos y procesos. Asimismo, no todas las tareas o actividades académicas involucran directamente la autorregulación, pues a veces, la ejecución de algunas tareas o actividades no implica necesariamente la planificación, control y evaluación estratégica por parte de los estudiantes, sino que puede realizarse de manera automática, a partir de su experiencia previa (Torrano y González, 2004).

Los procesos de autorregulación inician con la fase de planificación, con énfasis en algunas actividades importantes, como: establecer las metas que se desean alcanzar; activar los conocimientos previos acerca de la materia, los conocimientos metacognitivos, las creencias motivacionales (tales como el valor que se otorga a la tarea, la autoeficacia, el interés personal y las metas) y las emociones (aspectos motivacionales-afectivos); planificar el tiempo y el esfuerzo que se requerirán para realizar las tareas (aspectos comportamentales); y activar la percepción sobre el contexto en relación con las tareas (aspectos contextuales).

Seguidamente, en la fase de autoobservación están incluidas las estrategias que facilitan en la estudiante la observación consciente del estado de sus procesos cognitivos, afectivos, motivacionales y comportamentales (como su uso del tiempo y esfuerzo), así como el contexto y las condiciones de la tarea. Por ejemplo, en esta fase están incluidas las estrategias de autoobservación de la comprensión, que permiten al estudiante ser consciente de no haber logrado entender algún tema luego de haberlo escuchado o leído, así como ser capaz de identificar las causas, como la complejidad del texto o la lectura apresurada (Pressley y Afflerbach, 1995). Al mismo tiempo, esta fase incluye los procesos que los estudiantes ponen 
en marcha para ser conscientes de su propio comportamiento, de su patrón motivacional y de las características de las tareas y del contexto.

De acuerdo con los resultados de la fase anterior, se ponen en marcha las actividades de control, que implican la selección y el uso de estrategias para controlar el pensamiento (estrategias cognitivas y metacognitivas), la motivación (estrategias motivacionales), el afecto (estrategias de control emocional), la forma de regular el esfuerzo y tiempo, las diferentes tareas y actividades académicas y la estructura y el clima de la clase.

Asimismo, es necesario indicar la dificultad que existe para diferenciar las fases de autoobservación y control cognitivo, tal como se puede observar en algunas propuestas de autorregulación que consideran dichos elementos como procesos separados (Butler y Winne, 1995; Nelson y Narens, 1990). Si bien, conceptualmente, los procesos incluidos en la autoobservación y en el control de la cognición sí podrían diferenciarse, las investigaciones empíricas realizadas sobre el tema no sostienen su separación, pues consideran que mayormente suceden de manera simultánea (Pintrich, Wolters y Baxter, 2000).

Posteriormente, se da la fase de evaluación o reflexión, que abarca las evaluaciones y los juicios que los estudiantes realizan sobre su ejecución de la tarea, la comparación de dicha ejecución con aquellos criterios que ellos mismos (o el docente) establecieron previamente, las causas atribuidas a sus fracasos o éxitos, las reacciones afectivas que perciben ante dichos resultados como efecto de las atribuciones realizadas, la facultad de elegir el comportamiento que se llevará a cabo en los próximos retos, y las evaluaciones sobre el ambiente de clase y la tarea.

Acerca de la autorregulación, García, Castañeda y Mansilla (2018) anotan: “...la autorregulación constituye un proceso fundamental para mejorar la calidad en el aprendizaje que gana sentido si se contempla vinculada a la teoría de estilos de aprendizaje” (p. 3). 
Así, el modelo de Pintrich sirve como marco global y comprensivo desde el cual se pueden analizar los distintos procesos cognitivos, motivacionales-afectivos, comportamentales y contextuales que ayudan a promover el aprendizaje autorregulado, y que incluye la planificación (metas, conocimiento previo, conocimiento metacognitivo), la activación de creencias motivacionales y emociones, la planificación del esfuerzo y el tiempo para realizar las tareas, y la activación de las percepciones de la tarea y el contexto. Además, este modelo, a diferencia de otras propuestas de autorregulación, considera el contexto como un elemento que puede ser autorregulado.

\section{Características de los estudiantes que autorregulan su aprendizaje.}

Las investigaciones muestran que hay una serie de atributos que diferencian a los estudiantes que han desarrollado la autorregulación de su aprendizaje de aquellos que no lo han hecho, tal como mencionan Corno (2001), Weinstein, Husman y Dierking (2000), Winne (1995) y Zimmerman (1998, 2000, 2001, 2002): a) entienden y usan estrategias cognitivas, como la elaboración, la repetición y la organización, las cuales les facilitan la atención, elaboración, organización, transformación y recuperación de información; b) planifican, controlan y dirigen sus propios procesos mentales para lograr sus metas planteadas (metacognición); c) poseen una serie de emociones adaptativas, así como creencias motivacionales, como una sólida autoeficacia académica, metas de aprendizaje, emociones positivas relacionadas con la realización de tareas (como la satisfacción, el entusiasmo el gozo) y la capacidad de controlarlas y ajustarlas a las exigencias de la situación concreta de aprendizaje; d) controlan y planifican cuánto esfuerzo y tiempo requieren las tareas, y saben crear ambientes favorables de aprendizaje, tales como el lugar apropiado para estudiar o la ayuda académica de profesores y compañeros; e) son más participativos en el control y regulación de las tareas académicas y del clima y la estructura de la clase (por ejemplo, la forma de ser evaluados y las exigencias de las 
tareas); y f) usan estrategias volitivas enfocadas en evitar distracciones y mantenerse motivados y concentrados durante la realización de tareas académicas.

Según Medina, Álamo, Costa y Rodríguez (2019): “En la actualidad, uno de los requisitos que se exige al estudiante universitario es que sea capaz de aprender a aprender, para que pueda desenvolverse con solvencia en el contexto laboral" (p. 2). Entonces, las características antes mencionadas son relevantes para formar individuos con capacidad de reflexión y asimilación, y con estrategias de aprendizaje que permitan que sus conocimientos y habilidades continúen desarrollándose durante toda su vida profesional.

Por tanto, si bien es posible identificar un conjunto de características en los estudiantes que autorregulan su aprendizaje, es necesario hacer un énfasis en la necesidad de desarrollar emociones positivas, como la satisfacción, el entusiasmo y el gozo, ante las tareas que deben realizar, pues se espera que los estudiantes continúen aprendiendo a lo largo de su vida. Así, necesitarán saber observar y regular sus emociones, para que su aprendizaje continúe produciendo satisfacciones profundas, gran entusiasmo y gozo verdadero, lo cual marcará una gran diferencia con el aprendizaje no autorregulado.

\section{La enseñanza del aprendizaje autorregulado.}

La modelación es uno de los procedimientos más empleados para enseñar la autorregulación (Graham, Harris y Troia, 1998). Todos los procesos y elementos que se consideran en la autorregulación, como la planificación, el control de la ejecución, la distribución de los recursos cognitivos y la reflexión sobre lo ejecutado, pueden ser comprendidos por los estudiantes, si ellos observan cómo sus docentes y otros especialistas realizan su propia autorregulación (Schunk y Zimmerman, 1998, 2003).

Además, mediante prácticas guiadas de las estrategias de autorregulación, que luego pueden convertirse en prácticas independientes, junto con la retroalimentación del docente y otros expertos, se puede mejorar la motivación y el aprendizaje de los estudiantes, ya que dichas 
prácticas son una forma efectiva de transferir estrategias y darles continuidad. En este sentido, las prácticas tienen el objetivo de transferir la responsabilidad de generar, emplear y evaluar las estrategias, del docente a los estudiantes (Onrubia, 1996). Fue Vigotsky quien inicialmente propuso este tipo de aprendizaje mediado, considerado uno de los elementos principales de programas y modelos instruccionales, por ejemplo, la enseñanza recíproca y el andamiaje (Valle, González Cabanach, Vieiro y Suárez, 1998).

Algunas de las estrategias didácticas en las que concuerdan la mayoría de programas y propuestas son la modelación, las prácticas guiadas y autónomas de estrategias, la enseñanza directa de estrategias, la autoobservación, la retroalimentación, y el apoyo social y su retiro cuando los estudiantes han alcanzado cierto grado de autorreflexión y de participación responsable.

Mediante la enseñanza directa de estrategias, los docentes explican a los estudiantes las particularidades de las estrategias que los ayudarán a regular su aprendizaje, así como cuándo, cómo, por qué y para qué elegir y utilizar unas y otras. Por ejemplo, la autoobservación es fundamental en la intervención porque el estudiante que requiere aprender estrategias debe observar su aplicación, efectividad y, si fuera necesario, la manera de modificarlas o adaptarlas.

Respecto al apoyo social a los estudiantes por parte de los docentes y compañeros, Graham et al. (1998) sostienen que la supresión del apoyo o andamiaje debe ser efectuada de manera paulatina, desde una mediación que sea más intensiva y directiva en la fase inicial, hacia formas más autorreguladas, en las que se observe mayor competencia en el estudiante.

En la práctica autorreflexiva, los estudiantes utilizan de manera independiente las estrategias y habilidades obtenidas, reflexionan acerca de su propio proceso de aprendizaje, evalúan su rendimiento y la efectividad de las estrategias, y realizan los cambios necesarios para lograr un ambiente favorable de aprendizaje, lo cual incluye su entorno social y físico. Al respecto, Merchan y Hernández (2018) señalan lo siguiente: 
La globalización de la educación exige a los estudiantes ser conscientes de su propio aprendizaje mediante estrategias que optimicen su desempeño académico, respecto a la calidad y eficiencia y bajo la guía del profesor en el rol de facilitador, mediador y potenciador de las habilidades esenciales para aprender a aprender, para lo cual este último debe capacitarse en las formas de enseñar a aprender, modelar la autorregulación del aprendizaje mediante el propio ejemplo y generar conciencia en los alumnos para que reflexionen sobre su forma de aprender en sus tareas habituales. (p. 1).

Entonces, podemos afirmar que la enseñanza del aprendizaje autorregulado se ha convertido en una necesidad, teniendo en cuenta las exigencias actuales de la educación hacia los maestros, estudiantes y todos los profesionales involucrados en los procesos de enseñanzaaprendizaje. En estos tiempos, se espera mayor reflexión y efectividad, mejores estrategias y procedimientos, y estudiantes y maestros más comprometidos.

\section{Definiciones conceptuales de las subcategorías de aprendizaje autorregulado.}

\section{Cognición.}

Los principales orígenes de la teoría cognitiva se encuentran en las investigaciones acerca de los procesos relacionados con la memoria en adultos, de Bartlett (1932), y en el estudio de esquemas de los procesos de desarrollo intelectual de los niños, de Piaget (1926). Ambos psicólogos lograron identificar el rol de los esquemas cognitivos, la memoria y el aprendizaje, así como la relevancia de su coherencia conceptual y la lógica en su formulación. En estudios recientes, se ha utilizado el término teoría para hacer referencia a las bases representativas de cómo enseñar el aprendizaje autorregulado (Paris y Byrnes, 1989).

De acuerdo con este enfoque, el funcionamiento cognitivo tiene un rol muy activo y personal en los procesos de aprendizaje y recordación, por lo que su alcance en la autorregulación es muy relevante. No obstante, no se distingue a la motivación como un proceso apartado, porque se considera que en la búsqueda de conocimientos existe una motivación 
interior. Además, el aprendizaje autorregulado es interdisciplinario e incluye el esfuerzo, la autocompetencia, las estrategias cognitivas y las tareas académicas (Norabuena, 2011).

En términos de Weinstein et al. (2000), las estrategias cognitivas implican comportamientos o pensamientos que ayudan a obtener información, recuperarla e incorporarla al conocimiento existente. En tal sentido, se hará referencia a estrategias cognitivas, metacognitivas y de regulación de recursos.

Según Pintrich, Smith, García y McKeachie (1991) y Pintrich y García (1993), las estrategias cognitivas comprenden las estrategias de elaboración, repaso y organización. Las estrategias de repaso repercuten en los procesos de codificación y atención, pero no ayudan con la integración de la información nueva en los conocimientos previos o en la construcción de conexiones internas, de modo que, la información es procesada solo de manera superficial. Por el contrario, las estrategias de organización y elaboración facilitarían un procesamiento más profundo de la información. Asimismo, se considera que el pensamiento crítico es una estrategia cognitiva en la que los estudiantes procuran pensar de una manera más profunda y reflexiva.

Teniendo esto en consideración, los programas de intervención deben ser evaluados, abarcando dimensiones del aprendizaje autorregulado como la cognición, la metacognición y el comportamiento, pero considerando además la volición y la motivación (Efklides, 2011; Wang, Morin, Liu y Chian, 2016), porque la información o el conocimiento sobre el aprendizaje autorregulado no es suficiente para lograr desarrollarlo y ponerlo en práctica. Así, es necesario que los estudiantes comprendan la importancia de todas las dimensiones del aprendizaje autorregulado en sus propios procesos de aprendizaje.

Entonces, se puede afirmar que las estrategias cognitivas consideradas en el modelo de Pintrich (2004), como la organización, la elaboración, la repetición y el pensamiento crítico, siguen aplicándose, desde una perspectiva de transmisión de conocimientos, hasta un enfoque 
de utilización de tecnologías y estrategias cognitivas complejas, como la creatividad, la búsqueda de información, la toma de decisiones y la solución de problemas.

\section{Motivación / Afecto.}

La motivación es el proceso psicológico que activa la conducta y la dirige hacia una meta; gracias a la motivación, los estudiantes logran esforzarse para persistir y alcanzar sus objetivos. Este concepto incluye, como variables muy importantes relacionadas con la personalidad, las expectativas de logro, las atribuciones causales, la autoeficacia, la valía personal y, sobre todo, la autoestima y el autoconcepto.

Según Pintrich (2004), así como los estudiantes logran la regulación de su cognición, pueden también regular su afecto y su motivación. Así, el autor incluye en el diseño del Cuestionario de Motivación y Estrategias de Aprendizaje - MSLQ (Motivated Strategies for Learning Questionaire, por sus siglas en inglés), dos escalas, correspondientes a la motivación intrínseca y a la motivación extrínseca.

En ese sentido, es preciso señalar que la mayor parte de la literatura referente a la motivación trata acerca de la distinción existente entre motivación intrínseca y motivación extrínseca (Alonso, 1997; Huertas, 1997; Pintrich y García, 1993). Los distintos autores e investigadores parecen coincidir en relacionar la motivación intrínseca con las acciones que se realizan por el interés que origina la propia actividad, la cual no es considerada como un medio para lograr otras metas, sino como un fin en sí misma. En contraste, la motivación extrínseca se caracteriza por llevar al individuo a realizar determinadas acciones para lograr satisfacer necesidades que no guardan relación con la actividad en sí misma, sino con el logro de objetivos, como por ejemplo, en el campo académico, el reconocimiento y las distinciones, la obtención de buenas calificaciones, la evitación del fracaso, entre otros.

Entonces, para lograr el aprendizaje y mejorar el rendimiento, son fundamentales las variables cognitivas, tales como los conocimientos, las habilidades, las capacidades y las 
estrategias; además, son necesarias las variables motivacionales, como la intención, la motivación y la disposición, para poner en funcionamiento los mecanismos cognitivos orientados hacia los objetivos planteados (García y Pintrich, 1994).

En la actualidad, existen muchos programas de intervención diseñados e implementados para alcanzar el aprendizaje autorregulado en educación a nivel superior (Cerezo, Ato, Rabadán, Martínez y Orenes, 2010; Zheng, 2016), pero la eficacia de dichos programas, muchas veces, no ha sido evaluada en relación con las variables motivacionales de la autorregulación (Dörrenbächer y Perels, 2016; Pellas, 2014).

Tal como indican Roth, Ogrin, y Schmitz (2016), es notoria la necesidad de buenas escalas para la medición de la regulación motivacional y emocional. Esta dificultad parece ser menor en las evaluaciones de los niveles de conocimiento de aprendizajes autorregulados y en los autoinformes, pero solo si se asume que el constructo motivacional es accesible y consciente para el individuo.

De esta manera, para el logro de objetivos académicos y para buenos resultados de aprendizaje, los estudiantes necesitan la combinación de voluntad (hill) y habilidad (skill), es decir, una interrelación entre lo afectivo-motivacional y lo cognitivo en el aprendizaje. Por otro lado, es necesario decir que la motivación y el comportamiento en el aprendizaje autorregulado pueden ser ser ajustados y mejorados durante el proceso.

\section{Contexto del aprendizaje.}

De acuerdo con Pintrich (2000), a diferencia de otros campos, la autorregulación del contexto es la más complicada de lograr, ya que depende de la interrelación estudiante-contexto y no únicamente del estudiante. Tal vez por esta razón, de acuerdo con Bandura (1991), el contexto puede ser más influyente que los factores comportamentales y personales. Por otro lado, Zimmerman (1999) señala que los instrumentos psicométricos que hacen uso de escalas contextuales producen mejores desempeños futuros que aquellos que las omiten. 
Según Linder y Harris (1992), frecuentemente, el contexto no es identificado como un aspecto independiente e importante; además, en muchos de los modelos y propuestas de aprendizaje autorregulado, el contexto suele estar implícito en elementos relacionados con la sensibilidad o control del ambiente. Por ejemplo, Zimmerman y Martínez (1986) señalan algunas estrategias de aprendizaje que ayudan a la autorregulación de la influencia del contexto, como estrategias que sirven para la organización del ambiente, la revisión de registros, la búsqueda de información, la solicitud de ayuda y la observación.

Otras variables importantes relacionadas con la regulación del contexto son las percepciones de las tareas y las características de la clase (Pintrich, 2000; Zimmerman, 1989). La primera se refiere a analizar, controlar y evaluar las diferentes tareas de clase y las particularidades de las evaluaciones y exigencias del docente. La segunda trata de la manera de apreciar las normas en el aula, las características físicas del lugar de aprendizaje, el clima emocional e incluso las técnicas didácticas empleadas por los docentes.

Además, Linder y Harris (1992) subrayan que la capacidad de atención para manejar el contexto está relacionada con las características físicas y temporales (dónde y cuándo estudiar), las características del curso, las demandas del docente y la búsqueda de ayuda.

De acuerdo con Rodríguez (2008), la estrategia de gestión de recursos está relacionada con el control activo que los estudiantes tienen sobre los recursos a su disposición. La gestión del tiempo, el control del entorno de estudio o la ayuda de profesores y compañeros facilitan que los estudiantes se adapten al contexto y que lo modifiquen, en función de sus necesidades y objetivos (Corno, 1986; Zimmerman y Martínez, 1986).

Por otro lado, si bien los principales modelos o propuestas de aprendizaje autorregulado incluyen el contexto como un elemento importante de la autorregulación, no se han realizado suficientes estudios e investigaciones acerca de cómo el contexto del aprendizaje autorregulado influye en la tarea (Panadero, 2017). 
De este modo, el estudiante necesita una mejor adaptación y modificación del contexto, para adecuarlo a sus objetivos y necesidades propias, y para ello, requiere de la observación y regulación de sus influencias, el uso de estrategias de gestión de recursos (por ejemplo, la gestión del tiempo) y la ayuda de los docentes y compañeros de clase.

\section{Fundamentos teóricos sobre la categoría estrategia metodológica}

De acuerdo con Moya (2018), la estrategia metodológica es la planificación de una serie de acciones, a corto, mediano y largo plazo, orientadas a modificar la dirección del proceso de enseñanza- aprendizaje, teniendo como base los procedimientos, métodos y recursos didácticos, con la finalidad de alcanzar los objetivos concretos en un determinado tiempo. Asimismo, son acciones específicas en las cuales se movilizan capacidades didácticas, desarrollando acciones con intencionalidad, resolviendo problemas, examinando conceptos y recopilando información valiosa.

Desde la perspectiva de la labor que desarrollan los docentes, según Ocando (2009), las estrategias metodológicas son definidas como los métodos o procedimientos que emplea el docente para que sus estudiantes logren el aprendizaje, mediante el uso de medios y recursos necesarios. El docente emplea las estrategias intencional y conscientemente, las cuales son orientadas hacia el éxito de sus estudiantes en la ejecución de actividades de aprendizaje.

Armas, Perdomo, y Lorences (2011) señalan que la estrategia metodológica establece la dirección inteligente y las acciones enfocadas en la resolución de problemas pertenecientes a un área específica de la actividad humana. Asimismo, los problemas son considerados como las contradicciones existentes entre el estado actual y el estado deseado, teniendo en cuenta las expectativas provenientes de un proyecto educativo y social. Asimismo, el diseño de una estrategia metodológica representa una articulación entre los objetivos y la metodología.

Entonces, las estrategias metodológicas son utilizadas por los docentes, de manera intencional, para lograr los objetivos y contenidos propuestos en el desarrollo de las sesiones 
de aprendizaje, en las que ocurre la interacción entre estudiantes y docentes. Así, las estrategias metodológicas tienen un papel muy importante en el rendimiento académico y en el aprendizaje del estudiante. Es importante señalar que el docente debe poseer las habilidades que le permitan seleccionar las estrategias convenientes para el desarrollo de determinadas clases.

Entre los factores que se asocian a las estrategias metodológicas están los siguientes: a) capacidad de trabajo autónomo de los estudiantes, que incluye sus conocimientos previos y las prácticas con ritmos de aprendizajes diversos; b) motivación de los estudiantes, como un elemento muy significativo para desarrollar un aprendizaje eficaz; c) desarrollo del juicio crítico; d) fortalecimiento de la capacidad para adquirir conocimientos; e) evidencia de la asimilación y comprensión de la información que el docente proporciona; y f) desarrollo de las capacidades deductivas e inductivas (Valdez, 2012).

Las estrategias, según Tuñas (2007), establecen lo necesario para resolver las tareas encomendadas y determinan los métodos o técnicas más eficaces que se pueden emplear (como la repetición de la información, los esquemas, las reglas nemotécnicas, entre otras). Entonces, se observa que la estrategia metodológica orienta las acciones que serán desarrolladas durante el proceso de enseñanza-aprendizaje.

Según Alcaraz et al. (2004), las estrategias son métodos para la elección, aplicación y coordinación de habilidades. A nivel congnitivo, las acciones se orientan hacia la asimilación y adquisición de información nueva, y se originan en función de los valores y actitudes que se quieren fomentar.

Las estrategias precisan de control, ejecución y evaluación, y de la relación entre las técnicas y los recursos educativos para definir y organizar las acciones y actividades orientadas a alcanzar los objetivos planteados. Entonces, es posible afirmar que las estrategias son técnicas o procedimientos empleados en la enseñanza para generar y promover aprendizajes. 
Los docentes utilizan determinadas estrategias para programar actividades, reconocer conocimientos previos, plantear objetivos y generar y evaluar aprendizajes; estas son denominadas estrategias de enseñanza. Por otro lado, las estrategias de aprendizaje comprenden las acciones y procedimientos que el estudiante usa de manera intencional, como herramientas flexibles para lograr el aprendizaje de manera significativa (Torres y Girón, 2009).

Para Alcaraz et al. (2004), las estrategias de enseñanza abarcan un conjunto de decisiones planificadas por los docentes, con la finalidad de que los estudiantes adquieran habilidades y conocimientos.

Además, las estrategias de enseñanza permiten a los docentes determinar la manera de proceder en el aula, de organizar y orientar las explicaciones, preguntas y actividades, y de activar la motivación de los estudiantes a querer aprender (Romero, 2009).

Las estrategias de enseñanza marcan la pauta de intervención en el aula y son encaminadas por el profesor, y comprenden la organización en el aula, el uso de recursos didácticos y los aspectos de la medición del docente. También, las estrategias incluyen tareas que se desarrollan en situaciones y tiempos específicos, y procedimientos o conjuntos de tareas y técnicas, para el logro de objetivos específicos (Nisbet, 1991, citado por Alcaraz et al. 2004).

De acuerdo con Romero (2009), las estrategias de aprendizaje son un conjunto de actividades mentales que el estudiante emplea en una situación específica de aprendizaje, para favorecer la adquisición de conocimientos. Las estrategias de aprendizaje también son consideradas como actividades o procesos que permiten el almacenamiento y el uso de la información.

Por otro lado, las metodologías son mecanismos que proceden de una propuesta teórica específica sobre la actuación del estudiante y del docente en el proceso de enseñanzaaprendizaje. De este modo, la metodología didáctica se define como la manera de enseñar, desde una base científica y estratégica, que el docente desarrolla en el aula para que los 
estudiantes adquieran aprendizajes deeterminados. Las metodologías centradas en el estudiante permiten la transferencia de aprendizajes y el desarrollo de la motivación y del pensamiento. Entonces, se puede afirmar que una buena metodología resulta de la combinación de varias otras que se eligen a partir de una definición anticipada de lo que se quiere lograr, y del conocimiento de sus ventajas e inconvenientes.

Para Quintero (2011), las estrategias metodológicas permiten reconocer criterios y principios, mediante el uso de métodos, técnicas y procedimientos organizados y planificados de manera ordenada, para la construcción de conocimientos en el proceso enseñanzaaprendizaje. En este sentido, las estrategias metodológicas consisten en series ordenadas de técnicas, procedimientos de enseñanza y actividades que los docentes emplean en su práctica educativa con la finalidad de que los estudiantes aprendan. Por tanto, es necesario que los docentes seleccionen las estrategias metodológicas adecuadas, teniendo en cuenta los contenidos que desarrollarán y las edades y nivel académico de sus estudiantes.

En consecuencia, es importante indicar que las estrategias metodológicas que el docente puede emplear no son suficientes, puesto que a ellas se deben sumar las habilidades con que el docente las utiliza. Aquí serán determinantes la pericia y experiencia del docente para elegir y ejecutar una u otra estrategia, para realizar los ajustes necesarios en el proceso, para evaluar los resultados o avances, para replantear los procedimientos y para analizar los resultados.

\section{Importancia de las estrategias metodológicas.}

En educación, el término estrategia es entendido como "los procedimientos o recursos utilizados por el agente de enseñanza para promover aprendizajes significativos" (Díaz y Hernández, 2001, p. 1). Las estrategias metodológicas permiten a los docentes detallar, entender e interpretar los procesos de enseñanza-aprendizaje, y conocer en qué medida se están logrando los aprendizajes esperados. Es importante considerar que las estrategias metodológicas deben ir acompañadas de la habilidad y pericia de los docentes para seleccionar, diseñar y desarrollar 
una estrategia o una combinación de varias. Al respecto, Mayorga y Madrid (2010) sostienen lo siguiente:

Analizar los modelos didácticos y las estrategias de enseñanza del profesorado universitario puede proporcionar un importante caudal de información que permite describir, comprender e interpretar los procesos de enseñanza aprendizaje y, así, llegar a conclusiones acerca de en qué medida el aprendizaje de los alumnos/as universitarios constituye un aprendizaje relevante. (p. 92).

Así también, Mayorga y Madrid (2010) afirman que las estrategias comprenden los enfoques y formas de actuar de los docentes, para dirigir con destreza el aprendizaje de los estudiantes, es decir, que las estrategias metodológicas están referidas a las acciones que favorecen el aprendizaje. Por su parte, Medina (2017) señala:

Las estrategias metodológicas permiten identificar principios, criterios y procedimientos que configuran la forma de actuar del docente en relación con la programación, implementación y evaluación del proceso de enseñanza aprendizaje. Las actividades que realiza el estudiante en el aula y fuera de ella, son estrategias de aprendizaje diseñadas por el profesor para que el estudiante desarrolle habilidades mentales y aprenda contenidos. A través de ellas se desarrollan destrezas y actitudes e indirectamente capacidades y valores utilizando los contenidos y los métodos de aprendizaje como medios para conseguir los objetivos. (p. 126).

Por lo antes expuesto, la mediación del docente y su acercamiento al estudiante a través de estrategias son fundamentales en el proceso de enseñanza-aprendizaje, pues permiten que el estudiante perciba su aprendizaje como significativo y que adquiera conocimientos y habilidades que podrá aplicar en situaciones específicas a lo largo de su vida.

Según Lucarelli (1994, 1999), la inquietud didáctica por la relación que existe entre la teoría y la práctica es un elemento clave para lograr la calidad en la educación, teniendo en 
cuenta que dicha relación establece un rumbo seguro para la innovación, que puede ser entendida como la acción creadora para la mejora mensurable, sensible, premeditada y duradera de una situación actual.

Asimismo, la elección del momento pedagógico adecuado para cada estrategia determina el resultado o el producto del proceso de enseñanza-aprendizaje, de este modo, la acción de identificar la relevancia del nivel de desarrollo y de las diferentes destrezas en los estudiantes permite al docente situarse en el momento preciso para trabajar el desarrollo de habilidades a partir de los aprendizajes construidos o los conocimientos previos, y asimismo, a medida que se adquieren nuevos conocimientos, es posible mejorar la orientación y el diseño del modelo de evaluación.

Finalmente, el docente tiene el compromiso de seleccionar y emplear estrategias de apoyo cuando propone trabajos, tareas y ejercicios específicos para potenciar el desarrollo de habilidades y competencias que motiven a los estudiantes a perseverar en su proceso educativo. Mediante la reflexión acerca de los procesos y procedimientos que comprenden cada estrategia, se logran identificar las dificultades u obstáculos y las formas de resolverlos; de este modo, al finalizar el proceso de enseñanza-aprendizaje, es posible reconocer la efectividad de las estrategias empleadas, en función del logro de objetivos y del desarrollo de nuevos procesos.

\section{Definiciones conceptuales de las subcategorías de estrategia metodológica.}

\section{Planificación estratégica.}

De acuerdo con Moya (2018), la planificación estratégica se compone de una serie de procesos anticipados, generalizados y sistemáticos, para definir en el aula las acciones encaminadas a desarrollar equilibrada y coherentemente los procesos de enseñanza-aprendizaje, y para fijar objetivos, políticas, propósitos y estrategias rectoras que guíen a los docentes y atiendan las necesidades y demandas de los estudiantes. 
Por otro lado, Campusano y Díaz (2017) definen la planificación como un proceso mediante el cual se determinan las metas y se establecen los requisitos para lograrlas de la manera más eficiente y eficaz posible.

Entonces, se puede afirmar que la planificación es un conjunto de procesos que tienen como propósito asegurar el desarrollo de las actividades en el aula, con el objetivo de dirigir los procesos de enseñanza- aprendizaje de manera equilibrada, coherente y pertinente.

\section{Capacidad didáctica.}

De acuerdo con Moya (2018), la capacidad didáctica es definida como la destreza de los docentes para desarrollar los contenidos de manera que resulten comprensibles para los estudiantes; así también, es la capacidad de organizar los contenidos adecuadamente, para que formen parte de una guía integral, tomando en cuenta a los estudiantes, su contexto y los problemas y dificultades de aprendizaje que podrían enfrentar.

Según Monereo (1994), las capacidades hacen referencia al conjunto de disposiciones de tipo genético que, una vez desarrolladas mediante la experiencia que produce el contacto con un entorno culturalmente organizado, darán lugar a las habilidades individuales. De este modo, a partir de las capacidades innatas de ver y oír se forman observadores más o menos hábiles, de acuerdo a las experiencias que hayan tenido.

Mayorga y Madrid (2010), en su revisión conceptual acerca de la didáctica, mencionan que no existe una definición unívoca, sino varias, que la conciben como: ciencia, técnica, arte, norma, estudio, doctrina y procedimiento, hasta llegar a la didáctica entendida como una ciencia de la educación que estudia todo lo relacionado con la enseñanza, lo cual incluye las condiciones, el ambiente y el clima que favorecen el aprendizaje y el desarrollo integral de los estudiantes. Así, se puede observar la complejidad y evolución de la didáctica, como una ciencia teórico-práctica que estudia qué enseñar, cómo enseñar y cuándo enseñar. 
En resumen, la didáctica es una disciplina de carácter normativo y práctico, centrada en las técnicas de enseñanza, es decir, en el arte de orientar y dirigir eficientemente a los estudiantes en su aprendizaje, en su comprensión y organización de la información y contenidos del proceso de enseñanza-aprendizaje y en la solución de las diversas dificultades que se presentan en dicho proceso.

\section{Recursos educativos.}

Los materiales o recursos educativos, de acuerdo con Moya (2018), son todos aquellos instrumentos de soporte, implementos, materiales y apoyos didácticos (libros, guías, vídeos, esquemas, diapositivas, herramientas digitales, imágenes, entre otros) seleccionados por el docente con el propósito de facilitar el aprendizaje de los estudiantes mediante una mayor vinculación.

Los materiales educativos desarrollados con la ayuda de las TIC se caracterizan fundamentalmente por encontrarse en soportes digitales y por ser transmitidos a través de sistemas de telecomunicación.

Finalmente, es importante señalar que el sentido de los materiales educativos proviene de las decisiones que se toman con respecto a sus métodos de selección, a su organización y al uso que se les dará en las actividades, como resultado del análisis y la reflexión del docente acerca de lo que quiere enseñar, lo que espera que los estudiantes aprendan y los procedimientos que debe seguir para lograrlo. 


\section{Capítulo II}

\section{Diagnóstico o trabajo de campo}

\section{Características del campo de estudio}

En el presente capítulo, se detallan los resultados de la aplicación de los diferentes instrumentos y técnicas de recolección de datos. En la investigación se aplicó una encuesta de opinión a los estudiantes del primer ciclo de la carrera de Administración con el fin de evaluar su aprendizaje autorregulado en el proceso de enseñanza-aprendizaje; también, se realizaron entrevistas semiestructuradas a los docentes, para obtener información acerca de sus conocimientos teóricos y prácticos, y las estrategias metodológicas que usan en el proceso del aprendizaje autorregulado de los estudiantes; y finalmente, se realizaron observaciones de sesiones de clase para comprobar los conocimientos teóricos y prácticos de los docentes y estudiantes, así como las estrategias metodológicas usadas por los docentes en el proceso del aprendizaje autorregulado de los estudiantes del primer ciclo de la carrera de Administración.

\section{Análisis e interpretación de los hallazgos por técnicas e instrumentos}

En el trabajo de campo, se revisaron, organizaron y analizaron, de manera reiterada, los datos recopilados mediante los diferentes instrumentos, con el fin de identificar los códigos o conceptos clave relevantes para la investigación.

De acuerdo con Strauss y Corbin (2016), la codificación consiste en un proceso de análisis en el que los investigadores requieren percibir la lógica subyacente de la información, mediante el uso de técnicas y procedimientos, considerando su fluidez y dinamismo. Así, los códigos son comprendidos dentro de su contexto, que en este caso corresponde al proceso de enseñanza-aprendizaje.

Según Gibbs (2012), en la investigación cualitativa se pueden encontrar diferentes enfoques basados en el análisis textual, que pueden ser generales o específicos, según los datos 
que se estén analizando. Por esta razón, es muy importante que los datos sean recogidos y preparados de manera rigurosa, para que puedan ser analizados correctamente.

\section{Presentación de resultados por técnicas de investigación}

Los datos obtenidos en las entrevistas a los docentes, el cuestionario a los estudiantes y la observación de las sesiones de clase fueron tratados con rigurosidad durante todo el proceso, lo cual implicó su transcripción, revisión, codificación, análisis e interpretación, de forma ordenada y comprensible, considerando que los datos incluyen acciones, conversaciones y situaciones enmarcadas en un contexto educativo específico. La información ordenada por técnicas e instrumentos se detalla a continuación.

\section{Encuesta realizada a los estudiantes.}

Se aplicó una encuesta de opinión a los estudiantes del primer ciclo de la carrera de Administración de una universidad privada de Lima, a través de un cuestionario, y la información fue procesada con el software SPSS. La encuesta se realizó a un grupo de 38 estudiantes del primer ciclo de la carrera de Administración de una universidad privada de Lima, con el fin de verificar el aprendizaje autorregulado de los estudiantes en el proceso de enseñanza-aprendizaje. Seguidamente, se detallan los resultados del cuestionario aplicado.

En relación a la pregunta: ¿Usted demuestra capacidad en el procesamiento de información del tema que desarrolla en la sesión de clase?, los hallazgos demuestran que el $49.5 \%$ de los estudiantes encuestados indicaron que pocas veces demuestran capacidad en el procesamiento de información del tema que se desarrolla en la sesión de clase, 39.5\% señalaron que nunca y $11 \%$ respondieron que casi siempre.

En cuanto a la pregunta acerca de si el docente permite esclarecer las estrategias de repaso, elaboración y organización, los hallazgos muestran que el $47.4 \%$ de los estudiantes encuestados indicaron que pocas veces el docente les permite establecer las estrategias de 
repaso, elaboración y organización, 38.9\% señalaron que nunca y 13.7\% respondieron que casi siempre.

Aquí es importante mencionar que Barbosa, Canós, de Araujo, Perelló-Marin y Santandreu (2019) indican que "la elección de las estrategias de aprendizaje es individual porque cada alumno es único y debe valorar sus habilidades y conocimientos para cada una de las asignaturas" (p. 5). Entonces, la labor del docente implica valorar las características individuales de cada estudiante, y desde allí proponer y trabajar las diferentes estrategias en las sesiones de aprendizaje.

Acerca de la pregunta: ¿usted acostumbra adoptar metas en relación con los propósitos para implicarse en las tareas y actividades académicas?, el $44.7 \%$ de los estudiantes encuestados indicaron que pocas veces acostumbran adoptar metas en relación con los propósitos para implicarse en las tareas y actividades académicas; 39.5\% señalaron que nunca; y $15.8 \%$ respondieron que casi siempre.

Entonces, sobre las metas, Gaeta González (2014) citados por Moreno, Chiecher y Paoloni (2019), indican que el docente puede lograr influenciar en las metas de los estudiantes si estas son dinámicas y flexibles, y que en este proceso, el docente tiene las importantes tareas de ayudar a sus estudiantes, de seleccionar y utilizar las estrategias más adecuadas, de establecer metas, de reflexionar sobre sus maneras de aprender, de adoptar actitudes positivas y creencias motivacionales a fin de que ellos logren un aprendizaje autónomo.

Cuando se preguntó a los estudiantes si consideran que el docente contribuye en el desarrollo de sus creencias motivacionales, como la autoeficacia, interés personal y valor de las tareas, el $44.7 \%$ de los estudiantes encuestados indicaron que pocas veces; $39.5 \%$ señalaron que nunca y $15.8 \%$ respondieron que casi siempre. En relación con esto, Aparicio (2008) citado por Moreno, Chiecher y Paoloni (2019) señala: 
Las relaciones entre motivación, aprendizaje y rendimiento académico ocupan un importante espacio en la agenda de la investigación educativa y han sido ampliamente investigadas. Desde la perspectiva de los estudiantes, cada vez son más aquellos que manifiestan estar desmotivados frente a la carrera elegida, que expresan sentirse desgastados por los niveles extremos de exigencia y desilusionados por los pobres panoramas profesionales. Desde la visión de los docentes, son comunes las expresiones relativas al bajo rendimiento de los alumnos, la escasa preparación al iniciar la carrera, la falta de interés, entre otras. (p. 7).

Así, los resultados en esta parte de la investigación muestran que, efectivamente, existe una deficiencia en el procesamiento de información, en el uso de estrategias y en la adopción de metas y creencias motivacionales. En relación con dichas deficiencias, se debe mencionar que el procesamiento de información es fundamental para que los estudiantes organicen, analicen y reflexionen acerca de lo que van aprendiendo. Asimismo, las estrategias corresponden a las distintas maneras en que el estudiante puede dinamizar y potenciar su aprendizaje. Por otro lado, las metas permiten al estudiante evaluar sus propios progresos o avances, su rigurosidad con respecto a sus plazos y la flexibilidad de su propio proceso. Finalmente, las creencias motivacionales son las que ayudan a los estudiantes a continuar su proceso de aprendizaje, mediante la ayuda del docente. En las respuestas de los estudiantes se puede observar su percepción sobre la falta de estrategias, metas y creencias motivacionales que consideran importantes en su aprendizaje, y es evidente además que los estudiantes notan la falta de ayuda de los docentes en las sesiones de clase.

\section{Entrevista a los docentes.}

En las entrevistas realizadas a los docentes, se evidencia poco conocimiento sobre el aprendizaje autorregulado y su falta de uso en las estrategias. En relación a la pregunta: ¿de qué forma motiva a los estudiantes en las tareas y actividades académicas?, los entrevistados 
indicaron que desarrollan la tutoría de los estudiantes desde el primer ciclo, como un acompañamiento permanente, personalizado y de mayor cercanía, que algunos docentes denominan coaching; además, señalaron que el estudiante recibe orientaciones que buscan desarrollar una familiaridad entre docente y estudiante, en la que el docente determina qué hacer y qué no hacer.

Según Moreno, Chiecher y Paoloni (2019), la motivación no solo trata de la influencia de las expectativas sobre la forma de actuar, sino que es un proceso en el que la persona es capaz de dirigir su atención hacia una actividad y persistir en ella, para lograr un propósito específico; de allí la importancia de la motivación en el aprendizaje, pues permite a los estudiantes tener expectativas sobre los resultados y lograr un comportamiento persistente enfocado en sus metas académicas.

Los docentes entrevistados, ante la pregunta: ¿cuáles son los procesos anticipados, sistemáticos y generalizados que plantea para concretar los planes de desarrollo en las sesiones de clases?, ¿cómo los aplicas?, respondieron que aplican el silabo y la rúbrica del curso, que observan las competencias de los estudiantes y adaptan los materiales de clase según el grupo, por ejemplo, uno de los entrevistados mencionó que suele adaptar el material educativo en función del género predominante del grupo de estudiantes de la clase.

De acuerdo con Díaz et al. (2017), los desafíos del aprendizaje, cuando se habla de competencias personales y profesionales, involucran a la institución educativa y a todos sus integrantes académicos y administrativos. La institución debe ser flexible en sus enfoques y esquemas, para ello, son necesarios los cambios en el currículo, en la didáctica, en los métodos de evaluación y en los procedimientos de estudio, para mejorar la forma de aprender de los estudiantes, el planteamiento de objetivos y las maneras de educar, con el fin de lograr que los estudiantes adopten un rol activo y colaborativo en su propio proceso de aprendizaje. 
Acerca de la pregunta: ¿cuáles son las acciones tendientes que determina para el desarrollo equilibrado y coherente de los procesos de enseñanza-aprendizaje?, ¿cómo las aplicas?, los docentes entrevistados señalaron que emplean dinámicas grupales en las que se busca la participación de todos los estudiantes y se propicia su interacción. Los docentes mencionaron que insisten en su uso, a pesar de que la primera reacción de los estudiantes hacia este tipo de dinámicas es de rechazo, porque consideran que mediante ellas se logra la integración de todo el grupo.

En resumen, se evidencia poco conocimiento acerca del aprendizaje autorregulado y de estrategias y procesos anticipados, sistémicos y generalizados, necesarios en todo el proceso de enseñanza-aprendizaje, considerando que el docente es el encargado y el responsable de preparar las sesiones de clase de tal manera que sean aprovechadas al máximo por los estudiantes. Según Bandura (1986, 1997 y 2001) citado por Díaz et al. (2017), en los procesos de autorregulación del aprendizaje, el docente actúa como un modelo para sus estudiantes, en las expresiones de sus procesos cognitivos y metacognitivos, y en su disposición hacia el aprendizaje. Entonces, el docente no solo es especialista de los contenidos que enseña, sino también lo es en la orientación de diversas formas de estudiar, que pueden aplicarse antes, durante y después de las sesiones de clase.

\section{Observación de clase.}

En las observaciones de clase, se evidenció que los docentes no respetan las normas establecidas, como llegar a clase a tiempo, preparar con anticipación los materiales que serán usados en la sesión o cumplir con el desarrollo de los temas señalados en el sílabo de la asignatura. Cuando el docente llega tarde al aula, genera en los estudiantes un rechazo que se evidencia en la falta de atención. Asimismo, se pudo notar que los estudiantes consideran que esta situación es habitual y que no ha cambiado a pesar de sus reclamos. Los estudiantes indicaron que estos retrasos impiden que la exposición temática del docente, los ejercicios 
realizados en clase y la retroalimentación sean abordados en su totalidad, y que en consecuencia, se sienten menos preparados para afrontar las evaluaciones del curso, a pesar de estudiar por su propia cuenta fuera de las horas de clase.

También, se observó que el docente no cuenta con conocimientos sólidos sobre los temas que desarrolla en clase. Durante la mayor parte de la sesión, se evidenció un discurso docente carente de orden, de claridad y de propósito, y a la vez, se observó que la mayoría de estudiantes distraían su atención en otras actividades. Asimismo, se pudo observar que el docente no respondía las dudas mediante fundamentos teóricos, lo cual ocasionaba mayor confusión y frustración en los estudiantes, lo cual se hizo evidente en sus actitudes.

Asimismo, a partir de la revisión del sílabo del curso, se evidenció que el docente no desarrolla los temas programados, y que el tiempo designado para la sesión de clases muchas veces es utilizado para la revisión individual de los avances de proyectos que los estudiantes deben presentar al final del ciclo; sin embargo, dichas revisiones fueron de utilidad solo para una pequeña minoría. De acuerdo con la programación temática del sílabo del curso y la consulta al docente acerca de los temas pendientes de ser desarrollados, se pudo evidenciar su falta de planificación y cumplimiento de plazos.

Así también, los docentes que fueron observados en sus respectivas sesiones de clase evidenciaron deficiencias en sus habilidades comunicativas, que ocasionaban problemas de comunicación con sus estudiantes y confusión acerca de los temas. Se observaron deficiencias en el manejo de emociones de los docentes, que ocasionalmente derivaban en enfrentamientos con los estudiantes. Asimismo, se pudo notar una interacción escasa del docente con los estudiantes, si bien algunos de los estudiantes planteaban preguntas e inquietudes, el docente, en ocasiones, se mostraba indiferente y no las atendía. En general, se evidenció la falta de liderazgo de los docentes en la labor que desarrollan en el aula y en las relaciones que establecen con sus estudiantes. 
Según Naranjo (2019), un docente percibido como bueno por sus estudiantes debe poseer habilidades sociales y comunicacionales, también habilidades duras, pero principalmente habilidades blandas. También se tiene en consideración la calidad humana que el docente refleja en su profesionalismo, compromiso y responsabilidad. Los estudiantes observan atentamente a sus docentes y esperan encontrar en ellos no solo conocimientos sobre los temas que necesitan desarrollar, sino también líderes cercanos y modelos de vida y aprendizaje que los motiven a seguir adelante, que los reten a nuevos desafíos, pero que también los ayuden en las diferentes situaciones que se presentan en el proceso de enseñanzaaprendizaje.

\section{Análisis e interpretación de las categorías emergentes y las apriorísticas}

En este punto se muestran las categorías emergentes genéricas, las cuales son el resultado de clasificar, comparar y relacionar los códigos. Luego del proceso de codificación, categorización y triangulación metodológica y de datos, se procedió a redactar las conclusiones aproximativas para cada una de las 13 categorías emergentes, seis de las cuales corresponden a las categorías apriorísticas, mientras que siete son categorías nuevas.

Los resultados de la investigación fueron interpretados y sometidos a discusión, para lo cual se aplicó la triangulación teórica, que de acuerdo con Alzás, Casa, Luengo, Torres y Verissimo (2016), permite considerar y confrontar diferentes corrientes teóricas, para analizar y explicar el objeto de estudio, lo cual descarta posibles sesgos, brinda diferentes perspectivas, confirma o descarta hipótesis existentes y permite la aparición de hipótesis alternativas.

En el proceso interpretativo, es necesario que el investigador sea capaz de elaborar un informe reflexivo y crítico de los resultados obtenidos, en el que se evidencie la relación entre los grupos emergentes de categorías, las conclusiones aproximativas y la constatación de diferentes corrientes teóricas (Mayz, 2009). Así, se muestra el resumen de las categorías emergentes de la investigación en la siguiente figura: 


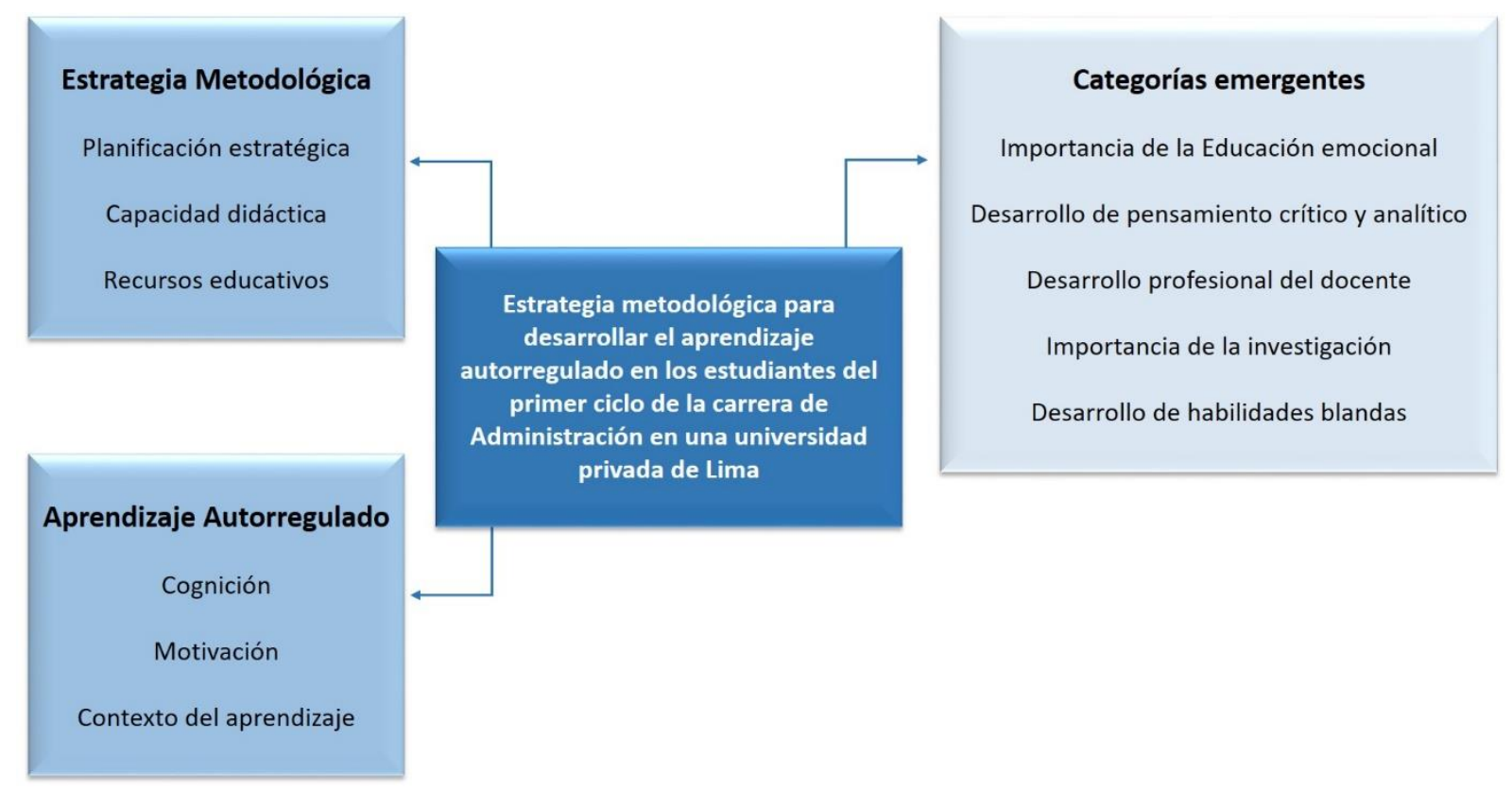

Figura 1. Categorías emergentes y apriorísticas.

A continuación, se detallan los resultados obtenidos con respecto a las subcategorías apriorísticas:

En relación con la cognición en los procesos de enseñanza-aprendizaje, los resultados evidencian que permite organizar y procesar información para aprender, recordar, planear, entender y percibir. Se observó que los docentes y estudiantes cuentan con recursos cognitivos escasos; por un lado, el docente no ha procesado la información de manera adecuada y por tanto su explicación en clase carece de orden, estructura, enfoque y fundamento teórico, y por otro lado, los estudiantes perciben que solo logran comprender una pequeña parte de las lecturas que profundizan los temas desarrollados en clase. Los recursos cognitivos son muy importantes en el proceso de enseñanza-aprendizaje porque los docentes y estudiantes necesitan procesar, organizar y comprender gran cantidad de información de manera continua, por lo cual, la cognición debe ser desarrollada desde la escuela básica; sin embargo, se evidencian carencias cognitivas tanto en docentes como en estudiantes universitarios.

De acuerdo con González et al. (2017), el procesamiento de la información considera dos aspectos del pensamiento de los estudiantes, que son la memoria y los esquemas. Los esquemas incluyen técnicas y estrategias para que el estudiante pueda representar la 
información de su propia autorregulación dirigida hacia una tarea; dichos esquemas permiten el encuentro entre cognición y motivación, y generan una guía para la autorregulación del aprendizaje. El estudiante necesita desarrollar procesos y estrategias para codificar, organizar, procesar y recuperar la información aprendida. El desarrollo de estas estrategias se inicia en la escuela básica con la ayuda del docente, luego, en el nivel superior, el docente acompaña y refuerza aspectos del procesamiento de información.

Por otro lado, la motivación, de acuerdo con los resultados obtenidos, permite actuar, orientarse hacia un objetivo y mantener la acción. Los docentes entrevistados consideraron que ellos no son los encargados de motivar a los estudiantes y afirmaron que cada estudiante debe buscar su motivación personal para alcanzar el éxito en sus proyectos. Asimismo, los estudiantes observados expresaron mucho desánimo ante las dificultades que afrontan en su proceso de aprendizaje; además, se pudo evidenciar sus expectativas de que los docentes fueran los agentes motivadores en el aula, mediante consejos, palabras de ánimo, retos académicos y recursos de orientación y perseverancia ante las dificultades.

La motivación es un componente necesario en el proceso de enseñanza-aprendizaje, puesto que los estudiantes requieren de un impulso adicional para persistir, lograr sus objetivos y alcanzar el éxito en su aprendizaje; entonces, el docente juega un papel clave, pues, a partir de su experiencia propia y su contacto directo con los estudiantes, se convierte en la primera fuente externa de motivación para ellos.

Según Torrano y González (2004), los estudiantes que autorregulan su aprendizaje poseen una serie de creencias motivacionales, como el sentido de autoeficacia académica, la adopción de metas de aprendizaje y el desarrollo de emociones positivas frente a las tareas, además de la capacidad de controlarlas, modificarlas y ajustarlas, de acuerdo con los retos y dificultades de su proceso de aprendizaje. Por ello, es necesario enfatizar su importancia en el proceso de enseñanza-aprendizaje, teniendo en cuenta que los estudiantes enfrentan 
continuamente diferentes situaciones que requieren de creencias motivacionales sólidas que influyan directamente en su motivación para aprender y en las maneras y la calidad con que gestionan la información.

La subcategoría apriorística contexto del aprendizaje, según los hallazgos, se entiende como el conjunto de características de la clase, como el clima emocional, la percepción de las normas en el aula, el ambiente físico, los métodos de enseñanza, la percepción de las tareas y evaluaciones, y las demandas del docente. El clima emocional debe ser regulado por el docente, sin embargo, se observó que las acciones de los docentes en las sesiones de clases dificultaban su vínculo con los estudiantes y generan un clima de confrontación. En el proceso de enseñanzaaprendizaje, es necesario que el vínculo entre docente y estudiante sea fortalecido por el respeto, la buena comunicación y la confianza, para que, a pesar de las situaciones de tensión o de dificultad en el aula, el clima emocional siga siendo positivo.

Por su parte, Nocito (2013) señala, acerca del contexto del aprendizaje, que las apreciaciones de las normas y el clima de la clase son aspectos importantes en el conocimiento de la información contextual, teniendo en cuenta su influencia en el proceso de enseñanzaaprendizaje. Aunque el docente tiene el mayor control del contexto del aprendizaje, no se puede negar las oportunidades que los estudiantes tienen para participar activamente en su regulación. Entonces, si bien tanto docentes como estudiantes pueden intervenir en la regulación y control de su contexto, es el docente quien lleva la mayor parte de responsabilidad, por ello, son necesarias las habilidades blandas que le permitan transformar su propio contexto para el desarrollo óptimo del proceso de enseñanza-aprendizaje.

De acuerdo con los resultados de la investigación, la subcategoría apriorística planificación estratégica puede ser entendida como el conjunto de procesos anticipados, sistemáticos y generalizados para concretar las acciones en las sesiones de clase. Se observó que los docentes no aplican dichos procesos, pues las sesiones fueron improvisadas y no se 
cumplieron los temas indicados en el sílabo del curso; asimismo, el desarrollo de la clase no evidenció un orden o una estructura prevista por el docente. Si bien es cierto que en el sílabo se establecen los temas, actividades y evaluaciones, también es importante que el docente cuente con una planificación estratégica sólida que le permita fortalecer el desarrollo de los contenidos, con la finalidad de que cada sesión de clases sea aprovechada al máximo por los estudiantes.

Según Camilloni (1998), los docentes deben tener en cuenta todos los temas que integrarán los programas, pero también es importante que consideren las maneras más efectivas de desarrollarlos en las sesiones de clase. Entonces, no es posible separar los temas de las estrategias para abordarlos, por lo que se requiere una etapa de planificación, en la que se revise el tema a profundidad y se seleccionen las mejores estrategias para presentarlo, desarrollarlo y evaluarlo. Es necesario que el docente trabaje mediante una minuciosa planificación estratégica que le permita lograr sesiones de clase dinámicas y reflexivas.

En relación con la subcategoría apriorística capacidad didáctica, en los hallazgos de la investigación se evidenció que es la capacidad de los docentes para desarrollar los contenidos de manera comprensible y conveniente para los estudiantes. En las sesiones de clase, se observó que los docentes desarrollaban los contenidos de manera desordenada, si un objetivo definido, y muchas veces, mediante un discurso desvinculado del tema correspondiente, lo cual dificultaba la comprensión de los estudiantes, ocasionaba confusión y desaprovechaba la oportunidad de aprendizaje. Considerando que cada docente tiene su propia manera de enseñar, y que el aprendizaje está sujeto a factores como el cansancio, el estrés o el desánimo, es vital que la información de cada sesión de clase sea plenamente comprensible por los estudiantes, y que puedan procesarla adecuadamente.

De acuerdo con Rivadeneira (2017), las habilidades didácticas son muy importantes, pues permiten a los docentes y estudiantes actuar de manera autónoma y responsable. El docente, gracias a esas habilidades, es capaz de transformar la información en conocimientos y 
de acercarlos a los estudiantes mediante la interacción en en el proceso de enseñanzaaprendizaje. También, es necesario mencionar que la calidad de la gestión de la didáctica es responsabilidad del docente y está relacionada directamente con su calidad profesional.

Del mismo modo, los resultados evidencian que la subcategoría apriorística recursos educativos incluye todos los instrumentos de apoyo que el docente usa para lograr un mayor acercamiento con los estudiantes. Si bien los docentes contaban con herramientas y recursos físicos y virtuales que podían ser usados en las sesiones de clase, fue evidente que no los aprovecharon de la mejor manera, pues mientras algunos de ellos desconocían el funcionamiento de los equipos visuales, otros simplemente no utilizaban recursos educativos y desarrollaban las sesiones únicamente mediante el discurso. Es importante que los docentes tengan en cuenta que los estudiantes de hoy son considerados nativos digitales, por lo que no es conveniente que las sesiones de clases sean únicamente discursivas. Entonces, es necesario que los docentes se capaciten en el manejo de nuevas tecnologías que les permitan tener acceso a recursos que apoyen y nutran sus sesiones de clases, para dinamizar y facilitar el aprendizaje de sus estudiantes.

Acerca de los recursos educativos virtuales, Pinto, Gómez-Camarero, FernándezRamos y Doucet (2017) mencionan los siguientes criterios que deben tenerse en cuenta en la selección de recursos educativos para favorecer el aprendizaje: objetivos y metas de aprendizaje, calidad del contenido, retroalimentación, usabilidad, motivación, accesibilidad, requerimientos técnicos, propiedad intelectual y efectividad del recurso desde el punto de vista del aprendizaje.

A continuación, se detallan los hallazgos encontrados sobre las categorías emergentes:

\section{Importancia de la educación emocional en los docentes y estudiantes.}

En las sesiones de clase se pudo observar en varias oportunidades un desborde de emociones de parte de docentes y estudiantes. Los docentes manifestaron que muchas veces no saben 
manejar sus emociones, lo cual les produce frustración, apatía y desánimo, por ejemplo, ante situaciones injustas en la institución, confrontaciones con otros docentes e incluso en las sesiones de clases, en las que se encuentran con un grupo de estudiantes que tampoco han desarrollado un dominio sobre sus propias emociones.

Los estudiantes señalaron que muchas veces se sienten molestos, frustrados, confundidos y muy desanimados por todas las situaciones y los problemas que deben afrontar, y que no encuentran la manera de resolverlos, y que a causa de eso, muchas veces reaccionan con rebeldía o apatía, lo cual influye negativamente en su desarrollo personal y académico. En ambos casos, la situación fue muy evidente, tanto los docentes como los estudiantes necesitaban ayuda para afrontar las diferentes dificultades diarias a través del manejo sus emociones, pues reconocieron que su vida personal y profesional estaba siendo afectada.

Es interesante señalar que Malaisi (2019) considera que la educación emocional es una estrategia educativa, no terapéutica, cuyo fin es mejorar la calidad de vida de los estudiantes, mediante el desarrollo de habilidades emocionales. La propuesta de Malaisi incluye también a los docentes y padres de familia, como parte de un trabajo integral para promover la salud emocional desde los espacios educativos, donde los estudiantes logran ser capaces de construir un proyecto de vida.

Es importante que los estudiantes se conozcan a sí mismos, que se conecten con su realidad, que la disfruten con sus altibajos y que proyecten su futuro desde un presente saludable. La educación emocional considera todo el contexto educativo, pues solo en un contexto saludable se puede mantener la salud de los docentes, de los padres de familia y de toda la institución educativa. 


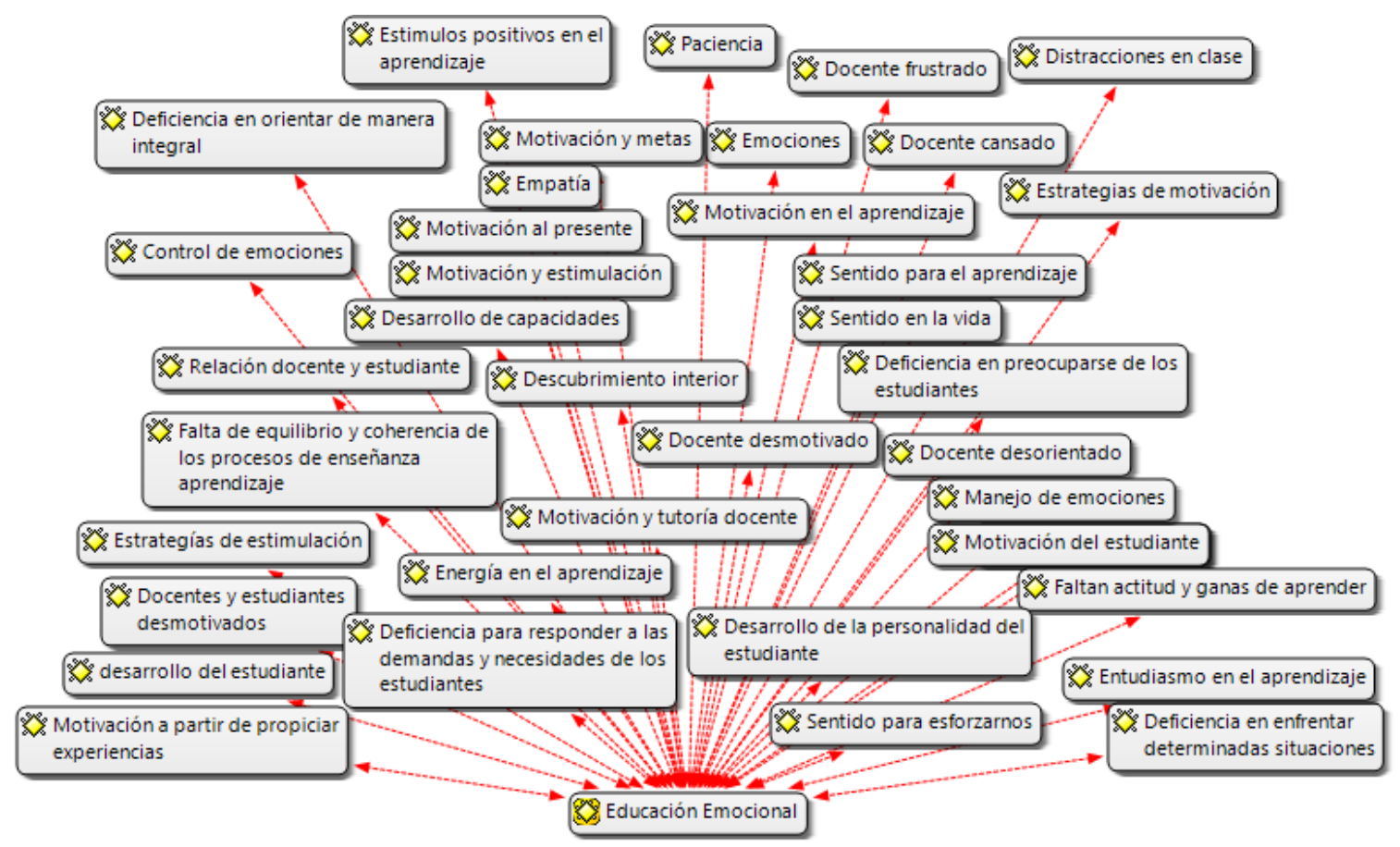

Figura 2. Importancia de la educación emocional en docentes y estudiantes.

\section{Desarrollo del pensamiento crítico y analítico.}

Los docentes y estudiantes mencionaron la importancia de las habilidades creativas y el pensamiento crítico y analítico, sin embargo, la observación de las sesiones de clase evidenció carencias en dichas áreas. Las sesiones se desarrollaron con un nivel muy básico, y fueron mecanicistas, tradicionalistas y memoristas. También, se observó la falta de pensamiento crítico, pues los docentes y estudiantes no analizaron ni evaluaron la información, de manera independiente, para entender las ideas y recordarlas, no distinguieron las cuestiones principales de las secundarias, no consideraron criterios razonables en la evaluación de la información, no consideraron puntos de vista alternativos, no estuvieron dispuestos a cambiar de opinión a pesar de las pruebas y argumentos, no percibieron sus propias contradicciones y no lograron explicar sus propias opiniones o creencias. Se observó un problema similar con respecto al pensamiento analítico, pues los docentes y estudiantes no lograron descomponer sistemáticamente un tema complejo en sus elementos, no lograron hallar conexiones entre dichos elementos, no 
recopilaron información suficiente sobre el tema y no lograron proponer soluciones o alternativas apropiadas. Respecto a esto, López et al. (2016) sostienen:

La educación superior debe formar ciudadanos críticos, reflexivos y analíticos, para que se puedan desarrollar de acuerdo con las pretensiones y necesidades que demanda el tercer milenio, y sobre todo, intencionar una actuación honesta; así la sociedad se ve retribuida de manera equitativa e igualitaria. Se trata de lograr en el estudiante habilidades reflexivas, pensamiento crítico, actitud investigativa y de comunicación, reforzando la competencia de aprender a aprender. (p. 2).

Es necesario, entonces, que las sesiones de clase sean desarrolladas de tal manera que fortalezcan el pensamiento crítico y analítico, mediante el uso de formas, estrategias y metodologías que correspondan a las tendencias actuales del aprendizaje. En los procesos de enseñanza-aprendizaje, se debe tener en cuenta la importancia de fortalecer las operaciones intelectuales, la reflexión y el pensamiento crítico y analítico; por ello, es necesario que las sesiones de clase sean procesos formativos coherentes, comprensibles, reflexivos e investigativos, en los que los estudiantes se transforman en individuos que aprenden a aprender.

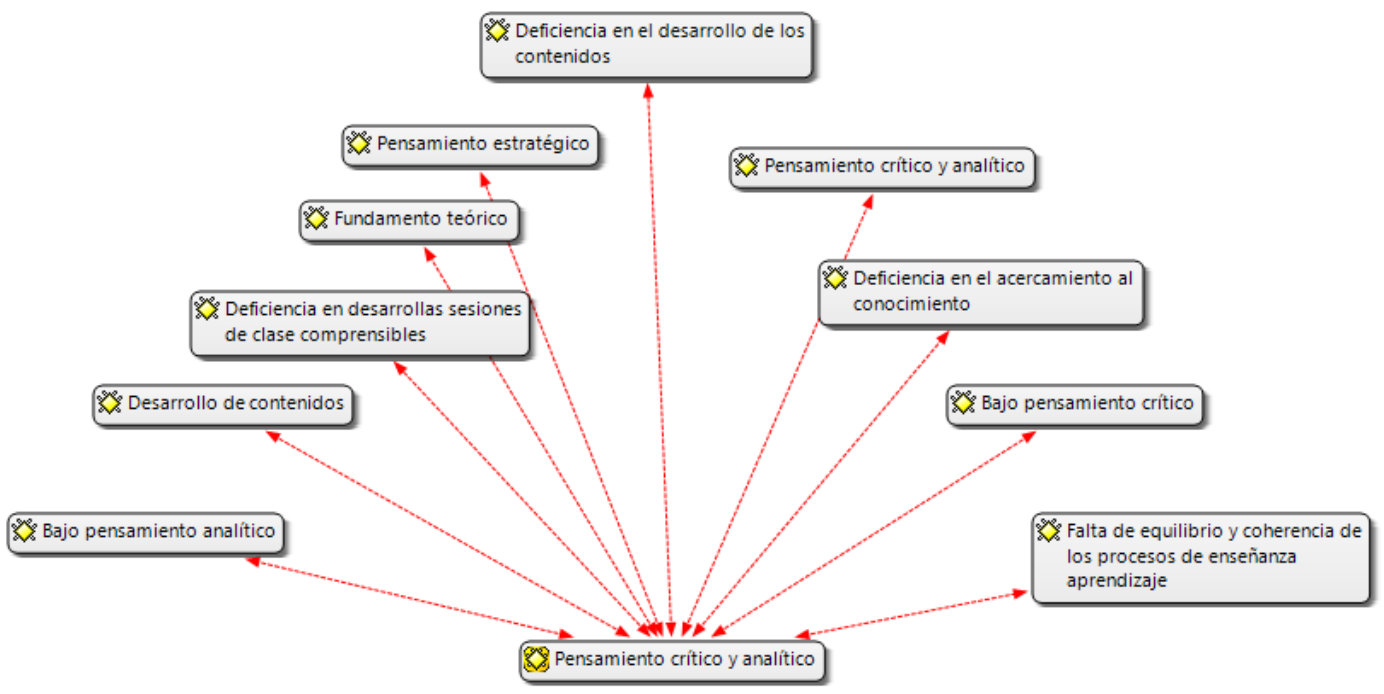

Figura 3. Desarrollo del pensamiento crítico y analítico. 


\section{Deficiencia en el desarrollo profesional de los docentes.}

A partir de la observación de las sesiones de clase, se evidenciaron deficiencias en el desarrollo profesional de los docentes, relacionadas con el aprendizaje continuo. Los docentes entrevistados contaban con algunas nociones teóricas sobre las nuevas estrategias, métodos y formas de aprendizaje, pero no las aplicaban en el aula. Las sesiones de clase carecían de fundamentos teóricos sólidos, estrategias didácticas y metodología. Por tal razón, las evaluaciones generaban frustración en los estudiantes, pues no habían logrado el aprendizaje de los temas del curso.

Korthagen, Loughran y Russell (2006) mencionan tres programas exitosos de desarrollo profesional de los docentes en Holanda, Australia y Canadá, en los que resaltan la importancia de los siguientes aspectos: el enfoque en la forma de aprender de la experiencia y la manera de construir conocimiento profesional, el conocimiento entendido como una materia por construir, el énfasis en los estudiantes desde el currículo, el fomento de la investigación, la integración, el fortalecimiento de las relaciones con las instituciones educativasy la concepción del formador como el modelo principal de los futuros docentes. De acuerdo con esto, se necesitan docentes que aprendan con la práctica y que continúen aprendiendo durante toda su vida, lo que implica mecanismos complejos y de largo plazo que requieren desde la voluntad individual hasta la participación de las instituciones educativas y del Gobierno. 


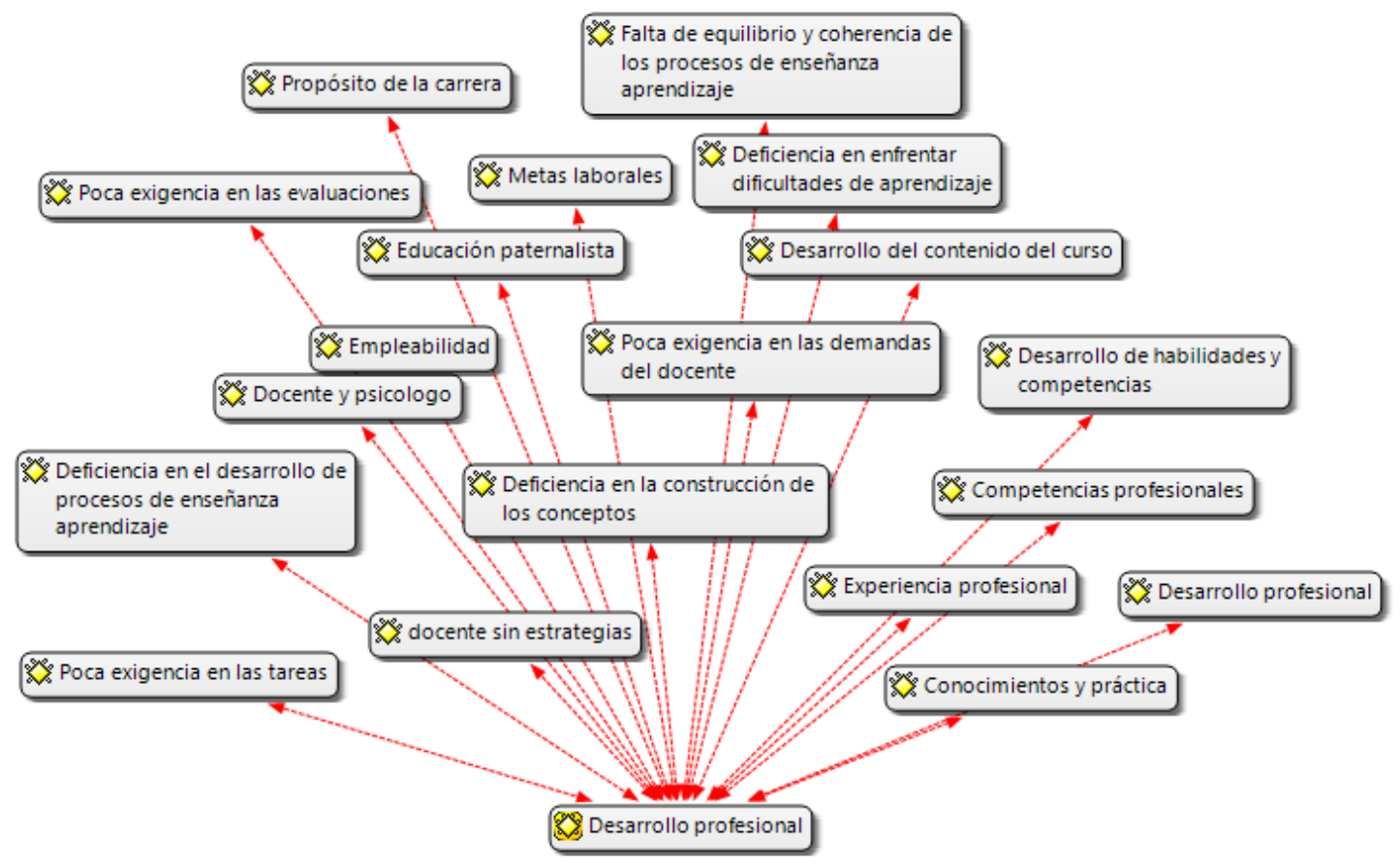

Figura 4. Deficiencias en el desarrollo profesional de los docentes.

\section{Importancia de la investigación en el proceso de enseñanza-aprendizaje.}

Los docentes entrevistados señalaron que en sus sesiones de clase se promueve la investigación y que los estudiantes tienen la oportunidad de investigar y profundizar sobre diferentes temas, con el propósito de enriquecer su aprendizaje; sin embargo, en las sesiones de clase se observó una realidad muy diferente. Se pudo evidenciar que el docente asignaba a los estudiantes la tarea de investigar de manera grupal sobre algún tema, para luego socializar los resultados en la clase. Muchos estudiantes no supieron cómo abordar los procesos requeridos en la investigación, la mayoría de ellos limitó su labor a la búsqueda de información en la red, sin rigurosidad ni supervisión docente. Al finalizar, los estudiantes socializaron los resultados de su investigación, y se observó que el docente únicamente confirmaba lo expuesto por los estudiantes, sin analizar ni reflexionar sobre la calidad de la información y las fuentes, y sin extraer conclusiones. Respecto a este punto, Wise (1996) citado por Gil (2017), señala lo siguiente: 
El principal elemento que diferencia a las estrategias metodológicas alternativas o innovadoras es el empleo de una enseñanza basada en la investigación, que implica un mayor protagonismo del alumnado en el aprendizaje a través de su participación en procesos de investigación guiados por el profesor. (p. 176).

Por lo antes expuesto, se necesita resaltar la importancia de la investigación en el proceso de enseñanza-aprendizaje, en el que el docente es el principal investigador que actúa como ejemplo y modelo para los estudiantes, quienes son continuamente retados a participar de forma activa en diferentes experiencias de investigación, dentro y fuera del aula. Sin la investigación, los docentes y estudiantes tendrían solo roles pasivos en las sesiones de clases.

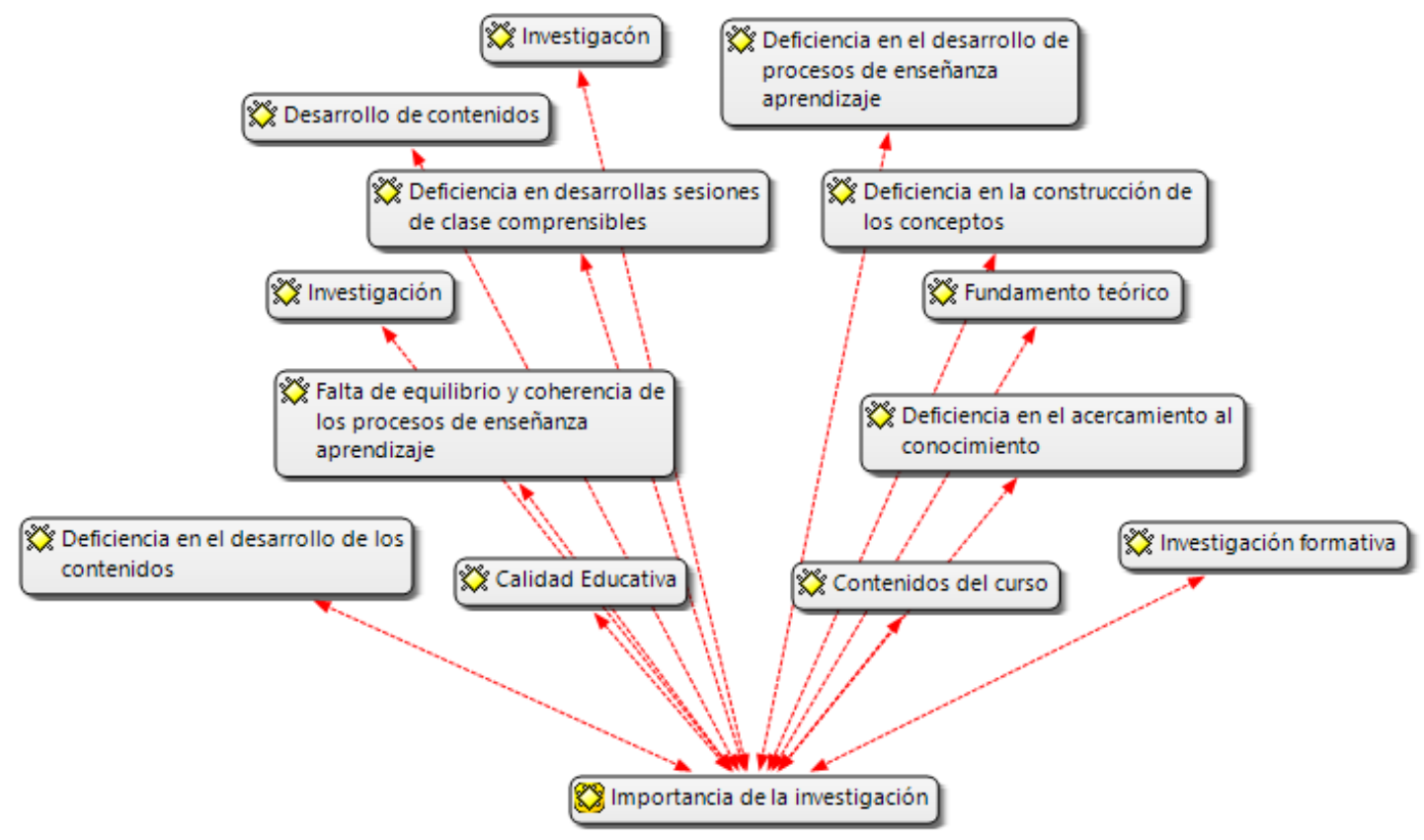

Figura 5. Importancia de la investigación en el proceso de enseñanza-aprendizaje.

\section{Desarrollo de habilidades blandas en los docentes y estudiantes.}

En las sesiones de clase, se notó la necesidad del desarrollo de habilidades blandas en los docentes y estudiantes, para mejorar su comunicación y sus relaciones interpersonales, su creatividad, su trabajo en equipo y su liderazgo, con el fin de favorecer el proceso de enseñanzaaprendizaje, que requiere de relaciones sólidas y saludables entre docentes y estudiantes. 
De acuerdo con Cimatti (2016), las habilidades blandas se refieren a las competencias personales transversales, como las capacidades comunicativas, las capacidades sociales, el trabajo en equipo, la amabilidad, entre otros rasgos de la personalidad. Las habilidades blandas se consideran tradicionalmente como complementarias de las habilidades duras, que son aquellas que permiten realizar un tipo de tarea o actividad concreta.

Las habilidades blandas tienen una importancia estratégica para el éxito en la vida personal y profesional, y son esenciales para cualquier candidato a un puesto de trabajo. Generalmente, las empresas contratan trabajadores, particularmente recién graduados, priorizando sus habilidades blandas sobre sus habilidades duras. Esto sucede también en las profesiones técnicas, como las ingenierías, pues las empresas necesitan crear equipos buenos y efectivos, y un ambiente de trabajo colaborativo, para ser competitivas.

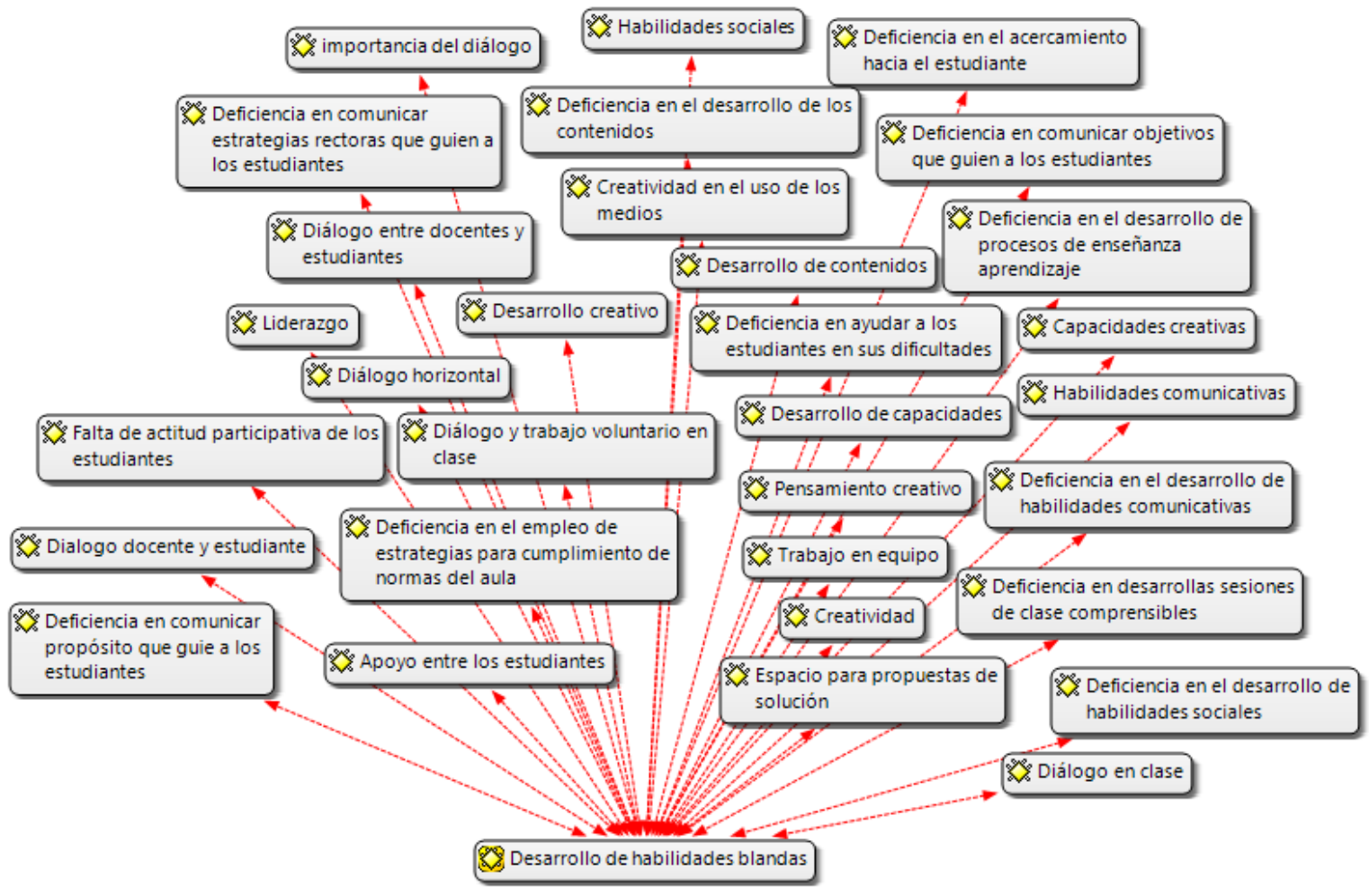

Figura 6. Desarrollo de habilidades blandas en los docentes y estudiantes. 


\section{Categorías influyentes en el problema}

En esta investigación, se observó un bajo nivel cognitivo en docentes y estudiantes, sobre todo en el procesamiento de la información, lo cual afectaba directamente el desarrollo de las sesiones de clases, las actividades y tareas que los estudiantes debían realizar en casa, y las evaluaciones. Al no conocer los pasos básicos de una investigación, los estudiantes tuvieron dificultad para conseguir información académica de buena calidad, para ordenar y organizar dicha información, y principalmente, para lograr aprendizajes a partir de ella. Del mismo modo, los docentes tuvieron dificultades para organizar la gran cantidad de información que debían procesar para cada sesión de clases, lo cual se evidenció en los problemas que se presentaron en las aulas.

También es preciso mencionar que se hallaron muchas deficiencias en las capacidades didácticas del docente. Las sesiones de clase fueron muy elementales, sin actividades ni recursos didácticos que ayudaran a mejorar el aprendizaje de los estudiantes. Los docentes contaban con ciertos conocimientos teóricos sobre didáctica, pero en la observación de las clases se pudo notar que no los ponían en práctica, lo cual perjudicaba enormemente el proceso de enseñanza-aprendizaje, pues los estudiantes percibían las clases como repetitivas y poco interesantes.

Asimismo, se logró observar muchas dificultades en el área de las emociones, tanto en docentes como en estudiantes, pues en las sesiones de clase se evidenciaban la tensión, la frustración, el enojo y otro tipo de emociones que perjudicaban el proceso de enseñanzaaprendizaje. Se observaron situaciones en las que no hubo control de las emociones, lo cual generó mayores niveles de cansancio y desgaste, y afectó las relaciones entre docentes y estudiantes.

Además, se observó la carencia de habilidades blandas, pues hubo muchos problemas de comunicación entre docentes y estudiantes; así, se pudo notar la necesidad de fortalecer el 
liderazgo dentro y fuera del aula, empezando por el liderazgo del docente. Así también, se observó que los estudiantes no supieron trabajar en equipo y que eso afectó el desarrollo de los temas, debido a la falta de dinámica. Finalmente, se encontró que las relaciones interpersonales debían mejorar, pues los docentes y estudiantes se encontraron en confrontación muchas veces, por diferentes motivos.

Luego de haber observado y escuchado a docentes y estudiantes, se concluye que la educación emocional en docentes y estudiantes es el punto de partida necesario para todo el trabajo que se necesita realizar, debido a su importancia en el proceso de enseñanzaaprendizaje. Es necesario que los docentes y estudiantes observen sus emociones, las conozcan y acepten, y que a partir de esa aceptación, las disfruten como parte importante de su vida.

En otros países de la región, la educación emocional es un tema vigente desde hace décadas, por tanto, es tiempo de que en el Perú se asuma la responsabilidad de la salud emocional, desde las aulas hacia toda la sociedad, para formar ciudadanos responsables de sí mismos y para cuidar a los docentes, que muchas veces enfrentan sin ayuda un sinnúmero de dificultades en su labor educativa. 


\section{Capítulo III}

\section{Modelación y validación de la propuesta}

\section{Propósito}

La propuesta de la investigación consiste en la aplicación de estrategias metodológicas en la práctica de los docentes, para que los estudiantes aprendan, en sus diferentes cursos, a autorregular su aprendizaje.

Entonces, se propone que los docentes adopten estas estrategias que potencian la autorregulación, para lograr sesiones de clase en las que el estudiante es retado a participar de manera más activa, a planificar, a gestionar su tiempo, a establecer metas, a regular sus procesos cognitivos y motivacionales, etc.; es decir, para lograr un cambio que inicie en el docente y se proyecte hacia los estudiantes.

En el trabajo de campo se comprobó la falta de autorregulación del aprendizaje tanto en la práctica docente como en la forma de aprender de los estudiantes. La realidad que se observó es alarmante: sesiones de clase sin una estructura definida, falta de fundamentos teóricos, docentes y estudiantes desmotivados, falta de planificación y, sobre todo, falta de estrategias autorreguladoras en todo el proceso. Si bien algunos docentes tenían algunos conocimientos sobre el aprendizaje autorregulado, no los ponían en práctica en sus sesiones de clase. Es necesario decir que la autorregulación del aprendizaje es un tema que se menciona mucho en el campo de la educación, pero suele aplicarse muy pocas veces en la práctica.

Por lo antes expuesto, se ha diseñado una propuesta de estrategia metodológica para desarrollar el aprendizaje autorregulado, estructurada en tres fases y basada en los modelos teóricos de Pintrich y Zimmerman.

\section{Justificación}

La presente propuesta se justifica en la necesidad de una nueva mirada en la formación y educación para todos, donde el aprender a lo largo de la vida deje de ser solo una expresión y 
se convierta en una realidad para todos los ciudadanos. Esta nueva manera de ver la educación implica que docentes y estudiantes desarrollen un aprendizaje autorregulado para enseñar y aprender. Es necesario que el estudiante tome una posición más activa en su proceso de aprendizaje, en el conocimiento de sus procesos cognitivos y motivacionales, para autogestionar su aprendizaje con la ayuda de los docentes. Por ello, el docente debe actuar como mediador, para lograr que sus estudiantes aprendan a aprender, y más importante aún, para ayudarlos a aprender a pensar, teniendo en cuenta todos aquellos elementos y variables necesarios para potenciar el aprendizaje autorregulado.

Es necesario seguir investigando sobre aprendizaje autorregulado, para profundizar sobre los diferentes enfoques que presentan los investigadores; pero dichas investigaciones deben conseguir que el aprendizaje autorregulado, como modo de aprender, llegue a las sesiones de clase, que esté presente en la práctica de los docentes y que sea una realidad en la experiencia educativa de los estudiantes.

Entonces, la propuesta está orientada a ayudar a los docentes y estudiantes a desarrollar el aprendizaje autorregulado mediante una estrategia metodológica que incluye la planificación estratégica, los recursos didácticos y las capacidades didácticas, con el fin de transformar el proceso de enseñanza-aprendizaje en uno en el que los docentes y estudiantes logran fluir, dentro y fuera de las aulas, en sus propios aprendizajes, de manera autorregulada.

\section{Fundamentación teórico-científica}

\section{Fundamentación socioeducativa.}

La investigación fue realizada en una institución ubicada en el distrito de Santiago de Surco, en la ciudad de Lima. El distrito está ubicado en una zona donde la mayoría de residentes pertenecen a una clase social media alta. Sin embargo, la mayoría de los estudiantes de la universidad son jóvenes provenientes de colegios públicos y privados de zonas de clase $\mathrm{C}$, si bien hay una minoría de clase A y B. 
La universidad tiene como visión al 2021 ser una de las primeras instituciones con reconocimiento de la excelencia de sus egresados por los empleadores y por la propia sociedad. La institución se identifica como promotora del desarrollo integral de la persona y del país, su plana docente está conformada por maestros y doctores expertos en enseñanza universitaria, con publicaciones indizadas y otras expresiones de creación cultural. Su reconocimiento internacional está plasmado en la movilidad de profesores y estudiantes con universidades extranjeras en todas sus carreras profesionales. La universidad tiene como misión la formación de personas integrales y de profesionales creadores y competitivos globalmente.

Actualmente, la universidad cuenta con ocho facultades: Arquitectura, Ciencias Biológicas, Ciencias Económicas y Empresariales, Derecho y Ciencias Políticas, Humanidades y Lenguas Modernas, Ingeniería, Medicina Humana y Psicología. Además, las autoridades de la universidad están organizadas de la siguiente manera: Asamblea Universitaria, Consejo Universitario, Rectorado y Consejos de Facultad. Asimismo, cada facultad cuenta con un decano y cada carrera, con un director académico.

\section{Fundamentación psicopedagógica.}

\section{Teoría sociocultural de Vigotsky.}

La propuesta de estrategia metodológica para desarrollar el aprendizaje autorregulado se fundamenta en la teoría sociocultural de Vigotsky (1978), teniendo en cuenta que uno de sus elementos fundamentales es considerar al individuo como un ser social cuyo proceso de desarrollo se encuentra condicionado por la mediación social e histórica, en la que el aprendizaje es fundamental y va de la mano con las funciones psicológicas superiores, las cuales también tienen un origen social. Entonces, el contexto social y cultural del estudiante es de vital importancia, porque la relación del individuo con su entorno le permitirá reconocerse en su propia realidad, para aprender y desarrollarse en ella. 
Según Ortiz (2015), el aprendizaje para Vigotsky es el resultado de la relación del individuo con el entorno social en el que se reconoce. Por eso, es importante que este entorno realmente colabore con el autodescubrimiento del individuo y con el papel que desarrolla en su propia vida y en la sociedad. Para algunos estudiantes, este descubrimiento implicará un viaje con muchos episodios de confusión y frustración, y para otros, será una travesía de entendimiento y claridad; pero todos estarán influenciados por el entorno, en diferentes medidas y con diferentes resultados. Esto es muy evidente en los estudiantes provenientes de realidades sociales muy distintas entre sí, unos muy favorables y otros llenos de situaciones problemáticas. Entonces, es importante que la relación que los estudiantes establecen con su entorno potencie su aprendizaje.

Además, en la teoría de Vigotsky se señala que las funciones psíquicas primarias como la atención, la memoria, el pensamiento y la percepción se convierten en funciones superiores mediante la interacción social. Acerca de ello, Acosta (2013) indica que la conversión de funciones primarias en funciones superiores a través de la interrelación social permite llegar al proceso de internalización, donde el sujeto genera aprendizajes, apropiándose de su entorno social y cultural, mediante instrumentos y signos. Por ello, es posible afirmar que la internalización se produce gracias a la interacción social y a la enseñanza.

A continuación, se aborda uno de los aportes más importantes de Vigotsky: la Zona de Desarrollo Próximo, proceso complejo en el que se puede identificar a dos participantes activos, el que aprende y el que ayuda al que aprende, y que se puede definir como la brecha que existe entre las capacidades que el individuo ya posee (denominado nivel de desarrollo real) y las capacidades que puede lograr aprender para resolver los problemas de manera independiente, (llamado nivel de desarrollo potencial), y en la que la resolución de los problemas se da bajo la guía de alguien más capaz (Vigotsky, 1988). 
Por ende, es necesario que el docente sea un guía para sus estudiantes durante todo el proceso de enseñanza-aprendizaje, porque la mayoría de ellos requieren la ayuda de docentes o compañeros más capaces para poder afrontar las diferentes dificultades que se presentan durante el aprendizaje. Algunas de estas situaciones podrían ser consideradas insignificantes, pero para un estudiante poco experimentado, muchas veces, podrían ser determinantes para su futuro académico.

En la Zona de Desarrollo Próximo se menciona el papel del mediador, que puede corresponder a docentes, otros profesionales de las instituciones educativas (por ejemplo, los psicólogos), familiares, compañeros, entre otros. Respecto a esto, Nieva y Martínez (2019) sostienen que el papel del mediador es muy significativo en la teoría de Vigotsky, y que gracias a su participación, el aprendizaje se observa como un proceso dinámico que involucra la intervención del medio y la comunicación, y que es preciso tener en cuenta la relación del individuo con todos estos elementos.

Por consiguiente, es de vital importancia tener en cuenta que el estudiante establece y desarrolla relaciones con su entorno social y cultural, que cada elemento (docentes, compañeros, ambiente físico, etc.) influye en su proceso de aprendizaje, en menor o mayor proporción, y que por este motivo, cada uno de ellos debe ser identificado y observado de manera individual y conjunta, a fin de comprender cómo interviene en dicho proceso.

\section{Teoría sociocognitiva - Pintrich y Zimmerman.}

La propuesta también se fundamenta en las teorías sociocognitivas de Paul Pintrich y Barry Zimmerman, teniendo en consideración las importantes investigaciones que ambos autores han realizado sobre el tema de la autorregulación.

Para Lepe (2016), la era de la información que actualmente vivimos y los rasgos tan personales de los estudiantes requieren que estos logren desarrollar las estrategias que les permitan un aprendizaje cada vez más autónomo. En esta propuesta, se profundizará en los 
aportes de Pintrich y Zimmerman, cuya diferencia central es que Pintrich entiende el aprendizaje como un proceso predominantemente social, mientras que Zimmerman propone que la responsabilidad recae principalmente en el sujeto que aprende. En esta propuesta, se ha buscado tomar lo mejor de ambos autores, a juicio de la investigadora, en beneficio de los estudiantes, de los docentes y de los profesionales interesados en el tema del aprendizaje autorregulado a nivel universitario.

De acuerdo con Zimmerman (2000), la autorregulación es un proceso compuesto de actividades planificadas, estratégicas y monitoreadas, en las que el individuo se plantea metas y objetivos personales, y abarca áreas como la cognición, la motivación y la conducta. Por otro lado, Pintrich (2000) menciona cuatro áreas del aprendizaje autorregulado: la cognición, la motivación, el comportamiento y el contexto, que se comentarán a continuación.

En relación con los temas cognitivos para la educación, de acuerdo con Anderson (2005) y Eysenck y Keane (2005), el proceso de aprendizaje es constructivo y no receptivo, las estructuras mentales organizan la memoria y orientan el pensamiento; de este modo, los autores indican que, en el desarrollo de las habilidades cognitivas, son fundamentales la práctica frecuente, la autorregulación y la autoconciencia, así como las creencias, la motivación y las interacciones sociales. Asimismo, señalan que el conocimiento y las estrategias son visiblemente contextuales, y que la orientación cognitiva de la enseñanza implica nuevas orientaciones de la evaluación.

Entonces, en el estudio de la cognición, se representa a los individuos como procesadores de información, considerando su interacción con las metas y las creencias, y su desarrollo en diferentes contextos dentro y fuera del aula. En la cognición se resalta la importancia de las actividades que desarrollan los estudiantes, las estrategias que diseñan, seleccionan y utilizan, y las estructuras mentales que construyen para llegar a la comprensión y a la creación de significados. 
Acerca de la motivación, Lens, Matos y Vanteenkiste (2008) sostienen que se trata de un proceso psicológico complejo, en el que interactúan diversos aspectos del individuo, como su personalidad y su percepción del entorno, y que es influenciado tanto por los cambios que la persona experimenta interiormente, como por los cambios en su ambiente. Por otro lado, Huertas (1997) y McClelland (1985) consideran que las personas vienen al mundo con una carga de motivación, y que la falta de motivación es aprendida más tarde.

Entonces, es posible afirmar que la motivación del estudiante por aprender, descubrir, investigar o crear es innata, y que se adapta a través de las distintas experiencias en las sesiones de aprendizaje. Por ello, es importante convertir la sesión de clase en una experiencia potenciadora de la motivación del estudiante, y es importante mencionar que la carga de motivación del docente influirá directamente sobre sus estudiantes, sea para potenciar su motivación o para inhibirla. Si bien la motivación es muy importante en los estudiantes, el docente es responsable de todo lo que se experimenta y aprende en el aula, por tanto, un docente motivado será más capaz y efectivo para enseñar a los estudiantes a automotivarse, como parte de su proceso de autorregulación.

Según Berridi y Martínez (2017), el comportamiento del estudiante en el aprendizaje autorregulado implica la planeación, el manejo de los esfuerzos y la elección, de modo que sus acciones son planeadas, ejecutadas y adaptadas cíclicamente para alcanzar sus metas propuestas. Además, los autores mencionan que los diferentes modelos de aprendizaje autorregulado asumen que los estudiantes son capaces de monitorear y controlar aspectos conductuales de su aprendizaje. Por ello, es importante, para los docentes y estudiantes, observar, estudiar y analizar su comportamiento en el aprendizaje autorregulado, para realizar los ajustes y cambios necesarios, pues si bien el proceso de autorregulación incluye varias fases y elementos internos, el comportamiento es la evidencia física de lo que sucede a nivel cognitivo, motivacional y contextual. 
En lo referente al contexto, se espera que en las aulas, los docentes permitan cierta libertad a los estudiantes, para que ellos mismos organicen sus tiempos y actividades, y combinen de manera efectiva sus responsabilidades académicas y laborales (Pintrich, 2000). Es decir, es importante que los estudiantes tengan un control cada vez mayor de su contexto de aprendizaje. Si bien los docentes pueden proponer diferentes metodologías, estrategias y recursos que varían según el grupo de estudiantes y sus necesidades específicas, estas propuestas deben incluir pensamiento crítico y analítico, investigación, reflexión, valoración de las tareas, entre otros elementos del aprendizaje autorregulado. De este modo, el docente fomentará la autorregulación de sus estudiantes, para que participen de manera activa en sus propios procesos de aprendizaje.

El estilo de enseñanza de cada docente es una parte importante del contexto del proceso de enseñanza-aprendizaje, por ello, es de suma importancia que los docentes tengan en cuenta en sus propios estilos las variables y elementos del aprendizaje autorregulado, para asegurar un contexto favorable para un aprendizaje eficaz y profundo.

Sin embargo, teniendo en cuenta la perspectiva cognitiva y social del aprendizaje autorregulado, se puede notar la ausencia de procesos de autorregulación, como producto de la falta de planificación, supervisión y control de las actividades que desarrollan docentes y estudiantes. Además, se carece de guías y modelos válidos que sean una ayuda real para manejar las diferentes dificultades que se presentan durante el proceso de enseñanza-aprendizaje, por ejemplo, la apatía de estudiantes y docentes (Zimmerman, 2000). Los tiempos actuales requieren que los estudiantes sean individuos que autorregulen su aprendizaje, y esto solo es posible si los docentes también lo son, pues son estos los mediadores en los procesos de autorregulación.

Por ello, el papel del docente es clave en el aprendizaje autorregulado, en el que actúa como orientador o mediador y ejerce una función de andamiaje en el aprendizaje de los 
estudiantes (Bruner, 1974), con el objetivo de que logren procesos cada vez más estratégicos, metacognitivos y autorregulados.

A nivel universitario, existen muchos docentes que asumen que la mayoría de estudiantes puede desarrollar un aprendizaje autorregulado sin ayuda u orientación, sin embargo, la realidad muestra que los estudiantes sí requieren de un acompañamiento en su proceso de aprendizaje en diferentes niveles y áreas, pues este acompañamiento es parte esencial de enseñar al estudiante a autorregularse. Así, el docente puede compartir con el estudiante conocimientos, estrategias, herramientas y recursos, así como su experiencia personal para afrontar retos y dificultades, motivarse, tomar control de las situaciones y reflexionar.

De acuerdo con Pintrich (1987) y Zimmerman (2002), las universidades deberían tener como uno de sus objetivos principales la formación de estudiantes capaces de aprender de manera autónoma, y no como un objetivo meramente académico, sino en relación con el futuro de sus estudiantes, con su desenvolvimiento laboral y con su aprendizaje continuo durante las diferentes etapas de su vida. Por esta razón, es necesario que los estudiantes comprendan de qué se trata el aprendizaje autorregulado, lo cual les permitirá regular sus estrategias cognitivas y afectivo-emocionales, que incidirán sobre su desarrollo, crecimiento y aprendizaje durante toda la vida.

En conclusión, se pueden encontrar muchas propuestas e ideas sobre el aprendizaje autorregulado, pero en la presente investigación, se considera que los modelos de Pintrich y Zimmerman reúnen sus fases y elementos más representativos. Por un lado, Pintrich presenta un enfoque predominantemente social, en el que el contexto está formado por una amplia gama de elementos que deben tenerse en cuenta para analizar el proceso de enseñanza-aprendizaje de manera más práctica y real; por ejemplo, el nuevo contexto actual originado por la pandemia de COVID-19 hace imprescindible el planteamiento de cambios profundos en la enseñanza. Por 
otro lado, Zimmerman se enfoca principalmente en la responsabilidad del estudiante, si bien este sigue necesitando de la mediación de los docentes, cuyo propósito es la formación de estudiantes cada vez más autorregulados.

\section{Fundamentación curricular.}

La Ley General de Educación 28044, en su artículo 3, señala que "la educación es un derecho fundamental de la persona y de la sociedad. El Estado garantiza el ejercicio del derecho a una educación integral y de calidad para todos y la universalización de la Educación Básica”. Así, el derecho a la educación permite a las personas lograr una vida social plena, por ello, es necesario que sea integral, que no solo se trate de adquirir conocimientos, sino que considere todos los aspectos, necesidades y dimensiones del individuo.

Asimismo, el artículo 13 de la ley define la calidad de la educación de la siguiente manera: "es el nivel óptimo de formación que deben alcanzar las personas para enfrentar los retos del desarrollo humano, ejercer su ciudadanía y continuar aprendiendo durante toda la vida”. La mención que hace la ley acerca del aprendizaje continuo tiene una relevancia especial en la presente investigacón, pues la propuesta de desarrollo de aprendizaje autorregulado no solo tiene un fin académico, sino también de desarrollo integral a lo largo de la vida de los estudiantes. De este modo, una educación de calidad debe incluir el aprender a aprender durante toda la vida, es decir, debe lograr que los individuos alcancen un aprendizaje autónomo que les permita regular sus procesos cognitivos, motivacionales, contextuales y conductuales.

Aquí es necesario mencionar las siguientes nociones de calidad en la educación superior desarrolladas por Harvey y Green (1993): a) la calidad es algo excepcional y está ligada a la excelencia; b) una cultura de la calidad está relacionada con la perfección o consistencia; y c) la calidad implica el desarrollo de las capacidades de los estudiantes y su capacitación para encargarse de su propia transformación. Entonces, se necesita que la calidad en la educación 
sea tomada en serio en la práctica, y no solo como una expresión, pues de ella depende la calidad de ciudadanos y el desarrollo como sociedad.

Por otro lado, la Ley 30220 establece la creación de la Superintendencia Nacional de Educación Superior Universitaria (SUNEDU), la cual es responsable de supervisar la calidad del servicio educativo a nivel universitario. Es importante mencionar que esta ley ha sido objeto de muchas críticas y cuestionamientos de parte de las llamadas "universidades chicha" (Lynch, 2019), que se caracterizan por su baja calidad educativa y se oponen a la supervisión. Sin embargo, se debe señalar que la SUNEDU ha puesto en evidencia, en muchos casos, la falta de condiciones básicas para una educación de calidad, que ha afectado a universidades públicas y privadas del país.

De acuerdo con Lynch (2019), la diferencia de fondo entre las universidades públicas y privadas consiste en que, mientras en las universidades públicas, su gratuidad permite la creación de condiciones apropiadas para la generación de conocimientos de forma desinteresada, en las universidades privadas priman los intereses privados, cuyo principal objetivo son las ganancias inmediatas y no la creación de espacios de libertad para producir conocimientos. Lamentablemente, en los últimos años, la falta de calidad ha afectado a la mayoría de universidades, razón por la cual se necesita mayor supervisión y exigencia en el cumplimiento de condiciones básicas para una educación de calidad, para que las universidades públicas y privadas conserven, promuevan y sigan creando espacios libres y democráticos que permitan el desarrollo del pensamiento y la producción de conocimientos.

La propuesta contribuirá con el logro de competencias de la carrera de Administración. A continuación, se presentan las competencias, contenidos y capacidades establecidos en el sílabo del curso Matemática I, correspondiente al primer ciclo de la carrera, con una duración de 17 semanas u 85 horas lectivas distribuidas en 5 horas semanales, 3 de teoría y 2 de práctica, además de 54 horas no lectivas. 
Tabla 2

Competencias, contenidos y capacidades

\begin{tabular}{|c|c|c|c|}
\hline \multicolumn{4}{|c|}{ Unidad I - Lógica matemática y conjuntos } \\
\hline Competencias & Contenidos & Capacidades & $\begin{array}{l}\text { Actividad de } \\
\text { Aprendizaje }\end{array}$ \\
\hline \multirow{3}{*}{$\begin{array}{l}\text { Aplica } \\
\text { acertadamente los } \\
\text { conceptos y } \\
\text { métodos de la } \\
\text { matemática } \\
\text { básica, en el } \\
\text { planteamiento y } \\
\text { solución de } \\
\text { problemas } \\
\text { específicos de su } \\
\text { formación } \\
\text { profesional. }\end{array}$} & $\begin{array}{l}\text { Proposición lógica. Proposición } \\
\text { simple y compuesta. Valor de } \\
\text { verdad. Operadores lógicos: } \\
\text { negación, conjunción, } \\
\text { disyunción, condicional y } \\
\text { bicondicional. } \\
\text { Tablas de verdad. Evaluación de } \\
\text { esquemas lógicos. } \\
\text { Implicación. }\end{array}$ & $\begin{array}{l}\text { Determina el valor de una } \\
\text { proposición lógica y las } \\
\text { operaciones que las } \\
\text { relacionan. } \\
\text { Evalúa un esquema } \\
\text { molecular. } \\
\text { Determina la validez de una } \\
\text { Implicación Lógica. }\end{array}$ & $\begin{array}{l}\text { Prueba de } \\
\text { entrada. } \\
\text { Exposición } \\
\text { dialogada. } \\
\text { Solución de } \\
\text { ejercicios y } \\
\text { casos. } \\
\text { Trabajo en } \\
\text { equipo. }\end{array}$ \\
\hline & $\begin{array}{l}\text { Conjuntos. Idea intuitiva de } \\
\text { conjunto. Determinación de } \\
\text { conjuntos. Relación de } \\
\text { pertenencia e inclusión. } \\
\text { Diagramas de Venn-Euler. } \\
\text { Clases de conjuntos. Potencia de } \\
\text { un conjunto. Conjuntos } \\
\text { numéricos. } \\
\text { Cuantificadores: universal y } \\
\text { existencial, y su uso en el } \\
\text { lenguaje matemático. }\end{array}$ & $\begin{array}{l}\text { Aplica correctamente las } \\
\text { relaciones de pertenencia e } \\
\text { inclusión para afirmaciones } \\
\text { propuestas. } \\
\text { Analiza y resuelve } \\
\text { problemas utilizando } \\
\text { subconjuntos y diagramas de } \\
\text { Venn. } \\
\text { Utiliza los cuantificadores } \\
\text { como lenguaje matemático. }\end{array}$ & $\begin{array}{l}\text { Exposición } \\
\text { dialogada. } \\
\text { Solución de } \\
\text { ejercicios y } \\
\text { casos. } \\
\text { Trabajo en } \\
\text { equipo. }\end{array}$ \\
\hline & $\begin{array}{l}\text { Operaciones con conjuntos: } \\
\text { unión, intersección, diferencia, } \\
\text { diferencia simétrica, } \\
\text { complemento. } \\
\text { Cardinal de un conjunto. }\end{array}$ & $\begin{array}{l}\text { Resuelve problemas } \\
\text { utilizando las operaciones } \\
\text { con conjuntos. } \\
\text { Resuelve problemas } \\
\text { relacionados con su } \\
\text { especialidad, utilizando la } \\
\text { cardinalidad de los } \\
\text { conjuntos. }\end{array}$ & $\begin{array}{l}\text { Exposición } \\
\text { dialogada. } \\
\text { Solución de } \\
\text { ejercicios y } \\
\text { casos. } \\
\text { Trabajo en } \\
\text { equipo. } \\
\text { Taller }\end{array}$ \\
\hline
\end{tabular}

Fuente: Adaptado del silabo del curso de matemática I de la UPC (2019).

\section{Diseño de la propuesta}

Se propone una solución al problema de cómo desarrollar el aprendizaje autorregulado en los estudiantes del primer ciclo de la carrera de Administración de una universidad privada. Se parte del estado real (diagnóstico), de acuerdo a lo hallado en el trabajo de campo y se realiza la intervención, para alcanzar un estado ideal o logros que responden a los objetivos de la investigación. La propuesta se elaboró a partir de fundamentos socioeducativos, psicopedagógicos y curriculares. A continuación, se muestra el esquema teórico funcional de la propuesta. 


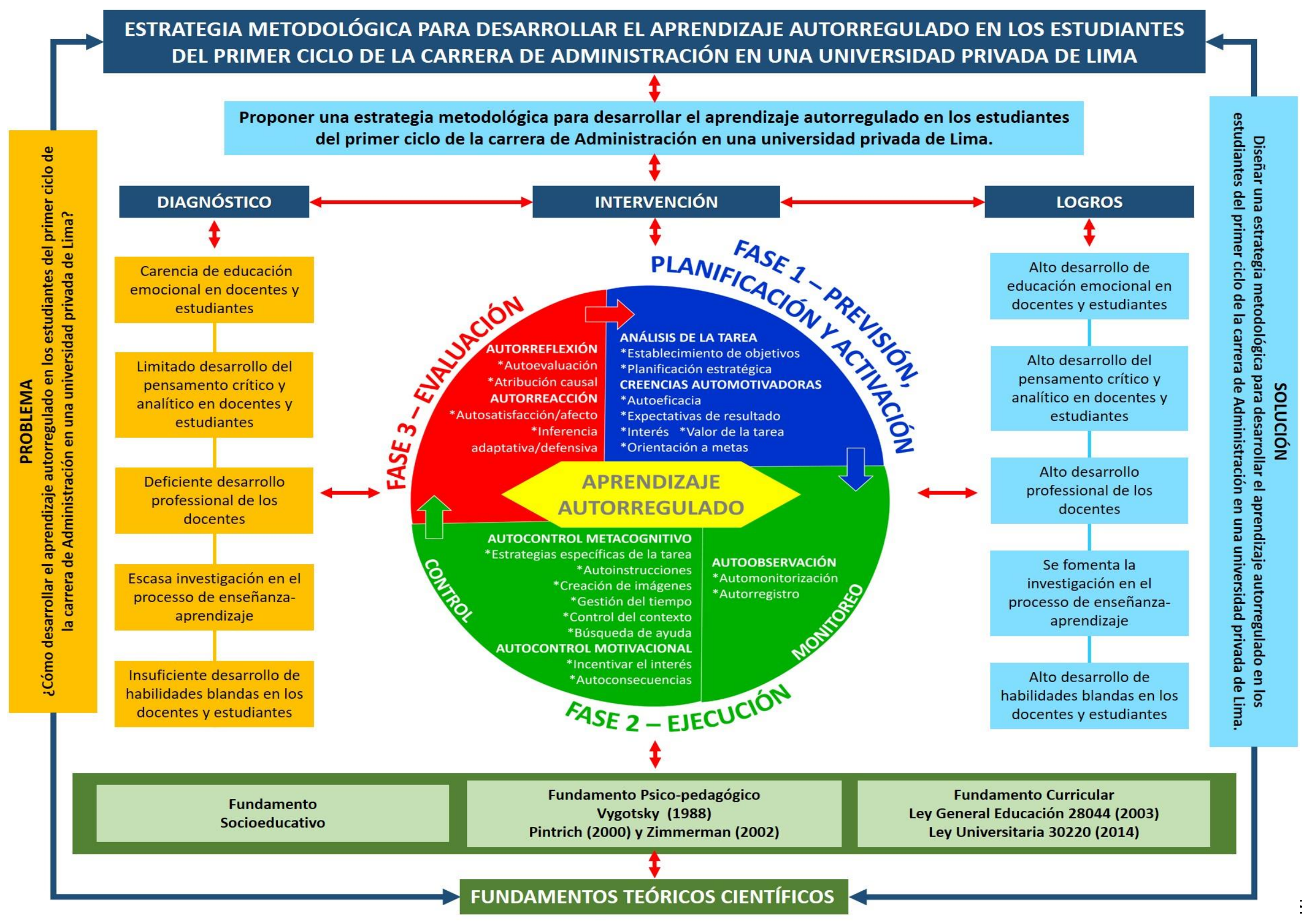




\section{Objetivos de la propuesta}

El objetivo general de la propuesta es diseñar una estrategia metodológica para lograr el desarrollo de aprendizaje autorregulado en los estudiantes del primer ciclo de la carrera de administración de una universidad privada, y se desarrollará en tres fases: previsión, planificación y activación; ejecución y evaluación,

Asimismo, se plantean los objetivos específicos para cada fase. En la fase de previsión, planificación y activación, el objetivo es que los estudiantes, con el uso de estrategias de autorregulación, se encuentren preparados y motivados para iniciar su proceso de aprendizaje. En la fase de ejecución, el objetivo es que los estudiantes afronten su proceso de aprendizaje de modo autorregulado. En la fase de evaluación, el objetivo es que los estudiantes logren reflexionar sobre su desempeño en su proceso de aprendizaje, autoevaluarse y estar listos y motivados para emprender un nuevo desafío académico, mediante el desarrollo de su aprendizaje autorregulado, lo cual involucra, cognición, motivación, contexto y conducta.

\section{Didáctica asumida en la propuesta}

Se asume la didáctica desarrolladora que, de acuerdo con Hernández, García, López, Velástegui y Ramírez (2016), es aquella en la que el estudiante realmente se siente el protagonista de su aprendizaje, deja de lado la posición de receptor pasivo y desarrolla una mayor actividad mental creadora, buscando significados y encontrando argumentaciones de forma constante, autodirigida y comprometida, estableciendo metas y plazos, asimilando sus propios errores y siendo consciente de sus capacidades, fortalezas y debilidades. Asimismo, en la didáctica desarrolladora, el estudiante asume el esfuerzo como un factor importante para conseguir resultados y valora en gran medida el acto de aprender, pues lo considera importante tanto en el aspecto académico como para su desarrollo personal.

Asimismo, Fernández, Rivero, Cañizares y Pastás (2016) indican que el aprendizaje desarrollador "garantiza en el individuo la apropiación activa y creadora de la cultura, 
propiciando el desarrollo de su autoperfeccionamiento constante, de su autonomía y autodeterminación, en íntima conexión con los necesarios procesos de socialización, compromiso y responsabilidad social” (p. 86). Así, el aprendizaje no es un proceso aislado, y el aprendizaje desarrollador, como se puede ver, involucra procesos que promueven el desarrollo integral del individuo (emociones, conocimientos, habilidades, destrezas, motivaciones, valores, ideales, etc.), que desarrollan su autonomía y autorregulación con capacidades para conocer, transformar y controlar su propia vida y su entorno, y que potencian su capacidad para aprender a aprender constantemente, a lo largo la vida.

\section{Rol del docente}

De acuerdo con McCombs (1993), teniendo en cuenta el contexto en el que se quiere lograr el aprendizaje autorregulado, los docentes deben cumplir las siguientes funciones: comprender a sus estudiantes (necesidades, objetivos e intereses), ayudarlos a establecer objetivos de aprendizaje, relacionar los contenidos y las actividades que se desarrollan en la sesión de clases con las necesidades, objetivos e intereses de los estudiantes, darles la oportunidades de asumir el control de su contexto de aprendizaje, crear en las sesiones de clases un clima de confianza, seguridad y apoyo para todos, fomentar la cooperación, destacar el valor de la responsabilidad y el cumplimiento de metas, valorar las habilidades y destrezas particulares de cada estudiante y estimular su autorrecompensa por los logros obtenidos.

El docente ha dejado de ser un transmisor de información y no puede considerarse como la única fuente de información para los estudiantes. El docente actual fomenta la responsabilidad y la actividad del estudiante en su propio proceso de aprendizaje, para lo cual le ofrece su experiencia y sus conocimientos. En relación con el aprendizaje autorregulado, es necesario que el docente asuma un rol de mediador, consejero, guía y facilitador. Asimismo, el docente debe tener en cuenta que cada estudiante aprende de manera única, por tanto, debe experimentar diferentes caminos, estrategias y herramientas con el fin de ser un ejemplo de 
adaptabilidad y flexibilidad para ellos, y de prepararlos para tiempos cambiantes, como los actuales, en los que se necesitan individuos capaces de autorregular su aprendizaje.

\section{Rol del estudiante}

Según Pérez et al. (2006), hoy en día, los estudiantes cuentan con mucha información al alcance de sus manos, por ello, deberían ser capaces de organizar, interpretar, discernir y darle sentido a dicha información, en beneficio de su proceso de formación. Entonces, el estudiante no puede continuar siendo solo un receptor pasivo de información, sino que debe participar de modo activo en los procesos de enseñanza-aprendizaje, siendo estratégico, planificando, manteniendo su motivación, esforzándose, confiando en sus capacidades, trabajando en equipo, innovando y creando. Este cambio convierte al estudiante en un gestor de su propio conocimiento.

El estudiante debe comprender que, para los tiempos actuales, es necesario que se adapte, que sea flexible y que autorregule su aprendizaje. Así, su responsabilidad se hace más amplia, significativa, necesaria y consciente, pues se encuentra en una etapa que puede definir el rumbo de su vida.

Actualmente, los estudiantes deben ser capaces de enfrentar desafíos dentro y fuera de las aulas, con las capacidades de analizar, integrar y sistematizar conocimientos. Asimismo, deben desarrollar un pensamiento crítico, pero también creativo, que intente hallar o crear soluciones desde nuevas perspectivas, relacionando y consolidando información, y usando la lógica. Además, deben cuestionar e investigar la realidad que los rodea desde un punto de vista científico.

\section{Desarrollo o implementación de la propuesta}

La propuesta consiste en una estrategia metodológica para desarrollar el aprendizaje autorregulado en estudiantes del primer ciclo de la carrera de Administración de una universidad privada de Lima. A continuación, se fundamentará y describirá cada fase de la propuesta; asimismo, en cada fase se describirán las acciones concretas correspondientes. Cabe 
señalar que todas las fases han sido diseñadas para que el docente pueda incluirlas en las sesiones de clase.

\section{Fase 1 - Previsión, planificación y activación.}

Es la fase inicial, en la que los estudiantes requieren la ayuda del docente, pues se encuentran en el primer ciclo y se exponen por primera vez a las actividades académicas universitarias. Por ello, se requiere la participación activa del docente para que los estudiantes logre analizar la tarea, valorar su propia capacidad para efectuarla, establecer metas y planificar acciones.

De acuerdo con López (2008), la planificación consiste en el establecimiento de metas y objetivos que se quieren lograr, y la definición de los pasos y medios necesarios para alcanzarlos. Entonces, el docente requiere una previsión y planificación que le permita enfrentar sus propias capacidades y retarse en su autopreparación; dicha previsión debe incluir la investigación, la preparación de recursos, la capacidad didáctica, el desarrollo de habilidades blandas, etc., con la finalidad de desarrollar el aprendizaje autorregulado del estudiante.

En esta fase, se consideran el análisis de la tarea y las creencias auto-motivadoras. A continuación, se explican estos procesos con mayor detenimiento.

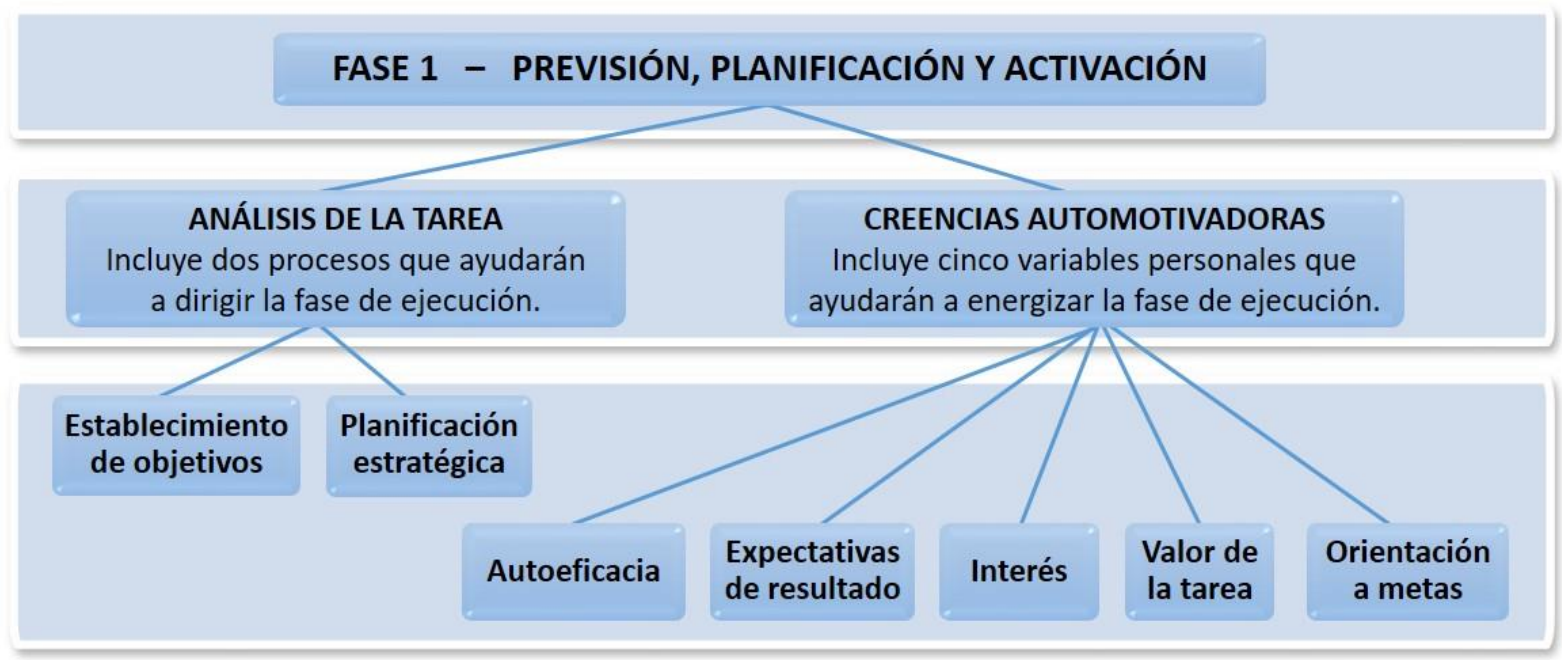

Figura 7. Previsión, planificación y activación. Adaptado de Panadero y Tapia (2014). 


\section{Análisis de la tarea.}

El proceso de autorregulación inicia con el análisis de la tarea. El estudiante divide la tarea en pequeñas partes, para un mejor entendimiento y para el establecimiento de su propia estrategia de ejecución (Zimmerman y Moylan, 2009). Aunque cada estudiante es responsable de su propio proceso, es importante la mediación y acompañamiento del docente.

El docente, con la colaboración de los estudiantes, realiza un análisis y valoración de las tareas y actividades que el curso requiere, de este modo se asegura de que los estudiantes comprendan los requerimientos y exigencias de las tareas, por ejemplo, el tiempo que tomarán, los niveles de dificultad y los posibles obstáculos que podrían enfrentar. Además, el docente relaciona las tareas con los intereses y objetivos personales de los estudiantes, motivando su interés por las mismas.

\section{Análisis de la tarea}

El docente ayuda a los estudiantes a establecer sus objetivos en el curso. Aquí, el docente comparte su propia experiencia para enfatizar la importancia de empezar el curso con objetivos claros. Algunos objetivos propuestos por el docente son: asistir a todas las clases de manera puntual, tomar notas en clase como un registro detallado de los conceptos y ejercicios, dedicar una hora diaria a repasar lo desarrollado en la sesión de clase, realizar las tareas en los plazos establecidos, plantear dudas y preguntas en clase, para resolverlas con ayuda del docente y otros estudiantes.

\section{Establecimiento de objetivos}

El estudiante diseña un plan estratégico para alcanzar sus objetivos trazados en el curso.

El docente ayuda al estudiante a identificar las estrategias que se ajustan mejor a sus necesidades. Algunas estrategias propuestas por el docente son: tomar notas en clase organizando los conceptos y ejercicios para su revisión posterior, utilizar el aula virtual para mantener contacto con el docente, enviarle ejercicios realizados de manera autónoma, comentarle las dudas acerca de los conceptos o ejercicios desarrollados en clase, para obtener una retroalimentación más rápida.

\section{Planificación estratégica}

Figura 8. Análisis de la Tarea. Elaboración propia (2020).

De acuerdo con Chaves y Rodríguez (2017), en esta fase, el estudiante plantea sus

objetivos y, de acuerdo con ellos, diseña su planificación estratégica. Se considera que el 
estudiante posee conocimientos previos que le permiten la ejecución de acciones, y que además, dicha ejecución está influenciada por las percepciones que el estudiante tiene de sí mismo, las cuales incluyen su motivación, su eficacia y sus expectativas de aprendizaje. Entonces, no es suficiente que el estudiante se plantee objetivos y metas, que planifique sus acciones y que conozca estrategias de cómo autorregular su aprendizaje, sino que también es importante que confíe en su propia capacidad para ejecutar todas esas estrategias de manera exitosa.

\section{Creencias automotivadoras.}

El estudiante cuenta con ciertas variables personales para realizar una actividad, entre ellas, las correspondientes a las creencias automotivadoras. Si bien es cierto que cada estudiante desarrolla su propio nivel y tipo de motivación, es importante la intervención del docente, que mediante su experiencia puede ayudarle a desarrollar sus variables personales hasta los niveles que le permitan tener éxito en la realización de sus actividades académicas.

De acuerdo con Panadero y Tapia (2014), las cinco variables propuestas de las creencias automotivadoras tienen un efecto poderoso en el estudiante, pero muchas veces no son percibidas de manera consciente; además, los autores mencionan que dichas variables tienen una importancia determinante en el movimiento inicial del estudiante para realizar una tarea, es decir, que son la chispa que enciende su querer hacer.

Por tanto, las creencias motivadoras son, en conjunto, un impulso muy poderoso para que el estudiante logre iniciar sus acciones y es crucial que los docentes ayuden a sus estudiantes a desarrollarlas, pues dicha labor determinará el poder y efectividad de la carga motivadora, la cual será de gran ayuda en la autorregulación de los estudiantes, para mantenerse activos y perseverantes hasta lograr sus metas. En la siguiente figura, se detallan las creencias motivadoras propuestas. 
El docente comparte su experiencia en el curso para ayudar a los estudiantes a generar creencias automotivadoras. Es importante que el docente enfatice sus propias creencias automotivadoras mientras comparte su experiencia, para lograr que los estudiantes se identifiquen con él.

El docente además promueve la participación de los estudiantes, muestra interés por sus situaciones personales y estimula su motivación.

\section{Creencias Automotivadoras}

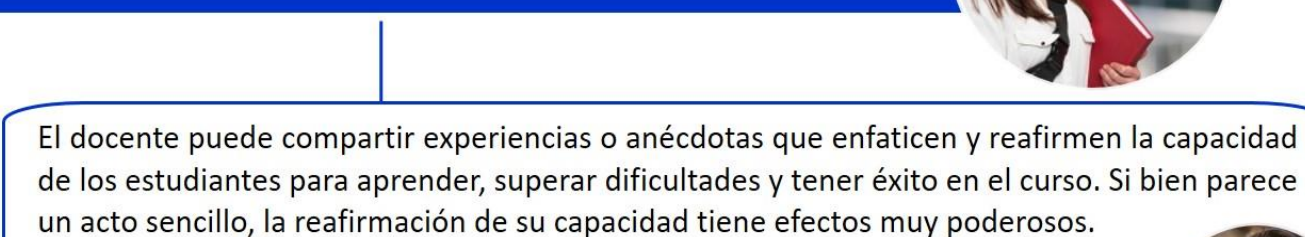
un acto sencillo, la reafirmación de su capacidad tiene efectos muy poderosos.

\section{Autoeficacia}

El docente comparte sus expectativas altas del curso, que se reflejarán en su compromiso. Mientras mayor sea compromiso del docente, mayor será el de los estudiantes.

\section{Expectativas de resultado}

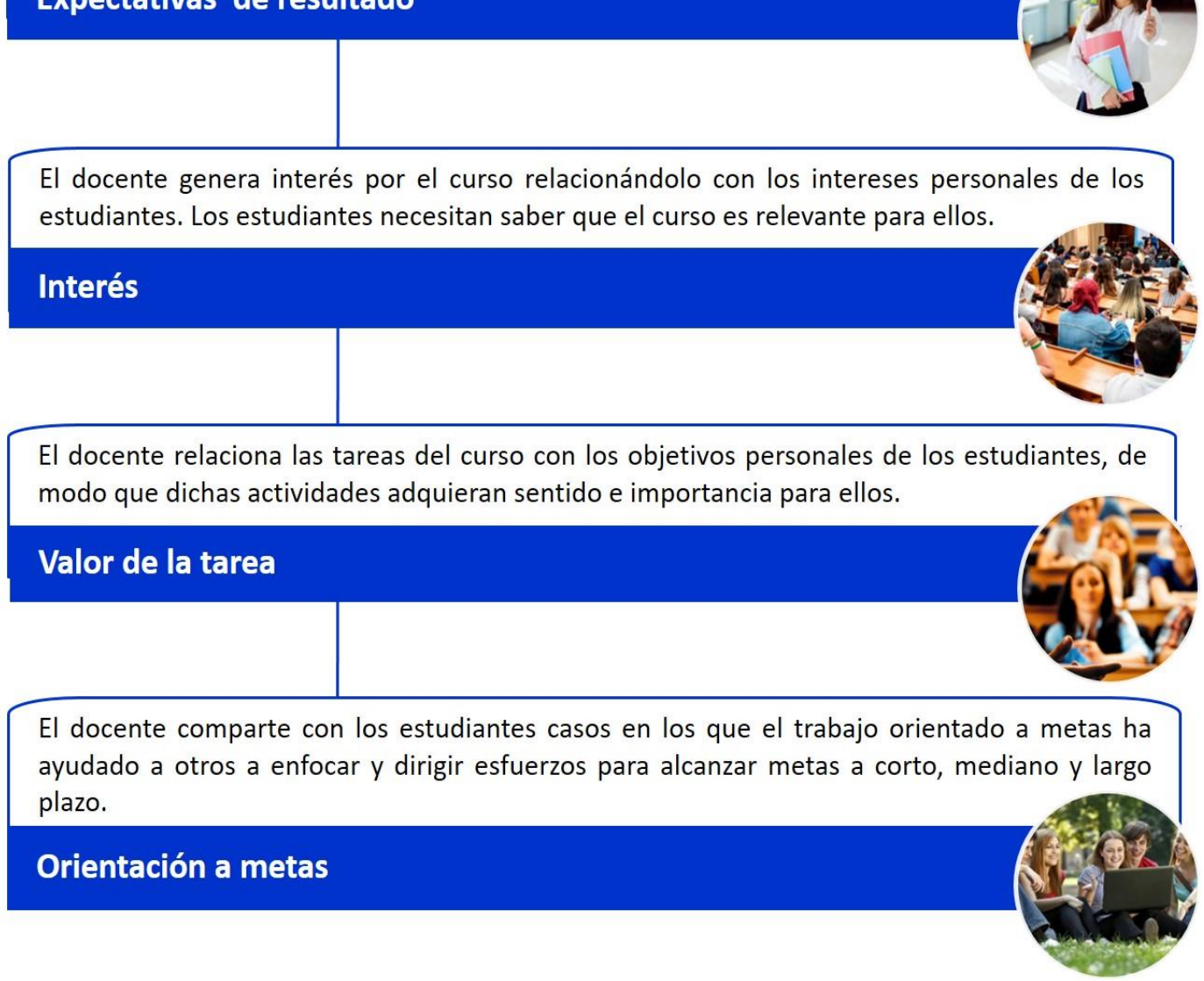

Figura 9. Creencias automotivadoras. Elaboración propia (2020). 


\section{Fase 2 - Ejecución.}

En esta fase, el docente ayuda a los estudiantes a mantener el interés y la motivación, y los asesora en el uso de las estrategias de aprendizaje. A continuación, se realiza una descripción del monitoreo y el control.

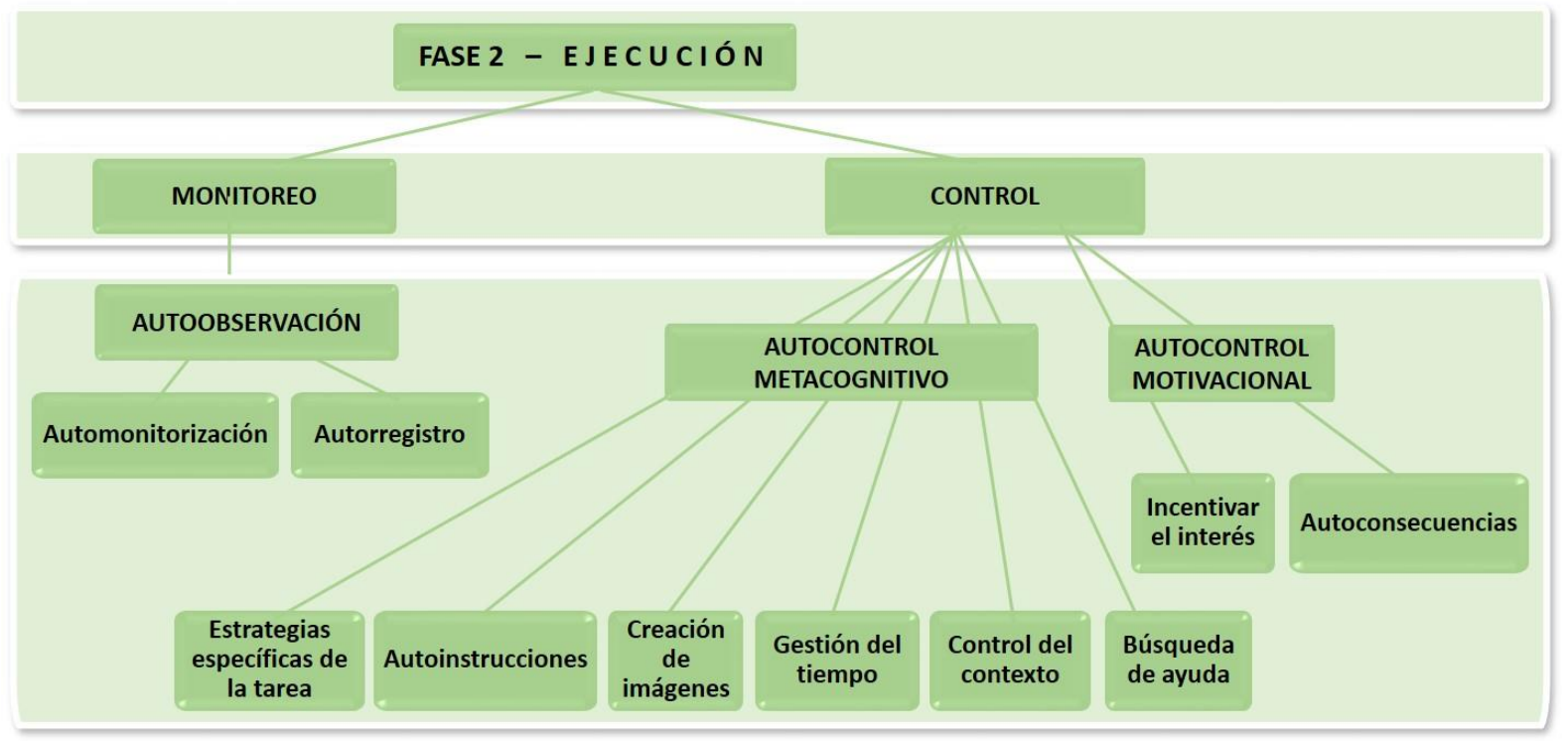

Figura 10. Ejecución. Adaptado de Panadero y Tapia (2014).

\section{Monitoreo.}

El monitoreo comprende la autoobservación. Es necesario que el estudiante logre autoobservarse, para ello se recomiendan dos tipos de actividades:

La automonitorización o también llamada autosupervisión, que consiste en que el estudiante compare las acciones que está realizando con una serie de criterios establecidos, para reconocer su nivel de ejecución (Winne y Hadwin, 1998).

El autorregistro, el cual consiste en llevar un registro de las propias actividades desarrolladas durante el proceso. Estas anotaciones luego ayudarán al estudiante a analizar y reflexionar sobre la ejecución de la tarea y sus progresos. El autorregistro es una estrategia de aprendizaje que permite que los estudiantes logren monitorearse y reflexionar (Panadero y Tapia, 2014). 
El docente, mediante pausas activas, enseña y ayuda a los estudiantes a autoobservarse mediante las estrategias de la automonitorización y el autorregistro. La sesión de clase es teórica y práctica, por lo tanto, es necesario que el docente desarrolle las estrategias durante la misma sesión, actuando como mediador, para que los estudiantes se familiaricen con ellas de manera paulatina.

Monitoreo

Autoobservación

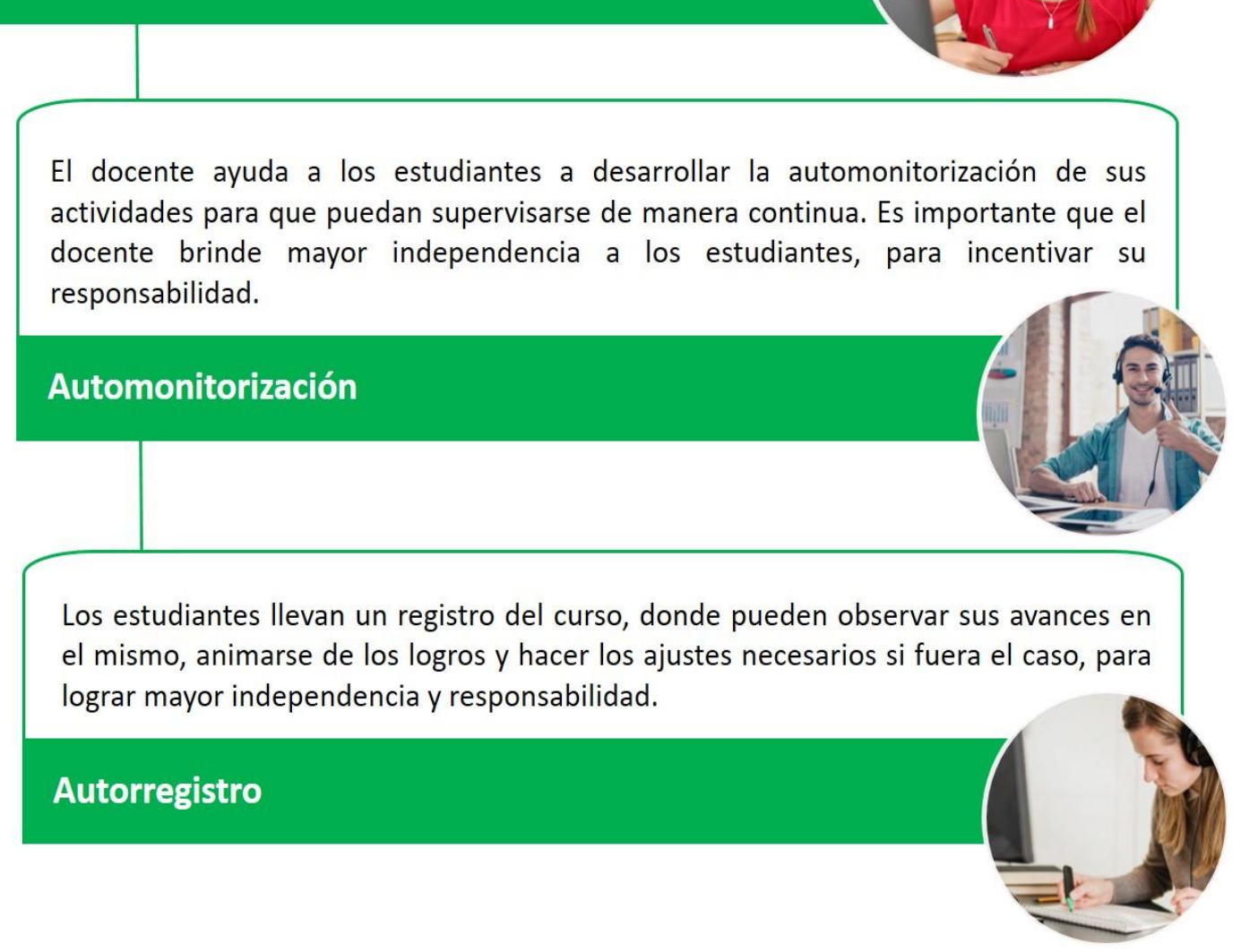

Figura 11. Monitoreo. Elaboración propia (2020).

\section{Control.}

En el control se considera el autocontrol metacognitivo, que incluye seis estrategias que ayudan a mantener la concentración; y el autocontrol motivacional, que incluye dos estrategias que sirven para mantener el interés (Panadero y Tapia, 2014). 
El docente comparte con los estudiantes su experiencia en el uso de estrategias metacognitivas para mantener la concentración.

Estas estrategias necesitan ir acompañadas de esfuerzo, disciplina y acciones concretas de parte de los estudiantes.

\section{Control \\ Autocontrol metacognitivo}

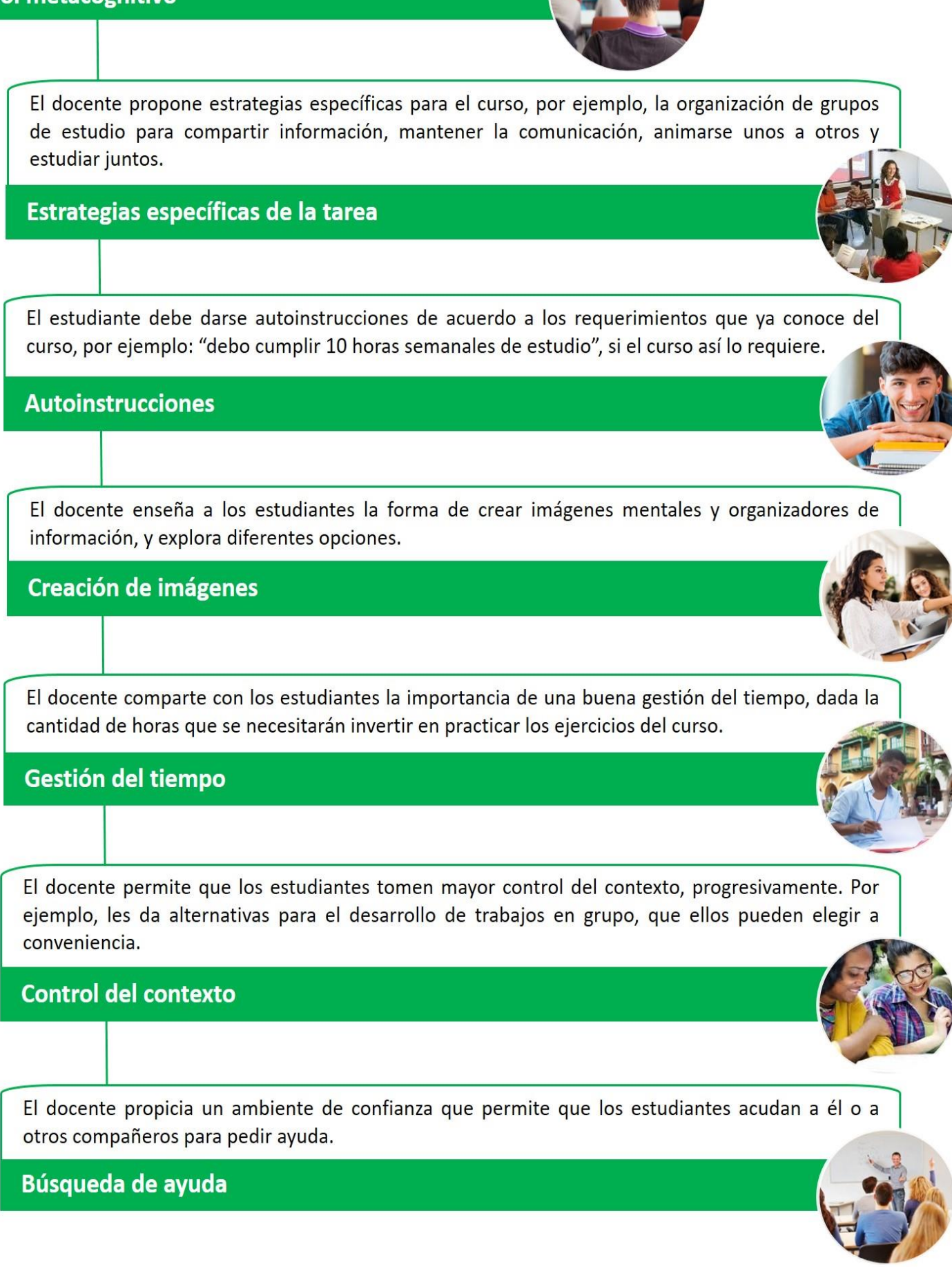

Figura 12. Autocontrol metacognitivo. Elaboración propia (2020). 
El docente comparte con los estudiantes su experiencia en el uso de estrategias motivacionales que ayudan a mantener el interés.

Estas estrategias necesitan ir acompañadas de esfuerzo, disciplina y acciones concretas de parte de los estudiantes.

\section{Control}

\section{Autocontrol motivacional}

El estudiante incentiva su interés en el curso mediante mensajes que le ayudan a recordar la meta, los avances que ha logrado y que sí es capaz de alcanzar sus objetivos.

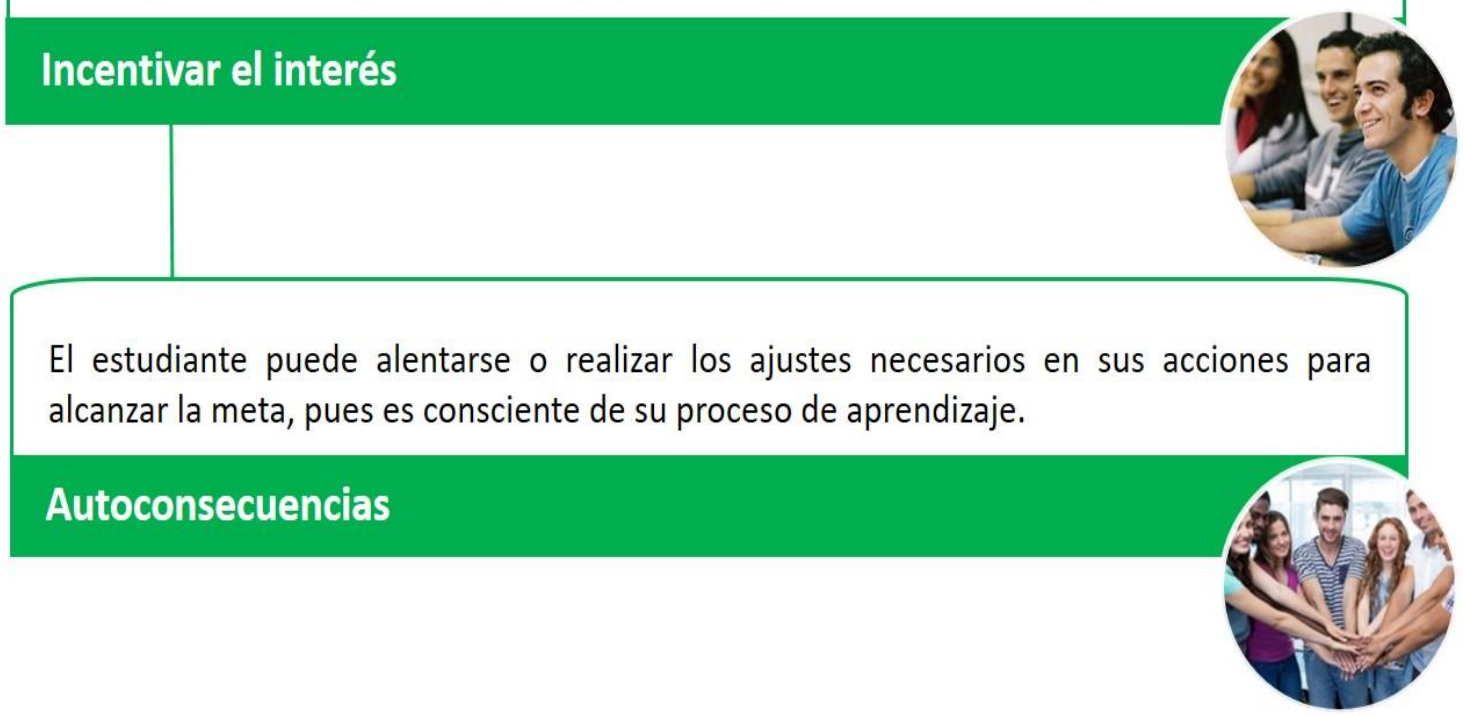

Figura 13. Autocontrol motivacional. Elaboración propia (2020).

El uso de estas estrategias, cada vez que los estudiantes alcanzan sus metas, permite mantener sus niveles de interés y sus ánimos de esforzarse, lo cual incrementa las posibilidades de que sigan autorregulándose (Corno, 2001; Zimmerman y Martínez, 1986). Es necesario señalar que las estrategias mencionadas en esta fase deben ser acompañadas de esfuerzo, disciplina y acciones específicas de los docentes y estudiantes.

\section{Fase 3 - Evaluación.}

En esta fase, el estudiante valora su trabajo y analiza sus resultados, para elaborar una explicación, de este modo, justifica las razones de sus triunfos o fracasos. Se debe mencionar 
que el estudiante experimentará emociones negativas o positivas que podrían influenciar en su motivación y capacidad de autorregularse (Panadero y Tapia, 2014).

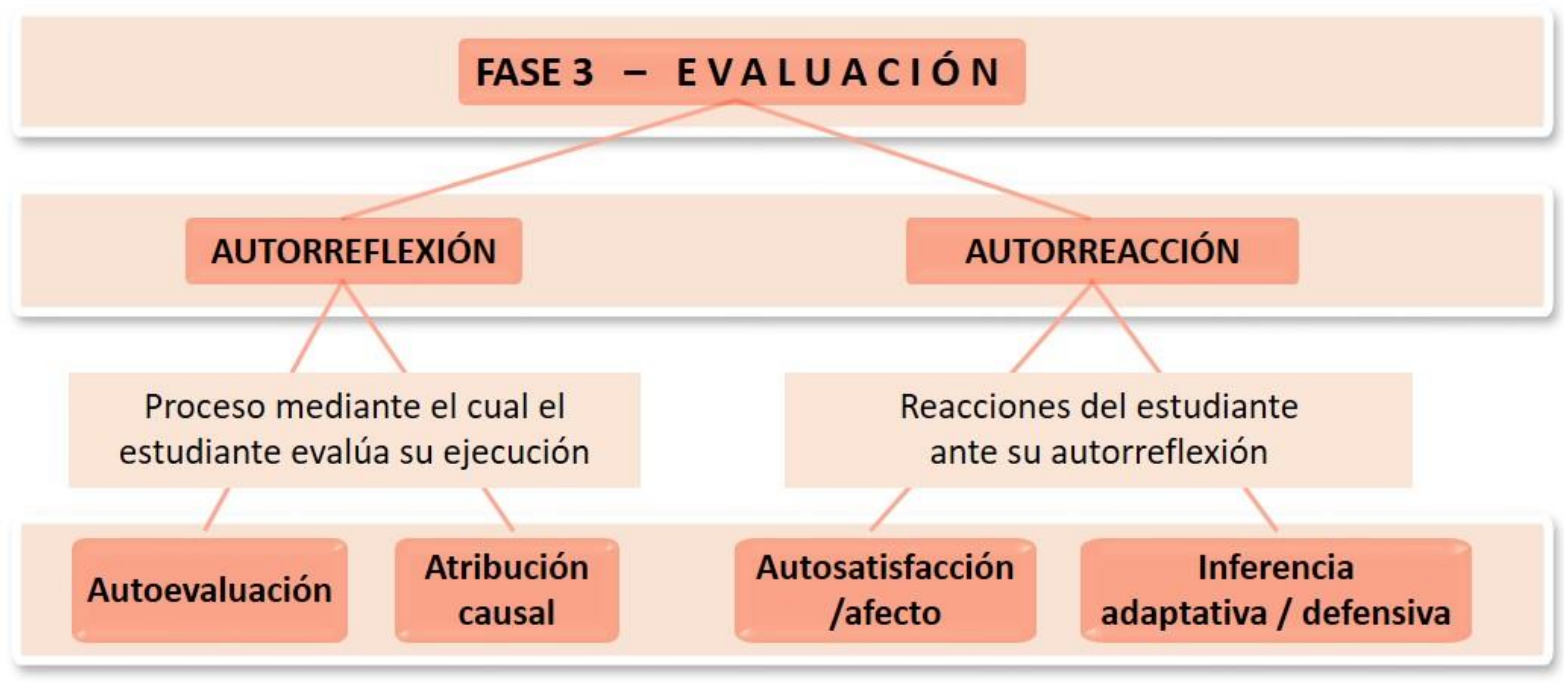

Figura 14. Evaluación. Adaptado de Panadero y Tapia (2014).

A continuación, se detallarán los procesos de autorreflexión y autorreacción.

\section{Autorreflexión.}

Según Winne (2011), la autoevaluación incluye los criterios de evaluación, los objetivos que los estudiantes se han fijado al iniciar la actividad y sus niveles de exigencia. La autoevaluación es un proceso en el que los estudiantes evalúan su ejecución de las tareas de manera objetiva y reflexiva y realizan atribuciones causales.

\section{Autorreacción.}

Panadero y Tapia (2014) señalan que el estudiante puede reaccionar emocional y cognitivamente, pero no de forma automática, pues debe ser capaz de controlar sus reacciones, a partir del aprendizaje de sus éxitos y fracasos. Aquí es importante señalar la experiencia del docente, pues el estudiante experimentará diferentes emociones que el docente debe ayudar a controlar. Asimismo, el docente debe valorar el esfuerzo de los estudiantes y prepararlos para las futuras actividades. 
El estudiante evalúa su ejecución de las tareas y actividades académicas de manera reflexiva y objetiva, para explicar su desempeño.

\section{Autorreflexión}

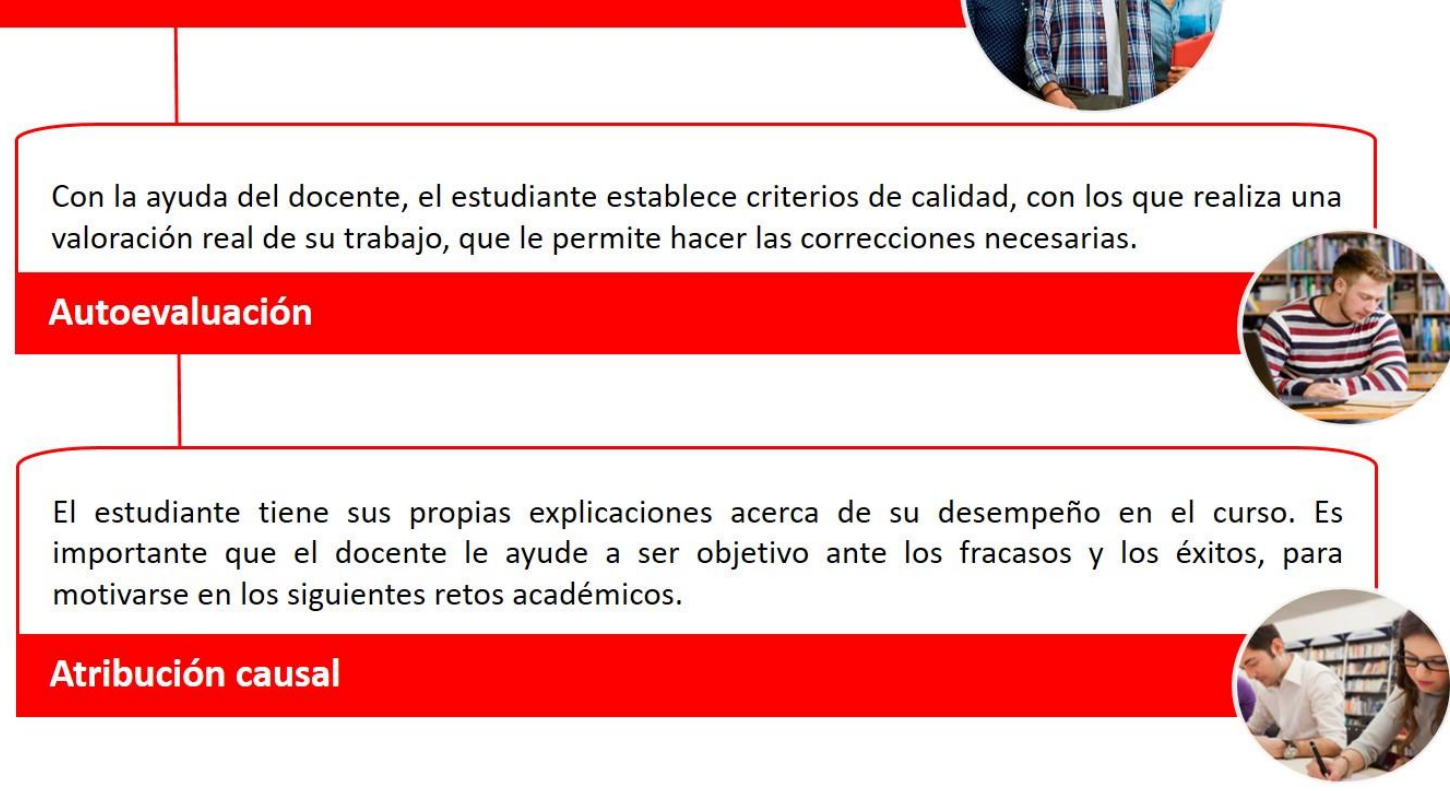

Figura 15. Autorreflexión. Elaboración propia (2020).

El docente ayuda a los estudiantes a aprender a controlar sus reacciones emocionales o cognitivas ante los éxitos o fracasos. La experiencia del docente es clave para que los estudiantes asimilen las victorias y derrotas, y para que comprendan que todas las situaciones que se presentan en la vida traen oportunidades de aprendizaje.

\section{Autorreacción}
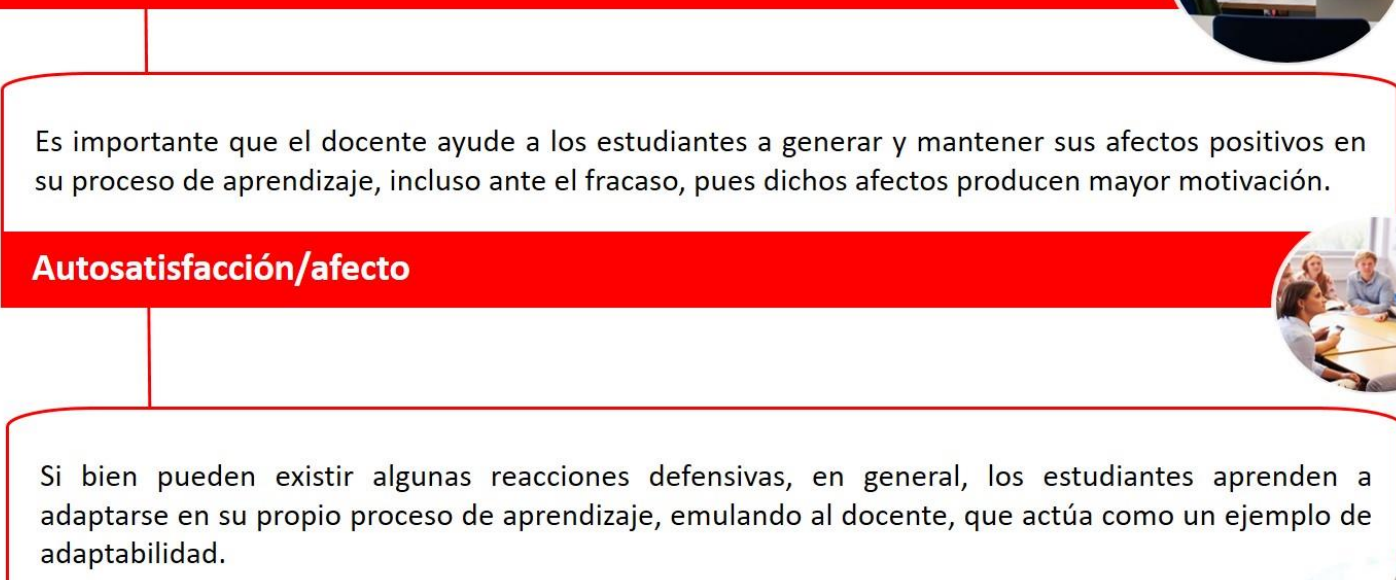

Inferencia adaptativa/defensiva

Figura 16. Autorreacción. Elaboración propia (2020). 


\section{Sesión de aprendizaje}

Proposición lógica. Proposición simple y compuesta. Valor de verdad. Operadores lógicos: negación, conjunción, disyunción, condicional y bicondicional

\section{Datos informativos}

\begin{tabular}{ll}
\hline Curso: Matemática I & Ciclo: Primer ciclo \\
Carrera: Administración de empresas & Universidad: UPC \\
Año: 2020 & Tiempo: 3 horas pedagógicas \\
Enfoque curricular: Constructivista & Tema: Lógica matemática
\end{tabular}

Aprendizaje esperado

\begin{tabular}{lll}
\hline \multicolumn{1}{c}{ Competencia } & \multicolumn{1}{c}{ Capacidad } & \multicolumn{1}{c}{ Indicadores } \\
\hline $\begin{array}{l}\text { Aplica la lógica matemática en la } \\
\text { resolución de problemas específicos de } \\
\text { su formación profesional. }\end{array}$ & $\begin{array}{l}\text { Determina el valor de una } \\
\text { proposición lógica y las operaciones } \\
\text { que las relacionan. }\end{array}$ & $\begin{array}{l}\text { Reconoce y explica las proposiciones } \\
\text { lógicas y las operaciones que las } \\
\text { relacionan. }\end{array}$ \\
\end{tabular}




\section{Secuencia didáctica}

\begin{tabular}{|c|c|c|c|c|}
\hline \multicolumn{2}{|c|}{$\begin{array}{c}\text { Procesos } \\
\text { Pedagógicos }\end{array}$} & Actividades & $\begin{array}{l}\text { Técnicas / } \\
\text { Estrategias }\end{array}$ & Tiempo \\
\hline 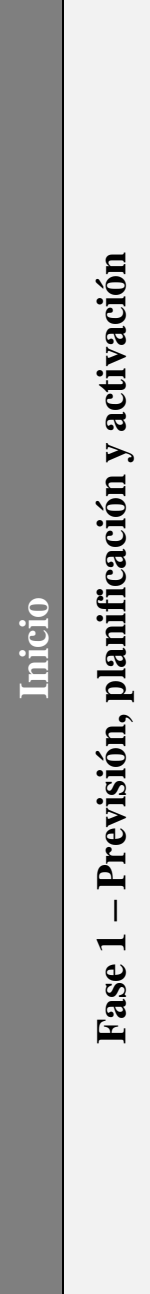 & $\begin{array}{c}\text { Creencias } \\
\text { automotivadoras }\end{array}$ & $\begin{array}{l}\text { El docente espera a los estudiantes en la puerta del salón de clase para saludarlos; y cuando la mayoría ha } \\
\text { llegado, hace una pequeña presentación de su experiencia como docente e incluye algunos datos personales } \\
\text { (nombre, especialidad y hobbies). Luego, anima a los estudiantes a que cada uno se presente con el grupo, } \\
\text { mencionando nombre, hobbies y qué espera del curso, para que los estudiantes se sientan en un ambiente } \\
\text { de confianza y perciban que el contexto de aprendizaje es positivo. } \\
\text { Es importante que el docente conozca a sus estudiantes y realice un diagnóstico de grupo, por ejemplo: } \\
\text { sus formas de aprender, intereses, motivaciones y objetivos. } \\
\text { El docente hace una presentación del tema de la sesión de clase: Proposición lógica. Proposición simple y } \\
\text { compuesta. Valor de verdad. Operadores lógicos: negación, conjunción, disyunción, condicional y } \\
\text { bicondicional. } \\
\text { El propósito es crear un ambiente de diálogo, donde los estudiantes comparten sus saberes previos y el } \\
\text { docente comparte sus experiencias. Todo ello sirve como una base sólida para la construcción de nuevos } \\
\text { conocimientos. } \\
\text { El docente y los estudiantes analizan las tareas y actividades académicas del curso, y según ese análisis, el } \\
\text { docente ayuda a los estudiantes a establecer objetivos claros y diseñar una planificación estratégica } \\
\text { adecuada a sus necesidades y requerimientos del curso, para ayudarlos a desarrollarlo de la manera más } \\
\text { eficiente. }\end{array}$ & $\begin{array}{c}\text { Diagnóstico } \\
\text { de grupo } \\
\text { Exposición } \\
\text { dialogada } \\
\text { Activar y usar } \\
\text { saberes previos } \\
\text { Establecimiento } \\
\text { de objetivos } \\
\text { Planificación } \\
\text { estratégica }\end{array}$ & $\begin{array}{l}10 \text { minutos } \\
20 \text { minutos }\end{array}$ \\
\hline
\end{tabular}




\begin{tabular}{|c|c|c|c|c|c|}
\hline \multicolumn{3}{|c|}{$\begin{array}{c}\text { Procesos } \\
\text { Pedagógicos }\end{array}$} & Actividades & $\begin{array}{c}\text { Técnicas / } \\
\text { Estrategias }\end{array}$ & Tiempo \\
\hline $\begin{array}{l}\frac{0}{\overline{0}} \\
\overline{2} \\
\frac{3}{6} \\
\frac{8}{8} \\
0\end{array}$ & 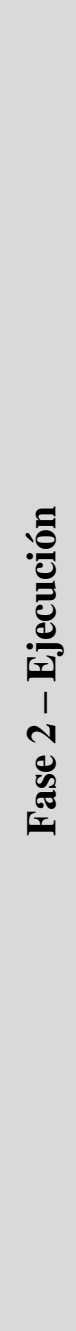 & $\begin{array}{l}\text { Autocontrol } \\
\text { metacognitivo } \\
\text { (Control) }\end{array}$ & $\begin{array}{l}\text { Tema de la sesión de clase: Proposición lógica. Proposición simple y compuesta. Valor de verdad. } \\
\text { Operadores lógicos: negación, conjunción, disyunción, condicional y bicondicional. } \\
\text { El docente desarrolla la sesión de clase mediante la didáctica desarrolladora y la estrategia del } \\
\text { modelamiento. } \\
\text { El docente ayuda a los estudiantes a autoobservarse en su desempeño en clase, mediante pausas activas } \\
\text { donde los estudiantes logren aplicar dos estrategias: la automonitorización, en la que el docente permite } \\
\text { mayor independencia a los estudiantes, para que ellos aprendan a autosupervisarse, tomando mayor } \\
\text { responsabilidad; y el autorregistro, en el que los estudiantes puedan visualizar de manera sistemática su } \\
\text { propio desempeño, a fin de alcanzar mayor independencia y responsabilidad. } \\
\text { Los ejercicios son seleccionados con el fin de fortalecer los conocimientos teóricos del tema y de que su } \\
\text { complejidad sea gradual, de menos a más, para que los estudiantes logren observar su propio avance y } \\
\text { habilidad al resolverlos. Además, se vincula el contexto de los estudiantes con los contenidos que se } \\
\text { desarrollan. } \\
\text { El docente enseña las estrategias de autocontrol metacognitivo, las cuales ayudarán a los estudiantes a } \\
\text { mantenerse concentrados. Por ejemplo: estrategias específicas de la tarea, como subrayar los puntos } \\
\text { importantes; autoinstrucciones ("debo cumplir con las } 10 \text { horas semanales de estudio"); creación de } \\
\text { imágenes para organizar los ejercicios mentalmente; gestión del tiempo, a fin de repasar la teoría y } \\
\text { practicar los ejercicios; control del contexto, como organizar sus grupos de trabajo; y búsqueda de ayuda } \\
\text { del docente y sus compañeros. Es importante que el docente ayude a los estudiantes a comprender que } \\
\text { estas estrategias necesitan ir acompañadas de esfuerzo, disciplina y acciones concretas. }\end{array}$ & $\begin{array}{c}\text { Estrategias } \\
\text { específicas } \\
\text { de la tarea } \\
\text { Autoinstrucciones } \\
\text { Creación de } \\
\text { imágenes } \\
\text { Gestión del tiempo } \\
\text { Control del } \\
\text { contexto } \\
\text { Búsqueda de ayuda } \\
\text { Incentivar el interés } \\
\text { Autoconsecuencias }\end{array}$ & $\begin{array}{l}\text { Ejercicios } \\
\text { prácticos } \\
40 \text { minutos }\end{array}$ \\
\hline
\end{tabular}




\begin{tabular}{|c|c|c|c|c|c|}
\hline \multicolumn{3}{|c|}{$\begin{array}{l}\text { Procesos } \\
\text { Pedagógicos }\end{array}$} & Actividades & $\begin{array}{l}\text { Técnicas / } \\
\text { Estrategias }\end{array}$ & Tiempo \\
\hline (2) & 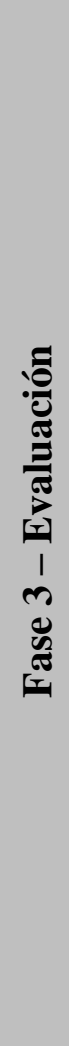 & Autorreflexión & $\begin{array}{l}\text { Para el cierre, el docente propone un trabajo en equipo para resolver unos ejercicios. El docente reparte } \\
\text { los ejercicios a los grupos, cada uno de cinco participantes. La idea es observar a los estudiantes los } \\
\text { primeros minutos para identificar su forma de trabajar en equipo y su forma de aplicar los conocimientos } \\
\text { aprendidos en la sesión de clase. } \\
\text { El docente se acerca a cada grupo, absuelve las consultas y aprovecha la oportunidad para interactuar con } \\
\text { ellos y ayudarlos a resolver algunos ejercicios. De este modo, el docente puede evaluar a cada grupo y } \\
\text { tener una idea general de cuánto se aprendió en la sesión de clase y del nivel de participación y } \\
\text { autorregulación de los estudiantes. } \\
\text { El docente ayuda a los estudiantes a reflexionar, para evaluar su propia ejecución de los ejercicios de } \\
\text { manera objetiva; y luego, los estudiantes comparten dicha evaluación con el grupo. } \\
\text { De este modo, el estudiante valora su propio trabajo y desempeño, teniendo en cuenta los criterios } \\
\text { establecidos por el docente al inicio de la sesión de clase, y haciendo las correcciones necesarias. } \\
\text { Además, el estudiante logra reconocer su desempeño en el curso de manera objetiva, para seguir motivado } \\
\text { ante las dificultades u obstáculos, y para ser capaz de afrontar nuevos retos. } \\
\text { El docente ayuda a los estudiantes a aprender a controlar sus reacciones (emocionales o cognitivas), ante } \\
\text { los fracasos o los éxitos. } \\
\text { La experiencia del docente es clave para que los estudiantes comprendan que en el desarrollo del curso se } \\
\text { presentarán momentos en los que deberán saber controlar sus reacciones, pues habrá ejercicios más } \\
\text { difíciles que otros, exámenes más complicados y trabajos que demanden mayor esfuerzo, pero lo } \\
\text { importante será controlar esas emociones, enfocarse en los objetivos y aprender de las derrotas y las } \\
\text { victorias. } \\
\text { Los estudiantes van desarrollando afectos positivos, los cuales les ayudan a seguir motivados en su proceso } \\
\text { de aprendizaje. Aquí es clave el ejemplo del docente en cuanto a la capacidad de adaptación, pues los } \\
\text { estudiantes lo observan e imitarán sus reacciones, sean estas adaptativas o defensivas. }\end{array}$ & $\begin{array}{c}\text { Autosatisfacción / } \\
\text { Afecto } \\
\text { Inferencia } \\
\text { adaptativa / } \\
\text { defensiva }\end{array}$ & 30 minutos \\
\hline
\end{tabular}




\section{Validación de la propuesta}

Se empleó el método de validación mediante juicio de expertos para evaluar la viabilidad de la propuesta que tiene como finalidad el desarrollo del aprendizaje autorregulado en los estudiantes del primer ciclo. Se usaron fichas de valoración interna y externa, que incluían diez criterios de valoración. Para la validación, el proyecto fue enviado a tres docentes especialistas elegidos por su trayectoria profesional y su experiencia en el campo de la investigación educacional.

\section{Características de los especialistas.}

Los especialistas que participaron en la validación de la propuesta son profesionales probos, imparciales, que cuentan con los grados académicos necesarios, amplia experiencia laboral y sólidos conocimientos en el campo de la educación y la investigación. Además, fue muy importante su buena disposición en colaborar con esta investigación. A continuación, se detallan los datos de los profesionales seleccionados para la validación de la propuesta.

Tabla 3

Especialistas de la validación de la propuesta

\begin{tabular}{|c|c|c|c|c|}
\hline Nombres y apellidos & Grado académico & Especialidad & Ocupación & $\begin{array}{c}\text { Años de } \\
\text { experiencia }\end{array}$ \\
\hline $\begin{array}{l}\text { Flores Valdiviezo, Hernán } \\
\text { Gerardo }\end{array}$ & Magister & Sociología & $\begin{array}{c}\text { Docente } \\
\text { investigador }\end{array}$ & 40 \\
\hline Muñoz Salazar, José Manuel & Doctor & $\begin{array}{l}\text { Ciencias de la } \\
\text { educación }\end{array}$ & $\begin{array}{c}\text { Docente } \\
\text { investigador }\end{array}$ & 35 \\
\hline $\begin{array}{l}\text { Herrera Montoya, María } \\
\text { Teresa }\end{array}$ & Magister & Psicopedagogía & $\begin{array}{c}\text { Docente } \\
\text { investigador }\end{array}$ & 33 \\
\hline
\end{tabular}

Fuente. Adaptado de USIL (2019).

\section{Valoración interna.}

En relación con la valoración interna, cuyo propósito fue evaluar la validez del contenido de la propuesta, se presentó a cada juez una ficha de validación que incluye los diez criterios de evaluación mostrados a continuación (véase la tabla 4). Asimismo, los valores posibles de la escala de calificación fueron: 1 (deficiente), 2 (bajo), 3 (regular), 4 (bueno) y 5 (muy bueno). Por otro lado, las fichas permitieron a los jueces anotar sus observaciones y recomendaciones. 
Tabla 4

Validación interna por juicio de expertos

\begin{tabular}{|c|c|c|c|c|c|c|}
\hline \multirow[t]{2}{*}{ Indicadores } & \multicolumn{2}{|c|}{ Juez 1} & \multicolumn{2}{|c|}{ Juez 2} & \multicolumn{2}{|c|}{ Juez 3} \\
\hline & $\mathrm{n}$ & $\%$ & $\mathrm{n}$ & $\%$ & $\mathrm{n}$ & $\%$ \\
\hline Factibilidad de aplicación del resultado que se presenta. & 5 & 10 & 5 & 10 & 4 & 8 \\
\hline Claridad de la propuesta para ser aplicado por otros. & 4 & 8 & 5 & 10 & 5 & 10 \\
\hline Posibilidad de la propuesta de extensión a otros contextos semejantes. & 4 & 8 & 4 & 8 & 5 & 10 \\
\hline Correspondencia con las necesidades sociales e individuales actuales. & 5 & 10 & 5 & 10 & 5 & 10 \\
\hline Congruencia entre el resultado propuesto y el objetivo fijado. & 5 & 10 & 4 & 8 & 5 & 10 \\
\hline Novedad en el uso de conceptos y procedimientos de la propuesta. & 4 & 8 & 4 & 8 & 4 & 8 \\
\hline La modelación contiene propósitos basados en los fundamentos & 5 & 10 & 4 & 8 & 5 & 10 \\
\hline educativos, curriculares y pedagógicos, detallado, preciso y efectivo. & & & & & & \\
\hline La propuesta esta contextualizada a la realidad en estudio. & 4 & 8 & 4 & 8 & 5 & 10 \\
\hline Presenta objetivos claros, coherentes y posibles de alcanzar. & 5 & 10 & 4 & 8 & 5 & 10 \\
\hline Contiene un plan de acción de lo general a lo particular. & 5 & 10 & 5 & 10 & 5 & 10 \\
\hline Total & 46 & 92 & 44 & 88 & 48 & 96 \\
\hline Promedio & & & 92 & & & \\
\hline
\end{tabular}

Fuente: Adaptado de USIL (2019).

De acuerdo a los resultados de la valoración interna, el Juez 1 indicó una valoración de 92\%, el Juez 2, de $88 \%$ y el Juez 3, de 96\%, y el resultado promedio de dicha valoración fue de 92\%; por tanto, la propuesta alcanzó una valoración interna de muy buena.

\section{Valoración externa.}

Para la valoración externa, que evalúa la forma de la propuesta, se elaboró una ficha de validación para que los jueces valoraran los siguientes diez criterios: claridad, objetividad, actualidad, organización, suficiencia, intencionalidad, consistencia, coherencia, metodología y pertinencia. Los valores de la escala de calificación fueron: 1 (Deficiente), 2 (Bajo, 3 (Regular), 4 (Bueno) y 5 (Muy bueno); asimismo, los jueces tenían la opción de anotar sus observaciones y recomendaciones en las fichas, según lo consideraran pertinente. 
Tabla 5

Validación externa por juicio de expertos

\begin{tabular}{|c|c|c|c|c|c|c|c|}
\hline \multirow[t]{2}{*}{ Indicadores } & & \multicolumn{2}{|c|}{ Juez 1} & \multicolumn{2}{|c|}{ Juez 2} & \multicolumn{2}{|c|}{ Juez 3} \\
\hline & & $\mathrm{n}$ & $\%$ & $\mathrm{n}$ & $\%$ & $\mathrm{n}$ & $\%$ \\
\hline Claridad & Es formulado con lenguaje apropiado. & 5 & 10 & 4 & 8 & 5 & 10 \\
\hline Objetividad & Está expresado en conductas observables. & 4 & 8 & 4 & 8 & 5 & 10 \\
\hline Actualidad & Adecuado al avance de la ciencia pedagógica. & 4 & 8 & 5 & 10 & 5 & 10 \\
\hline Organización & Existe una organización lógica. & 5 & 10 & 5 & 10 & 5 & 10 \\
\hline Suficiencia & Comprende los aspectos de cantidad y calidad. & 4 & 8 & 4 & 8 & 5 & 10 \\
\hline Intencionalidad & $\begin{array}{l}\text { Adecuado para valorar los aspectos de las } \\
\text { categorías. }\end{array}$ & 5 & 10 & 4 & 8 & 5 & 10 \\
\hline Consistencia & $\begin{array}{l}\text { Basado en aspectos teóricos científicos de la } \\
\text { educación. }\end{array}$ & 4 & 8 & 4 & 8 & 5 & 10 \\
\hline Coherencia & $\begin{array}{l}\text { Entre el propósito, diseño y la implementación } \\
\text { de la propuesta. }\end{array}$ & 5 & 10 & 4 & 8 & 5 & 10 \\
\hline Metodología & $\begin{array}{l}\text { La estrategia responde al propósito de la } \\
\text { investigación. }\end{array}$ & 5 & 10 & 4 & 8 & 5 & 10 \\
\hline Pertinencia & Es útil y adecuado para la investigación. & 5 & 10 & 4 & 8 & 5 & 10 \\
\hline Total & & 46 & 92 & 42 & 84 & 50 & 100 \\
\hline Promedio & & & & 92 & & & \\
\hline
\end{tabular}

Fuente: Adaptado de USIL (2019).

Según los resultados de la valoración externa, el Juez 1 indicó una valoración de 92\%, el Juez 2, de $84 \%$ y el Juez 3, de $100 \%$, y el resultado promedio de dicha valoración fue de 92\%; se aprecia, entonces, que la propuesta alcanzó una valoración externa de muy buena.

A continuación, se detalla la escala de valoración que permitió ubicar en qué rango se encuentra la propuesta evaluada.

Tabla 6

Escala de valoración

\begin{tabular}{lcc}
\hline Escala & Rango de frecuencia & Rango de porcentaje \\
\hline Deficiente & {$[10-17]$} & {$[20 \%-35 \%]$} \\
Baja & {$[18-25]$} & {$[36 \%-51 \%]$} \\
Regular & {$[26-33]$} & {$[52 \%-67 \%]$} \\
Buena & {$[34-41]$} & {$[68 \%-83 \%]$} \\
Muy buena & {$[42-50]$} & {$[84 \%-100 \%]$} \\
\hline
\end{tabular}

Fuente. USIL (2019). 


\section{Resultado de la valoración de los especialistas y conclusiones.}

Los resultados de la validación interna y externa de la propuesta, de acuerdo con la valoración de los jueces, se resumen a continuación:

Tabla 7

Validación interna y externa

\begin{tabular}{lcccc}
\hline & Juez 1 & Juez 2 & Juez 3 & Promedio \\
\hline Validación interna & $92 \%$ & $88 \%$ & $96 \%$ & $92 \%$ \\
Validación externa & $92 \%$ & $84 \%$ & $100 \%$ & $92 \%$ \\
Promedio & $92 \%$ & $86 \%$ & $98 \%$ & $92 \%$ \\
Promedio final & & & & $92 \%$ \\
\hline
\end{tabular}

Fuente. Adaptado de USIL (2019).

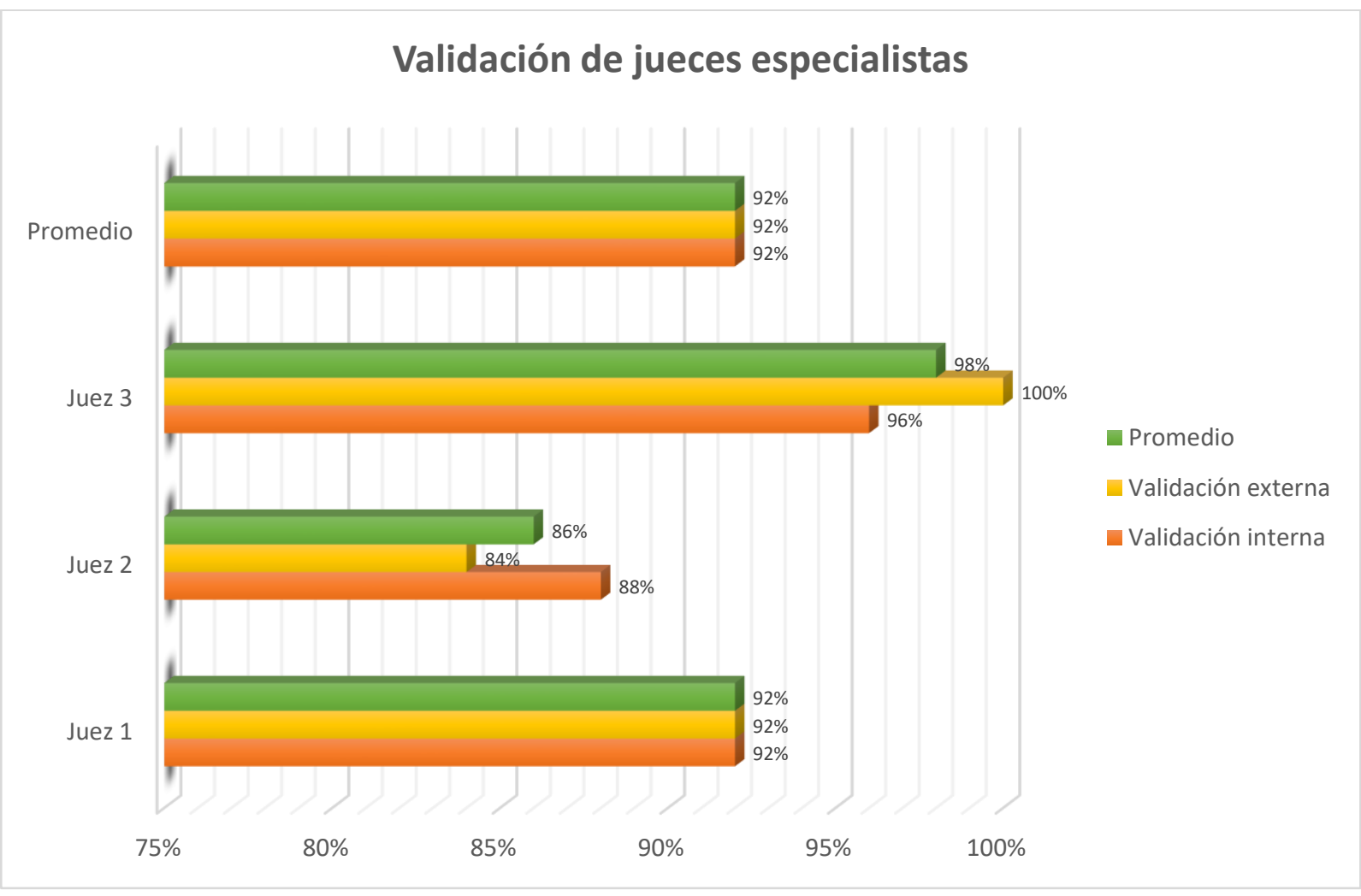

Figura 17. Validación interna y externa por jueces especialistas.

Elaboración propia (2020).

De acuerdo con los resultados de la validación de los expertos, y conforme a la escala de valoración, se determina que la propuesta pedagógica tiene un $92 \%$ de validez, es decir, alcanza una valoración de muy buena, considerando que responde a la realidad y a los objetivos planteados en la investigación. 


\section{Conclusiones}

El aprendizaje autorregulado es fundamental para lograr mejoras en los procesos de aprendizaje de los estudiantes, en los que logran transformarse en protagonistas activos y responsables de aprender de manera permanente, y en el desarrollo de la práctica profesional de los docentes, que actúan como mediadores de la autorregulación. De este modo, la investigación completa sus etapas con la exposición de las respectivas conclusiones, que responden a los objetivos de la investigación.

\section{Primera}

Se cumplió con el objetivo general de la investigación, al diseñar un modelo de estrategia metodológica para desarrollar el aprendizaje autorregulado en los estudiantes, mediante el cual se propone que los docentes desarrollen las sesiones de clase incluyendo estrategias de autorregulación en tres fases: planificación, ejecución y evaluación, en las que los estudiantes participan activamente en sus procesos de aprendizaje.

\section{Segunda}

Se cumplió con realizar el diagnóstico de campo y se evidenció, en la mayoría de estudiantes y docentes, el desconocimiento de las estrategias de aprendizaje autorregulado, además de otros problemas como la falta de educación emocional, el limitado desarrollo del pensamiento crítico y analítico, el insuficiente desarrollo de habilidades blandas, la escasa investigación en el proceso de enseñanza-aprendizaje y el deficiente desarrollo profesional de los docentes.

\section{Tercera}

Se cumplió con fundamentar teórica y metodológicamente las categorías apriorísticas: aprendizaje autorregulado, que según Pintrich (2000), es un proceso activo, en el que los estudiantes establecen metas para sus procesos de aprendizajes, y supervisan, regulan y controlan su cognición, motivación y conducta, orientados por sus metas y el entorno; y estrategia metodológica, que de acuerdo con Moya (2018), es la planificación de una serie de 
acciones que involucran capacidades didácticas, teniendo como base los procedimientos, métodos y recursos didácticos, con el fin de alcanzar los objetivos concretos.

\section{Cuarta}

Se cumplió con el modelamiento de la propuesta de estrategia metodológica para el desarrollo del aprendizaje autorregulado, que propone soluciones a los problemas hallados en el trabajo de campo, y se sostiene en los fundamentos del marco teórico y metodológico. La propuesta es pertinente, teniendo en cuenta que las investigaciones realizadas en la región registran niveles muy bajos de autorregulación; es funcional, porque las estrategias proponen acciones concretas que los docentes y estudiantes pueden emplear en las sesiones de clase; y es cíclica, porque incluye estrategias que pueden volver a utilizarse en cada nuevo reto académico.

\section{Quinta}

Se cumplió con la validación de la propuesta, mediante el método de juicio de expertos, que contó con la colaboración de tres jueces especialistas, dos metodólogos y uno temático, quienes evaluaron la propuesta de la investigación y calificaron su validez con un promedio de $92 \%$, lo que indica que la propuesta es aplicable y su valoración alcanza el nivel de muy buena. 


\section{Recomendaciones}

De igual manera, a continuación se comparten las recomendaciones derivadas de la investigación desarrollada, en relación con las conclusiones expuestas anteriormente.

\section{Primera:}

Continuar con las investigaciones acerca del aprendizaje autorregulado y las diferentes estrategias para desarrollarlo, con el fin de ahondar en el tema y conseguir mejores propuestas que complementen los estudios que existen hasta la fecha, teniendo en cuenta que en esta investigación se comprobó la necesidad e importancia de su desarrollo en los estudiantes para aprender a aprender a lo largo de su vida.

\section{Segunda:}

Implementar la propuesta de la investigación en los cursos de primer ciclo, considerando que los estudiantes que ingresan a las universidades se enfrentan a retos académicos mayores y que necesitan la mediación de los docentes, quienes deben ser capaces de guiarlos en estrategias autorreguladoras. Además, dicha implementación debe ser acompañada con mediciones y evaluaciones periódicas a los estudiantes y docentes, para valorar los avances obtenidos en el desarrollo del aprendizaje autorregulado en las sesiones de clases, con la finalidad de conocer y entender una realidad más actualizada para las futuras investigaciones y propuestas.

\section{Tercera:}

Difundir la importancia y la necesidad de las estrategias metodológicas para el desarrollo del aprendizaje autorregulado, teniendo en cuenta la información que resulte de su implementación, de modo que los estudiantes, docentes y todos los profesionales relacionados con los procesos de aprendizaje puedan contar con mediciones y evaluaciones que permitan realizar los ajustes necesarios y que avalen su difusión e implementación continua. 


\section{Cuarta:}

Se recomienda continuar con las investigaciones acerca de la educación emocional, considerando que es una parte fundamental del aprendizaje autorregulado. Asimismo, se recomienda implementar talleres abiertos a estudiantes, docentes y todos los profesionales involucrados en el campo educativo, para sensibilizar, informar y enseñar sobre la educación emocional y su relevancia en el proceso de enseñanza-aprendizaje; dichos talleres deben contar con las evaluaciones y mediciones respectivas que contribuyan a futuras investigaciones.

\section{Quinta:}

Se recomienda capacitar previamente a los docentes en las diferentes estrategias de desarrollo del aprendizaje autorregulado, que deben partir de la sensibilización sobre su importancia, con la finalidad de que luego puedan aplicarlas en las sesiones de clase de manera eficiente. 


\section{Referencias}

Abero, L., Berardi, L., Capocasale, A., García, S. \& Rojas, R. (2015). Investigación Educativa Abriendo puertas al conocimiento. Montevideo: Contexto.

Acosta, M. (2013). La perspectiva vygotskiana y el aprendizaje: Una reflexión necesaria para la práctica educativa. Revista Científica Teorías, Enfoques y Aplicaciones en las Ciencias Sociales, 5(12), 109-117.

Agüero, J. (2018). Habilidades académicas y autorregulación del aprendizaje en ingresantes a ciencias empresariales. Tesis de maestría, Universidad Nacional de Educación Enrique Guzmán y Valle.

Alcaraz, A., Cruz, M., Guzmán, M., Vidal, V., Pastor, M., Rodríguez, F. \& Sánchez, C. (2004). Didáctica de las Ciencias Sociales: Didáctica de las Ciencias Sociales para Primaria. Madrid, España: Pearson Educación.

Alegre, A. (2014). Autoeficacia académica, autorregulación del aprendizaje y rendimiento académico en estudiantes universitarios iniciales. Propósito y Representaciones, 2(1), 79-120.

Alonso, J. (1997). Motivar para el aprendizaje: Teorías y aprendizajes. España: EDEBÉ.

Alzás, T., Casa, L., Luengo, R., Torres, J. \& Verissimo, S. (2016). Revisión metodológica de la triangulación como estrategia de investigación. Investigação Qualitativa em Ciências Sociais, volume 3. V Congreso Ibero-americano em investigação qualitativa.

Anderson, J. (2005). Cognitive Psychology and its implications. Nueva York; Worth.

Armas, N., Perdomo, J. \& Lorences, J. (2011). Conceptualización y caracterización de los aportes teóricos metodológicos como resultados científicos de la investigación. Revista Avanzada, 14(1), 5.

Bandura, A. (1986). Social foundations of thought and action: A social cognitive theory. Englewood Cliffs, NJ: Prentice Hall.

Bandura, A. (1991). Social cognitive theory of self-regulation. Organizational Behavior and Human Decision Processes, 50, 248-287.

Barbosa, A., Canós, L., de Araujo, A., Perelló-Marin, M. \& Santandreu, C. (2019). Estilos y estrategias de aprendizaje de estudiantes: Un estudio comparativo entre España y Brasil. Journal of Management and Business Education, 2(3), 192-214.

Bartlett, F. (1932). Remembering. A study in Experimental and social psychology. Cambridge. Cambridge University Press.

Berridi, R., \& Martínez, J. (2017). Estrategias de autorregulación en contextos virtuales de aprendizaje. Perfiles educativos, 39(156). 
Biggs, J. (2005). Calidad del aprendizaje universitario. Madrid: Narcea.

Boekaerts, M., Pintrich, P. \& Zeidner, M. (Eds.) (2000). Handbook of self-regulation, San Diego, CA: Academic Press.

Bruner, J. (1974) From communication to language, a psychological perspective. Cognition, $3(3), 255-287$.

Butler, D. \& Winne, P. (1995). Feedback and self-regulated learning: A theoretical synthesis. Review of Educational Research, 65(3), 245-281.

Camargo, P. (2018). Estrategias de aprendizaje y aprendizaje autorregulado en estudiantes de 3er año de una facultad de educación en Lima. Tesis de maestría, Universidad Femenina del Sagrado Corazón.

Camilloni, A. (1998). La calidad de los programas de evaluación y de los instrumentos que la integran. En Camilloni, A., La evaluación de los aprendizajes en el debate didáctico contemporáneo. Buenos Aires: Paidos.

Campusano, K. \& Díaz, C. (2017). Manual de Estrategias Didácticas. Santiago: INACAP.

Castillo, L. (2005). Análisis documental. Biblioteconomía. Segundo cuatrimestre. Curso 20042005. Tema 5, Universidad de Valencia.

Cerezal, J. \& Fiallo, J. (2005). ¿Cómo investigar en pedagogía? (pp. 63 y 106). La Habana: Pueblo y Educación.

Cerezo, F., Ato, M., Rabadán, R., Martínez, F., Orenes, P.J., Calvo, A., Ruiz, M. \& Bernal, R. (2010). Convivencia escolar y familia. Percepción y participación en la Región de Murcia. Murcia: CARM y UMU.

Cimatti, B. (2016). Definition, development, assessment of soft skills and their role for the quality of organizations and enterprises. International Journal for Quality Research, 10(1), 97-130.

Cook, T. \& Reichardt, Ch. (1986). Métodos cualitativos y cuantitativos en la investigación evaluativa (p. 28). Madrid: Editorial Morata.

Corno, L. (1986). The metacognitive control components of self-regulated learning. Contemporary Educational Psychology, 11, 333-336.

Corno, L. (2001). Volitional aspects of self-regulated learning. En: B. Zimmerman \& D. Schunk (Eds.), Self-regulated learning and academic achievement: Theoretical perspectives (pp. 191-225). Hillsdale, NJ: Erlbaum.

Cruz, A., Cortés, P. \& Álvarez, N. (20-24 de noviembre de 2017). El modelo de autorregulación y el aprendizaje matemático. Memoria electrónica del XIV Congreso Nacional de Investigación Educativa. San Luis Potosí, México. 
Chaves, E., Trujillo, J. \& López, J. (2016). Acciones para la autorregulación del aprendizaje en entornos personales. Pixel-Bit Revista de Medios y Comunicación, 48, 67-82.

Chaves, E. \& Rodríguez, L. (2017). Aprendizaje autorregulado en la teoría sociocognitiva: Marco conceptual y posibles líneas de investigación. Revista Ensayos Pedagógicos, 12(2), 41-71.

Daura, F. (2017). Aprendizaje autorregulado e intervenciones docentes en la universidad. Revista Educación de la Universidad de Costa Rica, 41(2), 1-19.

Díaz, F. \& Hernández, G. (2001). Estrategias docentes para un aprendizaje significativo. Una interpretación constructivista. México: Mc Gran-Hill.

Díaz, A., Pérez, M., González-Pienda, J. \& Núñez, J. (2017). Impacto de un entrenamiento en aprendizaje autorregulado en estudiantes universitarios. Perfiles educativos, 39(157).

Dörrenbächer, A. \& Perels, F. (2016). More is more? Evaluation of interventions to foster selfregulated learning in college. International Journal of Educational Research, 78, 5065.

Efklides, A. (2011). Interactions of metacognition with motivation and affect in self-regulated learning: The MASRL Model. Educational Psychologist, 46(1), 6-25.

Eysenck, M. \& Keane, M. (2005). Cognitive Psychology: A studeñ̃ handbook. Nueva York: Psychology Press.

Fernández, E., Rivero, Y., Cañizares, M. \& Pastás, E. (2016). Estrategias de aprendizaje desarrollador en la formación matemática universitaria. Revista Científica UIsrael, 3(2).

García, C., Castañeda, E. \& Mansilla, J. (2018). Experiencia de innovación en el aula desde la autorregulación y los estilos de aprendizaje. Tendencias Pedagógicas, 31, 137-148.

García, T., \& Pintrich, P. (1994). Regulating motivation and cognition in the classroom: The role of self-schemas and self-regulatory strategies. En: D. Schunk \& B. Zimmerman (Eds.), Self-regulation of learning and performance: Issues and educational applications (pp. 127-153). Hillsdale, NJ: Lawrence Erlbaum Associates.

Gibbs, G. (2012). El análisis de datos en investigación cualitativa. Madrid: Ediciones Morata.

Gil, J. (2017). Rasgos del profesorado asociados al uso de diferentes estrategias metodológicas en las clases de ciencias. Revista Enseñanza de las ciencias, 35(1), 175-192.

González-Moreno, C. (2017). Efectos de la enseñanza en la autorregulación del aprendizaje de conceptos científicos en estudiantes universitarios. Summa Psicología UST, 14(2), 1-13.

González, C., Veas, A., Fernández, F., Jover, I., Navarro, I., Alejandro, A., González, M. \& García, D. (2017). Los procesos cognitivos de autorregulación clave para la mejora de 
la calidad en los diferentes aprendizajes en el ámbito universitario: La atención ejecutiva. Una experiencia en el aula. España: Memorias del programa de redes.

Graham, S., Harris, K. \& Troia, G. (1998). Writing and self-regulation: Cases from the selfregulated strategy development model. En: D. Schunk \& B. Zimmerman (Eds.), Selfregulated learning: From teaching to self-reflective practice (pp. 20-41). New York: Guilford.

Harry, D. (2003). Vigotsky y la pedagogía. México: Editorial Paidós.

Harvey, L., \& Green, D. (1993). Defining quality. Assessment and Evaluation in Higher Education, 18(1), 9-34.

Hernández, M., García, I., López, B., Velástegui, J. \& Ramírez, T. (2016). Acciones didácticas para un aprendizaje desarrollador desde las ciencias básicas en la carrera de Medicina. Revista Educación Médica del Centro, 8(3), 6-21.

Huertas, J. (1997). Motivación: Querer aprender. Buenos Aires: Aique

Korthagen, F., Loughran, J. \& Russell, T. (2006). Developing fundamental principles for teacher education programs and practices. ScienceDirect, 22(8), 1020-1041.

Labarrere, A. (2016). Desarrollo próximo como eje del desarrollo de los estudiantes: De la ayuda a la colaboración. Revista Summa Psicológica UST, 13(1), 45-56.

Lavado, P., Martínez, J. \& Yamada, G. (2014). ¿Una promesa incumplida?: La calidad de la educación superior universitaria y el subempleo profesional en el Perú. Lima: Universidad del Pacífico, Centro de Investigación.

Lens, W., Matos, L. \& Vansteenkiste, M. (2008). El profesor como fuente de motivación de los estudiantes: hablando del qué y del porqué del aprendizaje de los estudiantes. Revista Digital de Investigación en Docencia Universitaria, 4(1).

Lepe, N. (2016). Desarrollo teórico del concepto de autorregulación del aprendizaje. UCMaule, (51), 55-59.

Ley No. 28044 Ley General de Educación (2003). En Diario Oficial El Peruano. Perú.

Ley No. 30220 Ley Universitaria (2014). En Diario Oficial El Peruano. Perú.

Linder, R. \& Harris, B. (1992). Self-Regulated Learning and Academic Achievement in College Students. ERIC.

López, M. (2008). Planeación y Evaluación del proceso enseñanza-aprendizaje. México D.F: Trillas.

López, B., García, I., Hernández, M., López, B., López, M. \& Barbies, A. (2016). El pensamiento crítico-analítico en estudiantes del área de Biología de la Universidad de Guayaquil. Edumecentro, 8(3), 38-51. 
Lucarelli, E. (1994). Teoría y práctica como innovación en docencia, investigación y actualización pedagógica. Cuadernos de investigación, $N^{\circ} 10$, Instituto de Ciencias de la Educación. Buenos Aires, Facultad de Filosofía y Letras, UBA.

Lucarelli, E. (1999). Notas distintas de la Didáctica del Nivel Superior. Marco referencial de la asignatura. Buenos Aires, Facultad de Filosofía y Letras, UBA.

Lucci, M. (2006). La propuesta de Vygotsky: La psicología socio-histórica. Revista Profesorado, 10(2), 1-11.

Lynch, N. (2019). Demócratas, mediocres y técnicos. Las tensiones del futuro universitario en el Perú. Investigaciones Sociales. 22(41), 223-231.

Malaisi, L. (2019). Modo creativo - Educación emocional de jóvenes y adultos. Argentina: Grupo Planeta.

Martínez, R. \& Rodríguez, E. (2005). Manual de Metodología de la Investigación Científica. La Habana.

Mayorga, M. \& Madrid, D. (2010). Modelos didácticos y estrategias de enseñanza en el espacio europeo de educación superior. Tendencias pedagógicas, 15(1).

Mayz, C. (2009). ¿Cómo desarrollar, de una manera comprensiva, el análisis cualitativo de los datos?. Mérida: Universidad de los Andes.

McClelland, D. (1985). Human motivation. Scott Foresman and Comp. Trad cast. de G. Solana. Estudio de la motivación Humana. Madrid: Narcea.

McCombs, B. (1993). Intervenciones educativas para potenciar la metacognición y el aprendizaje autorregulado. En: J. Beltrán, M. Prieto \& D. Vence (Eds.), Intervención psicopedagógica. Madrid: Pirámide.

Medina, M. (2017). Estrategias metodológicas para el desarrollo del pensamiento lógicomatemático.Revista Didasc@lia: Didáctica y Educación, 9(1).

Medina, R., Álamo, D., Costa, M. \& Rodríguez, F. (2019). Aprendizaje autorregulado: una estrategia para enseñar a aprender en ciencias de la salud. Revista de la Fundación Educación Médica, 22(1).

Merchan, N. \& Hernández, N. (2018). Teacher role and self-regulating strategies for learning in higher education. Revista Espacios, 39(52), 1.

Molon, S. (1995). A questão da subjetividade e da constituição do sujeito nas reflexões de Vygotsky. Tesis de maestría, Pontifícia Universidade Católica de São Paulo.

Monereo. C. (1994). Estrategias de enseñanza y aprendizaje. Formación del profesorado y aplicación en la escuela. Barcelona: Graó. 
Monereo, C. (2001). Enseñar a aprender, una vieja aspiración con nuevas coordenadas. Escola Catalana, 376, 6-9.

Monereo, C. \& Pozo, J. (2001). ¿En qué siglo vive la escuela?: El reto de la nueva cultura educativa. Cuadernos de Pedagogía, 298, 50-55.

Monterroso, S. (2015). Aprendizaje autorregulado y su incidencia en el rendimiento académico de los adolescentes. Tesis de maestría, Universidad Rafael Landívar.

Moreno, J., Chiecher, A. \& Paoloni, P. (2019). Los estudiantes universitarios y sus metas académicas. Implicancias en el logro y retraso de los estudios. Argentina: Universidad Nacional de entre Ríos.

Moya, L. (2018). Estrategias para el aprendizaje. Universidad Panamericana Guatemala.

Naranjo, A. (2019). La importancia de las habilidades blandas para la docencia universitaria en el contexto actual. Madrid: Revista Pensamiento Académico de la Universidad UNIACC, 2(1), 82-100.

Nelson, T. \& Narens, L. (1990). Metamemory: A theoretical framework and new findings. En G. Boewr (Ed.), The psychology of learning and motivation (pp. 125-141). Vol. 26. New York: Academic Press.

Nieva, J., \& Martínez, O. (2019). Confluencias y rupturas entre el aprendizaje significativo de Ausubel y el aprendizaje desarrollador desde la perspectiva del enfoque histórico cultural de L. S. Vigotsky. Revista Cubana de Educación Superior, 38(1).

Nocito, G. (2013). Autorregulación del aprendizaje de alumnos de grado. Tesis de doctorado, Universidad Complutense de Madrid.

Norabuena, R. (2011). Relación entre el aprendizaje autorregulado y rendimiento académico en estudiantes de enfermería y obstetricia de la Universidad Nacional Santiago Antúnez de Mayolo. Tesis de maestría, Universidad Nacional Mayor de San Marcos.

Ocando, J. (2009). La formación académica del profesor universitario y las Estrategias que utiliza para promover el aprendizaje significativo. Tesis de doctorado, URBE. Maracaibo. Venezuela.

Oliveira, M. (1993). Vygotsky: aprendizado e desenvolvimento um processo sóciohistórico. São Paulo: Scipione.

Onrubia, J. (1996). Mediación y construcción de significados en la interacción profesor/alumnos y en la interacción entre alumnos. En: A. Barca, J. González-Pienda, R. González \& J. Escoriza (Eds.), Psicología de la instrucción: componentes contextuales y relacionales del aprendizaje escolar (pp. 21-43). Vol. 3. Barcelona: EUB. 
Ortiz, D. (2015). El constructivismo como teoría y método de enseñanza. Sophia: Colección de Filosofía de la Educación, 19(2), 93-110.

Padrón, J. (2006). Bases del concepto de "Investigación Aplicada”. EntreTemas (p. 5). [Web personal del autor].

Panadero, E. \& Tapia, J. (2014). ¿Cómo autorregulan nuestros alumnos? Revisión del modelo cíclico de Zimmerman sobre autorregulación del aprendizaje. Anales de Psicología, $30(2), 450-462$.

Panadero, E. (2017). A Review of Self-regulated Learning: Six Models and Four Directions for Research. Frontiers in Psychology.

Paris, S. \& Byrnes, J. (1989). The constructivist approach to self-regulation and learnig in teh classroom. En: B. Zimmerman \& D. Schunk (Eds.), Self-regulated Learning and Academic Achievement: Theory, Research and Practice. New York: Springer-Verlag.

Pellas, N. (2014). The influence of computer self-efficacy, metacognitive selfregulation and self-esteem on student engagementin online learning programs: Evidence from the virtual world of Second Life. Computers in Human Behavior, 35, 157-170.

Pérez, M., Pozo, J., Scheuer, N., De la Cruz, M., Martín, E., \& Mateos, M. (2006). Nuevas formas de pensar la enseñanza y el aprendizaje. Las concepciones de profesores y alumnos. Barcelona: Editorial GRAÓ.

Perry, N. (2002). Introduction: Using qualitative methods to enrich understandings of selfregulated learning. Educational Psychologist, 37(1), 1-3.

Piaget, J. (1926). The language and thought of the child. Harcourt, Brace.

Pinto, M., Gómez-Camarero, C., Fernández-Ramos, A. \& Doucet, A. (2017). Evaluareed: Desarrollo de una herramienta para la evaluación de los recursos educativos electrónicos. Investigación Bibliotecológica, 31(72).

Pintrich, P. (1987). Motivated learning strategies in the college classroom. Paper presented at the American Educational Research Association Convention, Washington, D.C., April.

Pintrich, P., Smith, D., García, T. \& McKeachie, W. (1991). A manual for the use of the Motivated Strategies for Learning Questionnaire (MSLQ). National Center for Research to Improve Postsecondary Teaching and Learning. University of Michigan.

Pintrich, P. \& García, T. (1993). Intraindividual diffrences in students motivation and selfregulated learning. German Journal of Educational Psichology, 7(3), 99-107.

Pintrich, P. (2000). The role of goal orientation in self-regulated learning. En: M. Boeckaerts, P. Pintrich \& M. Zeidner. (Eds.), The handbook of self-regulation (pp. 448-453). San Diego: Academic Press. 
Pintrich, P., Wolters, C. \& Baxter, G. (2000). Assessing metacognition and self-regulated learning. En: G. Schraw \& J. Ampara (Eds.), Issues in the measurement of metacognition (pp. 43-97). Lincoln: Buros Institute of Mental Measurements, University of Nebraska Press.

Pintrich, P. (2004). A conceptual framework for assessing motivation and self-regulated learning in college students. Educational Psychology Review, 16, 385-407.

Portocarrero, F. (2014). "Bestias frágiles aunque tenaces": el incierto futuro de la educación superior en el Perú. En Blanco y Negro, 5(2), 2.

Pressley, M. \& Afflerbach, P. (1995). Verbal protocols of reading: The nature of constructively responsive reading. Hillsdale, $\mathrm{NJ}$ : Erlbaum.

Quintero, M. (2011). Estrategia metodológica para el uso de la narrativa en investigación. En: Universidad Distrital Francisco José de Caldas (Eds.), Justificaciones y narraciones: orientaciones teóricas e investigativas. Bogotá.

Raynaudo, G. \& Peralta, O. (2017). Cambio conceptual: Una mirada desde las teorías de Piaget y Vygotsky. Revista Liberabit, 23(1), 5 y 137-148.

Reimers, F. (2015). El graduado ideal, según un experto en educación de Harvard. Diario Clarín.

Rego, C. (1998). Vygotsky: Uma perspectiva histórico-cultural da educação. Petrópolis, Rio de Janeiro: Vozes.

Reynaga, J. (1996). El método estadístico. En F. d. UNAM, Lecturas básicas para el apoyo de las unidades de estadística descriptiva y analítica (p. 33). México: Facultad de Medicina. Departamento de Salud Pública. UNAM.

Rivadeneira, E. (2017). Competencias didácticas-pedagógicas del docente, en la transformación del estudiante universitario. ORBIS, 13(37), 41-55.

Rodríguez, J. (2005). La investigación Acción Educativa ¿Qué es? ¿Cómo se hace? (pp. 13 y 15). Lima: DOXA.

Rodríguez, L. (2008). Variables cognitivo-motivacionales, comportamentales y contextuales y su relación con los procesos de autorregulación del aprendizaje en área de las matemáticas. Universidad de Oviedo.

Rodríguez, W. (2015). Reflexividad histórica, problematización e indagación dialógica como herramientas para repensar el concepto vygotskyano de zona de desarrollo próximo. Revista Puertorriqueña de Psicología, 26(1), 10-24.

Rodríguez A. \& Pérez A. (2017). Métodos científicos de indagación y de construcción del conocimiento. Revista Escuela de Administración de Negocios, 82, 175-195. 
Romero, G. (2009). La utilización de estrategias didácticas en clase. Revista Innovación y Experiencias, 23.

Roth, A., Ogrin, S. \& Schmitz, B. (2016). Assessing self-regulated learning in higher education: A systematic literatura review of self-report instrument. Educational Assessment, Evaluation and Accountability, 28, 225-250.

Ruiz, C. (2015). Hacia una comprobación experimental de la zona de desarrollo próximo de Vigotsky. Ciencia ergo-sum - revista científica multidisciplinaria de la Universidad Autónoma del Estado de México, 22(2), 167-171.

Schunk, D. \& Zimmerman, B. (1995). Self-regulation of learning and performance: issues and educational aplications. Mahwah, NJ: Erlbaum.

Schunk, D. \& Zimmerman, B. (1998). Self-regulated learning: From teaching to self-reflective practice. New York: Guilford.

Schunk, D. \& Zimmerman, B. (2003). Self-regulation and learning. En: W. Reynolds \& G. Miller (Eds.), Handbook of psychology: Educational psychology (59-78). Vol. 7. Hoboken, NJ: Wiley.

Schunk, D. \& Mullen, C. (2012) Autoeficacia como aprendiz comprometido. En: S. Christenson, A. Reschly \& C. Wylie (Eds.), Handbook of Research on Student Engagement. Springer. Boston, MA.

Sesento, L. (2017). Reflexiones sobre la pedagogía de Vigotsky. Revista CCCSS Contribuciones a las Ciencias Sociales, (abril-junio 2017).

Strauss, A. \& Corbin, J. (2016). Bases de la investigación cualitativa: Técnicas y procedimientos para desarrollar la teoría fundamentada. Medellín: Universidad de Antioquía.

Torrano, F. \& González, M. (2004). El aprendizaje autorregulado: Presente y futuro de la investigación. España: Universidad de Navarra.

Torrez, M. \& Girón, D. (2009). Didáctica General: Colección Pedagógica Formación Inicia de Docentes Centro Americano de Educación Básica. (Vol. 9). San José, Costa Rica: Editoram S.A.

Tuñas, J. (2007). Técnicas - estrategias de aprendizaje: Diferencias e incursión en las nuevas tecnologías. Educaweb, 149.

Valdez, F. (2012). Relación entre la implementación del aprendizaje cooperativo y el logo en el aprendizaje individual de estudiantes universitarios. Revista UNIBE, 1(1). 
Valle, A., González Cabanach, R., Vieiro, P. \& Suárez, J. (1998). Las estrategias de aprendizaje. En: A. Valle \& R. González Cabanach (Eds.), Psicología de la educación, I: variables personales y aprendizaje escolar (pp. 183-213). La Coruña: Universidade Da Coruña.

Vargas Díaz, A. (2017). Aprendizaje autorregulado y desarrollo de procesos cognitivos en estudiantes de administración. Tesis de maestría, Universidad San Martín de Porres.

Vicuña, M. \& Sanjinés, E. (2018). Habilidades de pensamiento y su relación con el aprendizaje autorregulado en estudiantes de educación de una universidad pública de Lima. Revista de Investigación en Psicología, 21(2), 225-235.

Villanueva Espinosa, C. (2016). Autorregulación del aprendizaje de estudiantes universitarios. Estudio dentro del contexto actual. Tesis de doctorado, Universidad Iberoamericana Puebla.

Vygotsky, L. (1978). Mind in society: The development of higher psychological processes. Cambridge, MA: Harvard University Press.

Vygotski, L. (1988). El desarrollo de los procesos psicológicos superiores. Barcelona: Grijalbo. 133

Wang, J., Morin, A., Liu, W. \& Chian, L. (2016). Predicting physical activity intention and behaviour using achievement goal theory: A person-centred analysis. Psychology of Sport and Exercise, 23, 13-20.

Weinstein, C., Husman, J. \& Dierking, D. (2000). Self-regulation interventions with a focus on learning strategies. En: M. Boekaerts, P. Pintrich \& M. Zeidner (Eds.), Handbook of self-regulation (pp. 728-748). San Diego, CA: Academic Press.

Winne, P. (1995). Inherent details in self-regulated learning. Educational Psychologist, 30(4), 173-187.

Winne, P. \& Hadwin, A. (1998). Studying as self-regulated engagement in learning. En: D. Hacker, J. Dunlosky \& A. Graesser (Eds.), Metacognition in educational theory and practice (pp. 277-304). Hillsdale, NJ: Erlbaum

Winne, P. (2011). A cognitive and metacognitive analysis of self-regulated learning. En: B. Zimmerman \& D. Schunk (Eds.), Handbook of selfregulation of learning and performance, 15-32. New York: Routledge.

Yamada, G., Castro, J., Bacigalupo, J. \& Velarde, L. (2013). Mayor acceso con menor calidad en la educación superior: algunas evidencias desde las habilidades de los estudiantes. Apuntes, 40(72), 10-12.

Yasnitsky, A. \& van der Veer, R. (Eds.) (2015). Revolución revisionista en los estudios de Vygotsky. Londres y Nueva York: Routledge. 
Zavershneva, E. (2014). The problem of consciousness in Vygotsky's cultural-historical psychology. En: A. Yasnitsky, R. van der Veer \& M. Ferrari (Eds.). The Cambridge Handbook of Cultural-Historical Psychology (pp. 63-97). Cambridge UK: Cambridge University Press.

Zheng, L. (2016). Analysis of socially shared regulation in CSCL En: Z. Shi \& S. Yu (Eds.), Perspectives on rethinking and reforming education (pp. 65-81). Singapore: Springer.

Zimmerman, B. \& Martinez, M. (1986). Development of a Structured Interview for Assessing Student Use of Self-Regulated Learning Strategies. American Educational Research Journal. 23(4). 614-628.

Zimmerman, B. (1989). Modelos de aprendizaje autorregulado y logros académicos. En: B. Zimmerman \& D. Schunk (Eds.), Aprendizaje autorregulado y rendimiento académico: teoría, investigación y práctica (pp. 1-25). Nueva York: Springer-Verlag.

Zimmerman, B. \& Schunk, D. (1997). Social origins of self-regulatory competence. Educational Psychologist, 32(4), 195-208.

Zimmerman, B. (1998). Developing self-fulfilling cycles of academic regulation: An analysis of exemplary instructional model. En: D. Schunk \& B. Zimmerman (Eds.), Selfregulated learning: From teaching to self-reflective practice (pp. 1-19). New York: Guilford.

Zimmerman, B. (1999). Commentary: toward a cyclically interactive view of self-regulated learning. International Journal of Educational Research, 31, 545-551.

Zimmerman, B. (2000). Attaining self-regulation: A social cognitive perspective. En: M. Boekaerts, P. Pintrich \& M. Zeidner (Eds.), Handbook of self-regulation (pp. 451-502). San Diego, CA: Academic Press.

Zimmerman, B. (2001). Achieving academic excellence: A self regulatory perspective. En M. Ferrari (Ed.), The pursuit of excellence though education. Mahwah (pp. 85-110). NJ: Erlbaum.

Zimmerman, B. (2002). Becoming self-regulated learned: An overview. Theory into Practice, 41(2), 64-70.

Zimmerman, B. \& Moylan, A. (2009). Self-regulation: Where metacognition and motivation intersect. En: D. Hacker, J. Dunlosky \& A. Graesser (Eds.), Handbook of Metacognition in Education (pp. 299- 315). New York: Routledge. 


\section{Anexos}

Anexo 1 - Matriz metodológica

\begin{tabular}{|c|c|c|c|c|c|c|c|c|c|c|}
\hline $\begin{array}{c}\text { Problema } \\
\text { general }\end{array}$ & Problemas específicos & $\begin{array}{c}\text { Objetivo } \\
\text { general }\end{array}$ & Objetivos específicos & Categorías & $\begin{array}{c}\text { Sub } \\
\text { categorías }\end{array}$ & $\begin{array}{c}\text { Paradigma, } \\
\text { enfoque, tipo y } \\
\text { diseño }\end{array}$ & $\begin{array}{c}\text { Población, muestra, } \\
\text { muestreo y unidad de } \\
\text { análisis }\end{array}$ & Métodos & Técnicas & Instrumentos \\
\hline $\begin{array}{l}\text { ¿Cómo } \\
\text { desarrollar el } \\
\text { aprendizaje } \\
\text { autorregulado } \\
\text { en los } \\
\text { estudiantes del } \\
\text { primer ciclo de } \\
\text { la carrera de } \\
\text { Administración } \\
\text { en una } \\
\text { universidad } \\
\text { privada de } \\
\text { Lima? }\end{array}$ & $\begin{array}{l}\text { ¿Cuál es el estado actual del } \\
\text { desarrollo del aprendizaje } \\
\text { autorregulado en los } \\
\text { estudiantes del primer ciclo de } \\
\text { la carrera de Administración } \\
\text { en una universidad privada de } \\
\text { Lima? } \\
\text { ¿Cuáles son los fundamentos } \\
\text { teóricos y metodológicos que } \\
\text { sustentan la estrategia } \\
\text { metodológica para desarrollar } \\
\text { el aprendizaje autorregulado } \\
\text { en los estudiantes del primer } \\
\text { ciclo de la carrera de } \\
\text { Administración en una } \\
\text { universidad privada de Lima? } \\
\text { ¿Qué criterios teóricos y } \\
\text { metodológicos se debe tener } \\
\text { en cuenta en la modelación de } \\
\text { una estrategia metodológica } \\
\text { para desarrollar el aprendizaje } \\
\text { autorregulado en los } \\
\text { estudiantes del primer ciclo de } \\
\text { la carrera de Administración } \\
\text { en una universidad privada de } \\
\text { Lima? } \\
\text { ¿Cómo validar la propuesta de } \\
\text { estrategia metodológica para } \\
\text { desarrollar el aprendizaje } \\
\text { autorregulado en los } \\
\text { estudiantes del primer ciclo de } \\
\text { la carrera de Administración } \\
\text { en una universidad privada de } \\
\text { Lima? }\end{array}$ & $\begin{array}{l}\text { Proponer una } \\
\text { estrategia } \\
\text { metodológica } \\
\text { para } \\
\text { desarrollar el } \\
\text { aprendizaje } \\
\text { autorregulado } \\
\text { en los } \\
\text { estudiantes } \\
\text { del primer } \\
\text { ciclo de la } \\
\text { carrera de } \\
\text { Administración } \\
\text { en una } \\
\text { universidad } \\
\text { privada de } \\
\text { Lima. }\end{array}$ & $\begin{array}{l}\text { Diagnosticar el estado actual } \\
\text { del desarrollo del } \\
\text { aprendizaje autorregulado } \\
\text { en los estudiantes del primer } \\
\text { ciclo de la carrera de } \\
\text { Administración en una } \\
\text { universidad privada de Lima. } \\
\text { Fundamentar teórica y } \\
\text { metodológicamente la } \\
\text { estrategia metodológica para } \\
\text { desarrollar el aprendizaje } \\
\text { autorregulado en los } \\
\text { estudiantes del primer ciclo } \\
\text { de la carrera de } \\
\text { Administración en una } \\
\text { universidad privada de Lima. } \\
\text { Determinar los criterios } \\
\text { teóricos y metodológicos que } \\
\text { se deben tener en cuenta en } \\
\text { la modelación de una } \\
\text { estrategia metodológica para } \\
\text { desarrollar el aprendizaje } \\
\text { autorregulado en los } \\
\text { estudiantes del primer ciclo } \\
\text { de la carrera de } \\
\text { Administración en una } \\
\text { universidad privada de Lima. } \\
\text { Validar por juicio de expertos } \\
\text { la propuesta de estrategia } \\
\text { metodológica para } \\
\text { desarrollar el aprendizaje } \\
\text { autorregulado en los } \\
\text { estudiantes del primer ciclo } \\
\text { de la carrera de } \\
\text { Administración en una } \\
\text { universidad privada de Lima. }\end{array}$ & $\begin{array}{l}\text { Estrategia } \\
\text { metodológica }\end{array}$ & $\begin{array}{l}\begin{array}{l}\text { Planificación } \\
\text { estratégica } \\
\text { Capacidad } \\
\text { didáctica } \\
\text { Recursos } \\
\text { educativos }\end{array} \\
\text { Cognición } \\
\text { Motivación } \\
\text { Contexto del } \\
\text { aprendizaje }\end{array}$ & $\begin{array}{l}\begin{array}{l}\text { Paradigmas } \\
\text { sociocrítico e } \\
\text { interpretativo. }\end{array} \\
\text { Enfoque } \\
\text { cualitativo. } \\
\text { Investigación } \\
\text { educacional de } \\
\text { tipo aplicada. } \\
\text { Diseño es no } \\
\text { experimental, } \\
\text { de corte } \\
\text { transversal } \\
\text { descriptivo. }\end{array}$ & $\begin{array}{l}\text { Población: } \\
\text { Todos los estudiantes y } \\
\text { profesores del primer } \\
\text { ciclo de la carrera de } \\
\text { Administración de una } \\
\text { universidad privada de } \\
\text { Lima. } \\
\text { Muestra: } \\
38 \text { estudiantes y } 2 \\
\text { profesores. } \\
\text { Muestreo: } \\
\text { Tipo no probabilístico. } \\
\text { Unidad de análisis: } \\
\text { Estudiantes del primer } \\
\text { ciclo de la carrera de } \\
\text { Administración de una } \\
\text { universidad privada; } \\
\text { docentes de la carrera } \\
\text { de Administración; } \\
\text { literatura y } \\
\text { documentos } \\
\text { especializados. }\end{array}$ & $\begin{array}{l}\text { Teóricos } \\
\text { Empíricos } \\
\text { Matemático- } \\
\text { estadísticos }\end{array}$ & $\begin{array}{l}\text { Observación } \\
\text { Entrevistas } \\
\text { Encuesta } \\
\text { Análisis } \\
\text { documental } \\
\text { Juicio de } \\
\text { expertos }\end{array}$ & 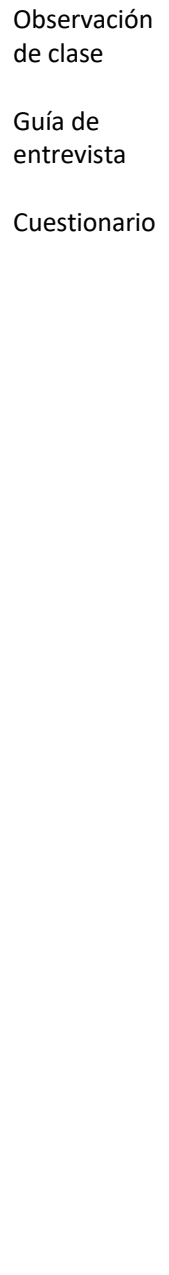 \\
\hline
\end{tabular}


Anexo 2 - Matriz de categorización

\begin{tabular}{|c|c|c|c|c|c|c|c|}
\hline $\begin{array}{l}\text { Problema de } \\
\text { investigación o } \\
\text { pregunta científica }\end{array}$ & Objetivo principal & Categorías principales & Subcategorías apriorísticas por categoría principal & Indicadores por subcategoría & $\begin{array}{l}\text { Ítems de } \\
\text { la Guía de } \\
\text { Entrevista }\end{array}$ & $\begin{array}{l}\text { Ítems del } \\
\text { Cuestionario }\end{array}$ & $\begin{array}{l}\text { Ítems de la } \\
\text { Observación } \\
\text { de clase }\end{array}$ \\
\hline \multirow{11}{*}{$\begin{array}{l}\text { ¿Cómo desarrollar } \\
\text { el aprendizaje } \\
\text { autorregulado en } \\
\text { los estudiantes del } \\
\text { primer ciclo de la } \\
\text { carrera de } \\
\text { Administración en } \\
\text { una universidad } \\
\text { privada de Lima? }\end{array}$} & \multirow{11}{*}{$\begin{array}{l}\text { Proponer una } \\
\text { estrategia } \\
\text { metodológica } \\
\text { para desarrollar el } \\
\text { aprendizaje } \\
\text { autorregulado en } \\
\text { los estudiantes } \\
\text { del primer ciclo } \\
\text { de la carrera de } \\
\text { Administración en } \\
\text { una universidad } \\
\text { privada de Lima. }\end{array}$} & \multirow{6}{*}{$\begin{array}{l}\text { Aprendizaje autorregulado. La } \\
\text { autorregulación es un proceso } \\
\text { activo, mediante el cual los } \\
\text { estudiantes establecen metas para } \\
\text { sus aprendizajes y logran supervisar, } \\
\text { regular y controlar su cognición, } \\
\text { motivación y conducta, dirigidos por } \\
\text { sus metas y por las características } \\
\text { de su entorno (Pintrich, 2000). }\end{array}$} & \multirow{2}{*}{$\begin{array}{l}\text { Cognición. La cognición es la capacidad que permite el } \\
\text { procesamiento de la información; entre las estrategias } \\
\text { cognitivas tenemos las estrategias de elaboración, } \\
\text { organización, repaso y pensamiento crítico (Pintrich, 2000). }\end{array}$} & Demuestra capacidad en el procesamiento de información. & 1 & 1 & 5 \\
\hline & & & & Desarrolla estrategias de repaso, elaboración y organización. & 1 & 2 & 5 \\
\hline & & & \multirow{2}{*}{$\begin{array}{l}\text { Motivación. La motivación es el proceso que nos orienta } \\
\text { hacia nuestros objetivos o metas; la activación y } \\
\text { planificación motivacional implican adoptar metas y activar } \\
\text { creencias motivacionales (Pintrich, 2000). }\end{array}$} & $\begin{array}{l}\text { Adopta metas en relación con los propósitos para implicarse en } \\
\text { las tareas y actividades académicas. }\end{array}$ & 2 & 3 & 5 \\
\hline & & & & $\begin{array}{l}\text { Demuestra creencias motivacionales como la autoeficacia, } \\
\text { interés personal y valor de la tarea en las actividades } \\
\text { académicas. }\end{array}$ & 3 & 4 & $1,2,3$ \\
\hline & & & \multirow{2}{*}{$\begin{array}{l}\text { Contexto del aprendizaje. El contexto consiste en todas las } \\
\text { características de la clase, las cuales incluyen clima } \\
\text { emocional, percepción de las reglas en el aula, métodos de } \\
\text { enseñanza, características del ambiente físico de } \\
\text { aprendizaje, percepciones de la tarea (análisis, control y } \\
\text { evaluación), características de las evaluaciones y demandas } \\
\text { de los docentes (Pintrich, 2000). }\end{array}$} & $\begin{array}{l}\text { Identifica y valora las características de la clase que incluyen la } \\
\text { percepción de las normas en el aula, el clima emocional, las } \\
\text { características del ambiente físico de aprendizaje y los } \\
\text { métodos de enseñanza aplicados. }\end{array}$ & 4 & 5,6 & 4 \\
\hline & & & & $\begin{array}{l}\text { Reconoce y valora las percepciones de las tareas que se } \\
\text { refieren al análisis, control y evaluación de las tareas, las } \\
\text { características de las evaluaciones y demandas del profesor. }\end{array}$ & 5 & 7 & $6,7,8,9,10$ \\
\hline & & \multirow{5}{*}{$\begin{array}{l}\text { Estrategia metodológica. Moya } \\
\text { (2018), considera que es la } \\
\text { planificación de una serie de } \\
\text { acciones a corto, mediano y largo } \\
\text { plazo, que permite modificar la } \\
\text { dirección del proceso de enseñanza- } \\
\text { aprendizaje, teniendo como base los } \\
\text { procedimientos, métodos y recursos } \\
\text { didácticos, con el fin de alcanzar los } \\
\text { objetivos concretos en un periodo } \\
\text { de tiempo determinado. Asimismo, }\end{array}$} & \multirow{3}{*}{$\begin{array}{l}\text { Planificación estratégica. La planificación estratégica es una } \\
\text { serie de procesos anticipados, generalizados y sistemáticos } \\
\text { que determinan acciones encaminadas a desarrollar } \\
\text { equilibrada y coherentemente los procesos de enseñanza- } \\
\text { aprendizaje, y fija objetivos, políticas, propósitos y } \\
\text { estrategias rectoras que atienden las necesidades y } \\
\text { demandas de los estudiantes (Moya, 2018). }\end{array}$} & $\begin{array}{l}\text { Plantea procesos anticipados, sistemáticos y generalizados } \\
\text { para concretar los planes de desarrollo en el aula de clases. }\end{array}$ & 6 & 8 & $6,7,8,9,10$ \\
\hline & & & & $\begin{array}{l}\text { Determina acciones tendientes al desarrollo equilibrado y } \\
\text { coherente de los procesos de enseñanza - aprendizaje. }\end{array}$ & 7 & 9 & $6,7,8,9,10$ \\
\hline & & & & $\begin{array}{l}\text { Establece propósitos, objetivos, políticas y estrategias } \\
\text { rectoras, que guíen su actuación y respondan a las demandas y } \\
\text { necesidades de sus estudiantes. }\end{array}$ & 8 & 10 & $6,7,8,9,10$ \\
\hline & & & \multirow{2}{*}{$\begin{array}{l}\text { Capacidad didáctica. La capacidad didáctica es definida } \\
\text { como la destreza de los docentes para desarrollar } \\
\text { contenidos de manera comprensible por los estudiantes y } \\
\text { para organizarlos de forma adecuada como parte de una } \\
\text { guía integral, teniendo en cuenta el contexto y las } \\
\text { dificultades de aprendizaje y problemas que podrían }\end{array}$} & $\begin{array}{l}\text { Desarrolla los contenidos de manera adecuada y de una forma } \\
\text { comprensible en cada sesión de clase. }\end{array}$ & 9 & 11 & $6,7,8,9,10$ \\
\hline & & & & $\begin{array}{l}\text { Orienta desde el punto de vista integral, preocupándose del } \\
\text { estudiante, del medio de las dificultades de aprendizaje y los } \\
\text { posibles problemas que se podrían enfrentar en determinadas }\end{array}$ & 10 & 12 & $6,7,8,9,10$ \\
\hline
\end{tabular}




\section{Entrevista semi estructurada a los docentes}

Datos informativos

Entrevistador: Mónica García Álvarez

Lugar y Fecha:

Duración:

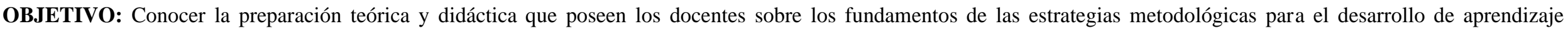
autorregulado en los estudiantes del I ciclo de la carrera de Administración de una universidad privada de Lima.

Preguntas:

1. ¿Usted qué estrategias emplea con los estudiantes para el procesamiento de información, repaso, elaboración y organización? ¿Cómo las aplica?

2. ¿Usted considera importante que el estudiante adopte metas en relación con los propósitos para implicarse en las tareas y actividades académicas? ¿Por qué?

3. ¿De qué forma motiva a los estudiantes en las tareas y actividades académicas?

4. ¿De qué forma logra que los estudiantes puedan identificar y valorar las características de la clase? (Incluyen la percepción de las normas en el aula, el clima emocional, las

características del ambiente físico de aprendizaje y los métodos de enseñanza aplicados)

5. ¿Cómo desarrolla en los estudiantes la valoración de las tareas, las características de las evaluaciones y sus demandas como profesor?

6. ¿Cuáles son los procesos anticipados, sistemáticos y generalizados que plantea para concretar los planes de desarrollo en las sesiones de clases? ¿Cómo los aplicas?

7. ¿Cuáles son las acciones tendientes que determina para el desarrollo equilibrado y coherente de los procesos de enseñanza - aprendizaje? ¿Cómo las aplicas?

8. ¿De qué manera establece propósito, objetivos y estrategias rectoras, que guíen a los estudiantes y les respondan a sus demandas y necesidades?

9. ¿Cómo logra desarrollar los contenidos de manera adecuada y de una forma comprensible en las sesiones de clase?

10. ¿Qué estrategias emplea para orientar y ayudar a los estudiantes en sus problemas de aprendizaje? ¿Cómo las aplica?

11. ¿Qué recursos materiales y digitales selecciona y diseña para lograr los aprendizajes significativos en los estudiantes? ¿Cómo los emplea? 


\section{Cuestionario a los estudiantes}

\section{Datos generales}

Carrera:

Ciclo:

Edad: Sexo: Femenino ( ) Masculino ( ) Fecha:

Objetivo: Constatar el nivel de satisfacción que experimentan los estudiantes del primer ciclo con la manera en que el docente de la carrera Administración dirige el proceso de enseñanza - aprendizaje para contribuir al desarrollo de aprendizaje autorregulado en la carrera de Administración de una universidad privada de Lima.

\section{Instrucciones:}

Estimado estudiante, como parte de una investigación necesitamos que colabores con tu opinión respecto a los contenidos de la asignatura y de la forma como el docente dirige la sesión de clase. Para ello te pedimos que leas atentamente el siguiente cuestionario para responder con sinceridad las siguientes preguntas.

\section{Preguntas:}

1. ¿Usted demuestra capacidad en el procesamiento de información del tema que desarrolla en la sesión de clase?

Siempre ( ) Casi siempre ( ) Pocas veces ( ) Nunca ( ) 2. ¿El docente le permite esclarecer las estrategias de repaso, la elaboración y organización?

Siempre ( ) Casi siempre ( ) Pocas veces ( ) Nunca ( ) 3. ¿Usted acostumbra adoptar metas en relación con los propósitos para implicarte en las tareas y actividades académicas?

Siempre ( ) Casi siempre ( ) Pocas veces $(\quad)$ Nunca ( ) 4. ¿Usted considera que el docente contribuye en el desarrollo de sus creencias motivacionales, como la autoeficacia, interés personal y valor de las tareas?
Casi siempre ( )
Pocas veces ( ) Nunca (

5. ¿Usted aprecia que el docente, en las sesiones de clase, emplea estrategias que permiten a los estudiantes cumplir las normas del aula y de ese modo propiciar un clima emocional adecuado?

Siempre ( ) Casi siempre ( ) Pocas veces ( ) Nunca ( )

6. ¿Cómo valora usted el ambiente físico de aprendizaje? Por ejemplo, iluminación, ventilación, limpieza, etc.

Muy bueno ( ) Bueno ( ) Regular ( ) Malo ( )

7. ¿Cómo valora usted el nivel de exigencia de las tareas, las características de las evaluaciones y demandas del profesor?

Muy exigente ( ) Exigente ( ) Poco exigente ( ) Nada exigente $\left(\begin{array}{l}\text { ) } \\ \text { ) }\end{array}\right.$ 8. ¿Usted percibe que el docente plantea procesos anticipados, sistemáticos y generalizados para concretar los planes de desarrollo en el aula de clases?

Siempre ( ) Casi siempre ( ) Pocas veces ( ) Nunca ( )

9. ¿Considera usted que el docente determina acciones tendientes al desarrollo equilibrado y coherente de los procesos de enseñanza aprendizaje?

Siempre ( ) Casi siempre ( ) Pocas veces ( ) Nunca ( )

10. ¿Usted observa que el docente, al iniciar cada sesión de clase, precisa propósito, objetivos y estrategias rectoras, que guíen a los estudiantes y respondan a sus demandas y necesidades?

Siempre ( ) Casi siempre ( ) Pocas veces ( ) Nunca ( ) 11. ¿Usted percibe que el docente desarrolla los contenidos de manera adecuada y de una forma comprensible en las sesiones de clase?

Siempre ( ) Casi siempre ( ) Pocas veces $(\quad) \quad$ Nunca $(\quad$ )

12. ¿Considera usted que el docente orienta desde el punto de vista integral, preocupándose del estudiante, del medio de las dificultades de aprendizaje y los posibles problemas que se podrían enfrentar en determinadas situaciones?

Siempre ( ) Casi siempre ( ) Pocas veces $($ ) Nunca ( )

13. ¿Usted aprecia que el docente selecciona los instrumentos de apoyo, herramientas y ayudas didácticas con el fin de tener mayor acercamiento a los estudiantes, al conocimiento y a la construcción de los conceptos para facilitar de esta manera el aprendizaje? Siempre ( ) Casi siempre ( ) Pocas veces ( ) Nunca ( ) 14. ¿Usted observa que el docente emplea los instrumentos de apoyo, herramientas y ayudas didácticas pertinentes en las sesiones de clase (guías, libros, materiales impresos y no impresos, esquemas, videos, diapositivas, imágenes, herramientas digitales, etc.)?

Siempre ( ) Casi siempre ( ) Pocas veces ( ) Nunca ( ) 


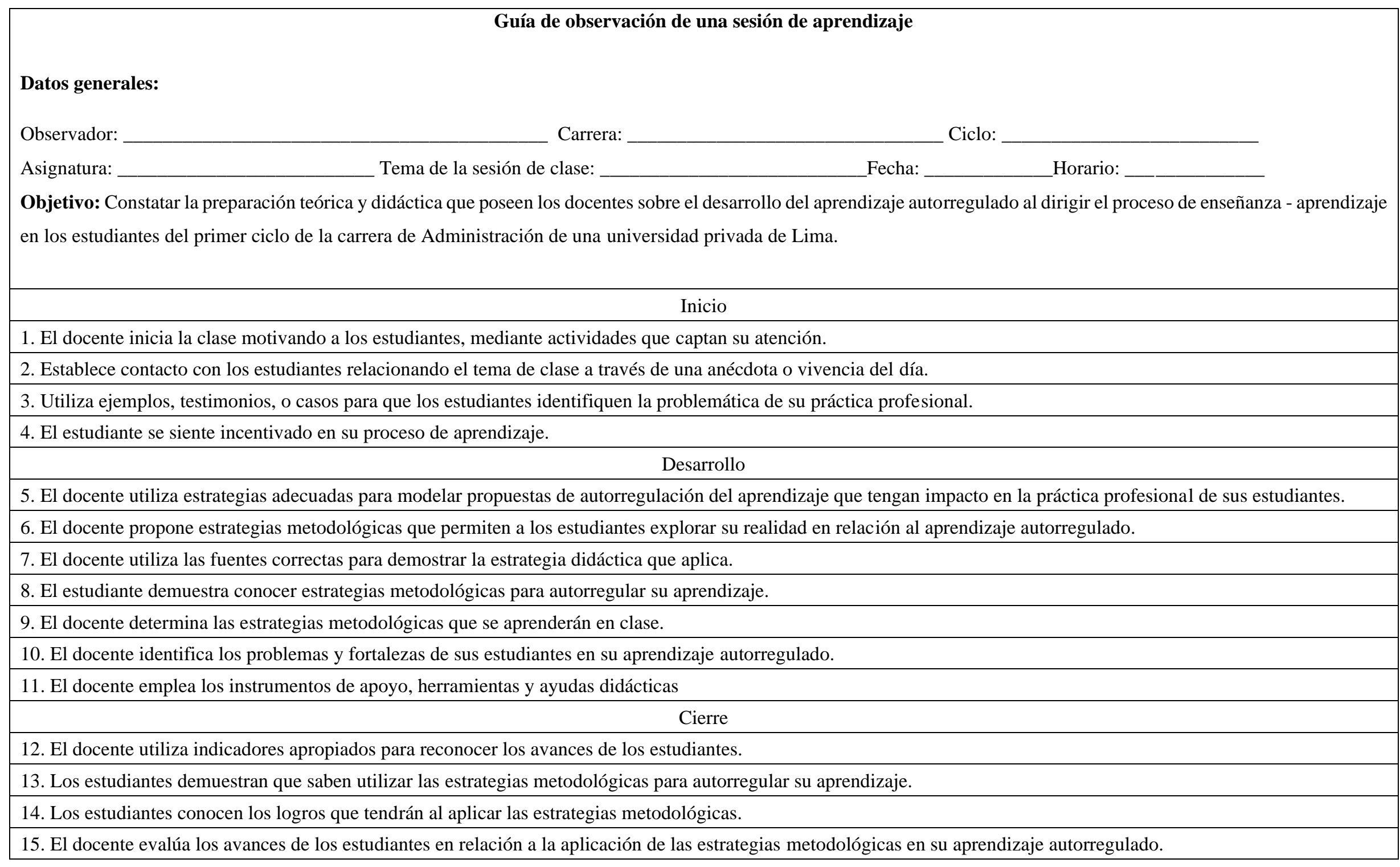


Anexo 4 - Validación de los instrumentos de recolección de datos

\section{CERTIFICADO DE VALIDEZ DE CONTENDO DE LA ENTREVISTA A DOCENTES}

\begin{tabular}{|c|c|c|c|c|c|c|c|c|c|}
\hline \multirow{2}{*}{$\mathbf{N}^{\circ}$} & \multirow{2}{*}{ Formulación del item } & \multicolumn{2}{|c|}{ Pertinencia $^{1}$} & \multicolumn{2}{|c|}{ Relevancia $^{2}$} & \multicolumn{2}{|c|}{ Construcción } & \multirow{2}{*}{ Observaciones } & \multirow{2}{*}{ Sugerencia: } \\
\hline & & Si & No & $\mathrm{Si}$ & No & $\frac{\text { gran }}{\mathrm{Si}}$ & & & \\
\hline 1 & $\begin{array}{l}\text { ¿Usted qué estrategias emplea con los estudiantes para el procesamiento de información, repaso, } \\
\text { elaboración y organización? CCómo las aplica? }\end{array}$ & $\checkmark$ & & 2 & & 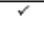 & & & \\
\hline 2 & $\begin{array}{l}\text { Uusted considera importante que el estudiante adopte metas en relación con los propósitos para implicarse } \\
\text { en las tareas } \mathrm{y} \text { actividades académicas? por qué? }\end{array}$ & $\checkmark$ & & 2 & & r & & & \\
\hline 3 & DDe qué forma motiva a los estudiantes en las tareas y actividades académicas? & $\bar{r}$ & & 2 & & 2 & & & \\
\hline 4 & $\begin{array}{l}\text { iDe qué forma logra que los estudiantes puedan identificar y valorar las características de la clase? (Incluyen } \\
\text { la percepción de las normas en el aula, el clima emocional, las características del ambiente fisico de } \\
\text { aprendizaje y los métodos de ensenanza aplicados) }\end{array}$ & 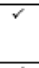 & & 2 & & 2 & & & \\
\hline 5 & $\begin{array}{l}\text { ¿Cómo desarrolla en los estudiantes la valoración de las tareas, las caracteristicas de las evaluaciones y sus } \\
\text { demandas como profesor? }\end{array}$ & $\bar{r}^{\prime}$ & & 2 & & 2 & & & \\
\hline 6 & $\begin{array}{l}\text { Cuáles son los procesos anticipados, gistemáticos y generalizados que plantea para concretar los planes } \\
\text { de desarrollo en las sesiones de clases? Cómo los aplicas? }\end{array}$ & $\checkmark$ & & 2 & & $\mathrm{r}$ & & & \\
\hline 7 & $\begin{array}{l}\text { ¿Cuáles son las acciones tendientes que determina para el desarrollo equilibrado y coherente de los } \\
\text { procesos de enseâanza - aprendizaje? CComo las aplicas? }\end{array}$ & $\checkmark$ & & r & & r & & & \\
\hline 8 & $\begin{array}{l}\text { ¿De qué manera establece propósito, objetivos y estrategias rectoras, que guien a los estudiantes y les } \\
\text { respondan a sus demandas y necesidades? }\end{array}$ & $\checkmark$ & & $\checkmark$ & & r & & & \\
\hline 9 & $\begin{array}{l}\text { ¿Cómo logra desarrollar los contenidos de manera adecuada y de una forma comprensible en las sesiones } \\
\text { de clase? }\end{array}$ & $\checkmark$ & & $\checkmark$ & & $\mathrm{r}$ & & & \\
\hline 10 & $\begin{array}{l}\text { ¿Qué estrategias emplea para orientar y ayudar a los estudiantes en sus problemas de aprendizaje? ¿Cómo } \\
\text { las aplica? }\end{array}$ & $\checkmark$ & & $r$ & & r & & & \\
\hline 11 & $\begin{array}{l}\text { QQuérecursos materiales y digitales selecciona y diseña para lograr los aprendizajes significativos en los } \\
\text { estudianten? Cómolos emvles? }\end{array}$ & $\checkmark$ & & 2 & & r & & & \\
\hline
\end{tabular}

OPINIÓN DE APLICABILIDAD DE LA ENTREVISTA

Opinión de aplicabilidad: Aplicable [ $]$ Aplicable después de corregir [ ] No aplicable [ ]

\begin{tabular}{|c|c|c|c|}
\hline Nombres y Apellidos & Torellanel Howorsalazan & $D^{2} I^{\circ} N^{\circ}$ & 05536783 \\
\hline Dirección domiciliaria & & Teléfono / Celular & \\
\hline $\begin{array}{l}\text { Titulo profesional/ } \\
\text { Especialidad }\end{array}$ & & Firma & \\
\hline Grado Académico & 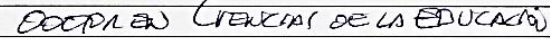 & & \\
\hline Metodólogo/ temático & & Lugar y fecha & \\
\hline
\end{tabular}

'Pertinencia: El item corresponde al concepto teórico formulado.

o dimensión especifica del constructo

"Claridad: Se entiende sin dificultad alguna el enunciado del item, es conciso, exacto y directo

Nota: Suficiencia, se dice suficiencia cuando los items planteados son suficientes para medir la dimensión

CERTIFICADO DE VALIDEZ DE CONTENDO DE LA OBSERVACIÓN DE CLASE

\begin{tabular}{|c|c|c|c|c|c|c|c|c|c|}
\hline \multirow{2}{*}{$\mathrm{N}^{\mathrm{N}}$} & \multirow{2}{*}{ Formulación del item } & \multicolumn{2}{|c|}{ Pertinencia $^{1}$} & \multicolumn{2}{|c|}{ Relevancia $^{2}$} & \multicolumn{2}{|c|}{$\begin{array}{c}\text { Construcción } \\
\text { gramatical }\end{array}$} & \multirow[t]{2}{*}{ Observaciones } & \multirow[t]{2}{*}{ Sugerencias } \\
\hline & & Si & No & Si & No & $\frac{\mathrm{grax}}{\mathrm{Si}}$ & & & \\
\hline 1 & El docente inicia la clase motivando a los estudiantes, mediante actividades que captan su atención & 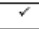 & & 2 & & $\mathrm{~s}$ & & & \\
\hline 2 & $\begin{array}{l}\text { Establece contacto con los estudiantes relacionando el tema de clase a través de uma anécdota o vivencia } \\
\text { del dia }\end{array}$ & $\checkmark$ & & 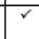 & & r & & & \\
\hline 3 & $\begin{array}{l}\text { Utiliza ejemplos, testimonios, o casos para que los estudiantes identifiquen la problemática de su práctica } \\
\text { profesional. }\end{array}$ & $\bar{r}$ & & 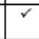 & & $\checkmark$ & & & \\
\hline 4 & El estudiante se siente incentivado en su proceso de aprendizaje. & a & & r & & r & & & \\
\hline 5 & $\begin{array}{l}\text { El docente utiliza estrategias adecuadas para modelar propuestas de autorregulación del aprendizaje que } \\
\text { tengan impacto en la práctica profesional de sus estudiantes. }\end{array}$ & $\checkmark$ & & $\checkmark$ & & $\checkmark$ & & & \\
\hline 6 & 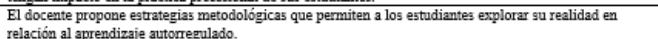 & $\checkmark$ & & $\checkmark$ & & $\checkmark$ & & & \\
\hline 7 & El docente utiliza las fuentes correctas para demostrar la estrategia didáctica que aplica. & r & & 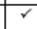 & & $\bar{r}$ & & & \\
\hline 8 & El estudiante demuestra conocer estrategias metodológicas para autorregular su aprendizaje. & ${ }^{\prime}$ & & 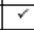 & & ${ }^{\prime}$ & & & \\
\hline 9 & El docente determina las estrategias metodológicas que se aprenderán en clase. & r & & 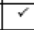 & & ${ }^{2}$ & & & \\
\hline 10 & El docente identifica los problemas y fortalezas de sus estudiantes en su aprendizaje autorregulado. & r & & 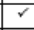 & & r & & & \\
\hline 11 & El docente emplea los instrumentos de apoyo, herramientas y ayudas didácticas & $\bar{r}$ & & $\bar{r}$ & & $\bar{r}$ & & & \\
\hline 12 & El docente utiliza indicadores apropiados para reconocer los avances de los estudiantes. & $\checkmark$ & & $\checkmark$ & & $\checkmark$ & & & \\
\hline 13 & $\begin{array}{l}\text { Los estudiantes demuestran que saben utlizar las estrategias metodológicas para autorregular su } \\
\text { anvendiza.e }\end{array}$ & 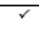 & & 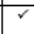 & & 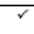 & & & \\
\hline 14 & 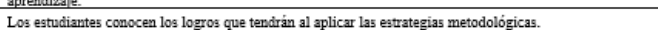 & $\bar{r}$ & & $\bar{r}$ & & $\bar{r}$ & & & \\
\hline 15 & El docente evalía los avances de los estudiantes en relación a la aplicación de las estrategias & $\checkmark$ & & 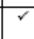 & & r & & & \\
\hline
\end{tabular}

OPINIÓN DE APLICABILIDAD DE LA OBSERVACIÓN:

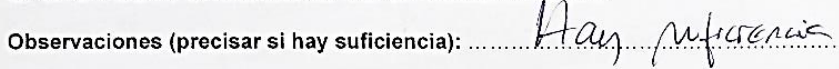

Opinión de aplicabilidad: Aplicable [A_ Aplicable después de corregir [ ] No aplicable [ ]

\begin{tabular}{|c|c|c|c|}
\hline Nombres y Apellidos & 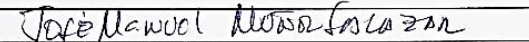 & DNIN $^{\circ}$ & 09336753 \\
\hline Dirección domiciliaria & & Teléfono / Celular & \\
\hline $\begin{array}{l}\text { Titulo profesional/ } \\
\text { Especialidad }\end{array}$ & & Firma & \\
\hline Grado Académico & 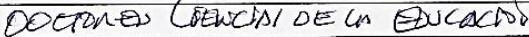 & & \\
\hline Metodólogo/ temático & & Lugar y fecha & \\
\hline
\end{tabular}

Pertinencia: El ítem corresponde al concepto teórico formulado.

Pertinencia: El lem cos apropiado para representar al componente o dimensión especifica del constructo

Claridad: Se entiende sin dificultad alguna el enunciado del item, es conciso, exacto y directo

Nota: Suficiencia, se dice suficiencia cuando los items planteados son suficientes para medir la dimensión 


\begin{tabular}{|c|c|c|c|c|c|c|c|c|c|}
\hline \multirow[t]{2}{*}{$\mathrm{N}^{\circ}$} & \multirow[t]{2}{*}{ Formulación del ítem } & \multicolumn{2}{|c|}{ Pertinencia $^{1}$} & \multicolumn{2}{|c|}{ Relevancia $^{2}$} & \multicolumn{2}{|c|}{$\begin{array}{c}\text { Construcción } \\
\text { gramatical }^{2}\end{array}$} & \multirow[t]{2}{*}{ Observaciones } & \multirow[t]{2}{*}{ Sugerencias } \\
\hline & & Si & No & $\mathrm{Si}$ & No & $\mathrm{Si}$ & No & & \\
\hline 1 & $\begin{array}{l}\text { ¿Usted demuestra capacidad en el procesamiento de información del tema que desarrolla en la sesión de } \\
\text { clase? }\end{array}$ & 2 & & 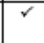 & & r & & & \\
\hline 2 & ¿El docente le permite esclarecer las estrategias de repaso, la elaboración y organización? & 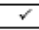 & & 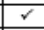 & & $\checkmark$ & & & \\
\hline 3 & $\begin{array}{l}\text { ¿Usted acostumbra adoptar metas en relación con los propósitos para implicarte en las tareas y actividades } \\
\text { académicas? }\end{array}$ & $\bar{r}$ & & r & & $\checkmark$ & & & \\
\hline 4 & $\begin{array}{l}\text { ¿Usted considera que el docente contribuye en el desarrollo de sus creencias motivacionales, como la } \\
\text { autoeficacia, interés personal y valor de las tareas? }\end{array}$ & $\checkmark$ & & $\checkmark$ & & $\bar{r}$ & & & \\
\hline 5 & $\begin{array}{l}\text { ¿Usted aprecia que el docente, en las sesiones de clase, emplea estrategias que permiten a los estudiantes } \\
\text { cumplir las normas del aula y de ese modo propiciar un clima emocional adecuado? }\end{array}$ & $\bar{r}$ & & ${ }^{2}$ & & $\bar{r}$ & & & \\
\hline 6 & $\begin{array}{l}\text { ¿Cómo valora usted el ambiente fíico de aprendizaje? Por ejemplo, illuminación, ventilación, limpieza, } \\
\text { etc. }\end{array}$ & $\checkmark$ & & $\sigma^{\prime}$ & & $\bar{r}$ & & & \\
\hline 7 & $\begin{array}{l}\text { ¿Cómo valora usted el nivel de exigencia de las tareas, las características de las exaluaciones y demandas } \\
\text { del profesor? }\end{array}$ & $\checkmark$ & & $\checkmark$ & & $\checkmark$ & & & \\
\hline 8 & $\begin{array}{l}\text { ¿Usted percibe que el docente plantea procesos anticipados, sistemáticos y generalizados para concretar } \\
\text { los planes de deasrollo en el aula de clases? }\end{array}$ & 2 & & 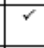 & & r & & & \\
\hline 9 & $\begin{array}{l}\text { ¿Considera usted que el doccunte determina acciones tendientes al desarrollo equilibrado y coherente de los } \\
\text { procesos de enseñanza aprendizaje? }\end{array}$ & $\checkmark$ & & $\bar{r}$ & & $\bar{r}$ & & & \\
\hline 10 & $\begin{array}{l}\text { ¿Usted observa que el docente, al iniciar cada sesión de clase, precisa propósito, objetivos y estrategias } \\
\text { rectoras, que guien a los estudiantes y regpondan a sus demandas y necesidades? }\end{array}$ & $\bar{r}$ & & 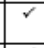 & & $\bar{r}$ & & & \\
\hline 11 & $\begin{array}{l}\text { ¿Usted percibe que el docente desarrolla los contenidos de manera adecuada y de una forma comprensible } \\
\text { en las sesiones de clase? }\end{array}$ & 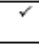 & & $\checkmark$ & & $\bar{r}$ & & & \\
\hline 12 & $\begin{array}{l}\text { ¿Congidera usted que el docente orienta desde el punto de vista integral, preocupándose del estudiante, del } \\
\text { medio de las dificultades de aprendizaje y los posibles problemas que se podrian enfrentar en } \\
\text { determinadas situaciones? }\end{array}$ & $\checkmark$ & & $\bar{r}^{\prime}$ & & $\bar{r}$ & & & \\
\hline 13 & $\begin{array}{l}\text { Usted aprecia que el docente selecciona los instrumentos de apoyo, herramientas y ayudas didácticas con } \\
\text { el fin de tener mayor acercamiento a los estudiantes, al conocimiento y a la construcción de los conceptos } \\
\text { para facilitar de esta manera el aprendizaje? }\end{array}$ & $r$ & & $\checkmark$ & & $\bar{r}$ & & & \\
\hline 14 & $\begin{array}{l}\text { ¿Usted observa que el docente emplea los instrumentos de apoyo, herramientas y ayudas didácticas } \\
\text { pertinentes en las sesiones de clase (guáas, libros, materiales impresos y no impresos, esquemas, videos, } \\
\text { diapositivas, imágenes, herramientas digitales, etc.)? }\end{array}$ & $\checkmark$ & & $r$ & & 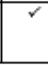 & & & \\
\hline
\end{tabular}

\section{OPINIÓN DE APLICABILIDAD DEL CUESTIONARIO:}

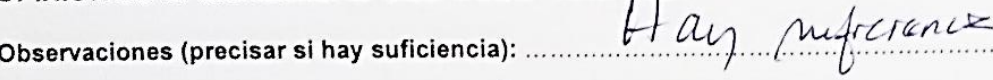

Opinión de aplicabilidad: Aplicable [ 1 Aplicable después de corregir [ ] No aplicable [ ]

\begin{tabular}{|c|c|c|c|}
\hline Nombres y Apellidos & José Whuoch Munoz Jacazar & $\mathrm{DNIN}^{\circ}$ & 0,9536793 \\
\hline Dirección domiciliaria & & Teléfono / Celular & \\
\hline $\begin{array}{l}\text { Titulo profesional/ } \\
\text { Especialidad }\end{array}$ & & Firma & \\
\hline Grado Académico & 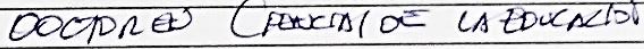 & & \\
\hline Metodólogo/ temático & & Lugar y fecha & \\
\hline
\end{tabular}

1Pertinencia: El item corresponde al concepto teórico formulado.

2Relevancia: El item es apropiado para representar al componente o dimensión especifica del constructo

'Claridad: Se entiende sin dificultad alguna el enunciado del item, es conciso, exacto y directo

Nota Suficiencia se dice suficiencia cuando los items planteados son suficientes para medir la dimensión 
CERTIFICADO DE VALIDEZ DE CONTENDO DE LA ENTREVISTA A DOCENTES

\begin{tabular}{|c|c|c|c|c|c|c|c|c|c|}
\hline \multirow[t]{2}{*}{$\mathrm{N}^{*}$} & \multirow[t]{2}{*}{ Formulación del item } & \multicolumn{2}{|c|}{ Pertinencia $^{1}$} & \multicolumn{2}{|c|}{ Relevancia $^{2}$} & \multicolumn{2}{|c|}{$\begin{array}{c}\text { Construcción } \\
\text { gramatical }^{2}\end{array}$} & \multirow[t]{2}{*}{ Observaciones } & \multirow[t]{2}{*}{ Sugerencias } \\
\hline & & $\mathrm{Si}$ & No & $\mathrm{Si}$ & No & $\mathrm{Si}$ & No & & \\
\hline 1 & $\begin{array}{l}\text { ¿Usted qué estrategias emplea con los estudiantes para el procesamiento de información, repaso, } \\
\text { elaboración y organización? ¿Cómo las aplica? }\end{array}$ & $r$ & & $r$ & & $\checkmark$ & & & \\
\hline 2 & $\begin{array}{l}\text { ¿Usted considera importante que el estudiante adopte metas en relación con los propósitos para implicarse } \\
\text { en las tareas y actividades académicas? } \text { Por qué? }\end{array}$ & $\checkmark$ & & $r$ & & $\checkmark$ & & & \\
\hline 3 & De qué forma motiva a los estudiantes en las tareas y actividades académicas? & $\checkmark$ & & $\checkmark$ & & $\checkmark$ & & & \\
\hline 4 & $\begin{array}{l}\text { DDe qué forma logra que los estudiantes puedan identificar y valorar las características de la clase? (Incluyen } \\
\text { la percepción de las normas en el aula, el clima emocional, las características del ambiente físico de } \\
\text { aprendizaje y los métodos de enseñanza aplicados) }\end{array}$ & $r$ & & $r$ & & $\checkmark$ & & & \\
\hline 5 & $\begin{array}{l}\text { ¿Cómo desarrolla en los estudiantes la valoración de las tareas, las características de las evaluaciones y sus } \\
\text { demandas como profesor? }\end{array}$ & $r$ & & $r$ & & $\checkmark$ & & & \\
\hline 6 & $\begin{array}{l}\text { ¿Cuáles son los procesos anticipados, sistemáticos y generalizados que plantea para concretar los planes } \\
\text { de desarrollo en las gesiones de clases? ¿Cómo los aplicas? }\end{array}$ & $r$ & & $\checkmark$ & & $\checkmark$ & & & \\
\hline 7 & $\begin{array}{l}\text { ¿Cuáles son las acciones tendientes que determina para el desarrollo equilibrado y coherente de los } \\
\text { procesos de enseñanza - aprendizaje? ¿Cómo las aplicas? }\end{array}$ & $r$ & & $\checkmark$ & & $\checkmark$ & & & \\
\hline 8 & $\begin{array}{l}\text { De qué manera establece propósito, objetivos y estrategias rectoras, que guien a los estudiantes y les } \\
\text { respondan a gus demandas y necesidades? }\end{array}$ & $\checkmark$ & & $r$ & & $\checkmark$ & & & \\
\hline 9 & $\begin{array}{l}\text { ¿Cómo logra desarrollar los contenidos de manera adecuada y de una forma comprensible en las seaiones } \\
\text { de clase? }\end{array}$ & $\checkmark$ & & $r$ & & $\checkmark$ & & & \\
\hline 10 & $\begin{array}{l}\text { ¿Qué estrategias emplea para orientar y ayudar a los estudiantes en sus problemas de aprendizaje? ¿Cómo } \\
\text { las aplica? }\end{array}$ & $r$ & & $\checkmark$ & & $\checkmark$ & & & \\
\hline 11 & $\begin{array}{l}\text { ¿Qué recursos materiales y digitales selecciona y diseña para lograr los aprendizajes significativos en los } \\
\text { equdiantes? Cómo los emplea? }\end{array}$ & 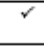 & & $\bar{r}$ & & $\checkmark$ & & & \\
\hline
\end{tabular}

\section{OPINION DE APLICABILIDAD DE LA ENTREVISTA:}

Observaciones (precisar si hay suficiencia):

Opinión de aplicabilidad: Aplicable [X] Aplicable después de corregir [ ] No aplicable [ ]

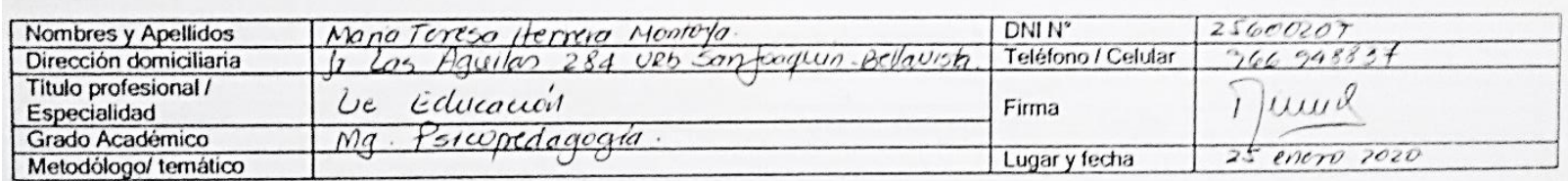

'Pertinencia: El item corresponde al concepto térico formulado.

2Relevancia: El item es apropiado para representar al componente o dimensión especifica del constructo

tClaridad: Se entiende sin dificultad alguna el enunciado del item, es conciso, exacto y directo

Nota: Suficiencia, se dice suficiencia cuando los items planteados son suficientes para medir la dimensión

CERTIFICADO DE VALIDEZ DE CONTENDO DE LA OBSERVACIÓN DE CLASE

\begin{tabular}{|c|c|c|c|c|c|c|c|c|c|}
\hline \multirow[t]{2}{*}{$\mathrm{N}^{*}$} & \multirow[t]{2}{*}{ Formulación del ítem } & \multicolumn{2}{|c|}{ Pertinencia $^{1}$} & \multicolumn{2}{|c|}{ Relevancia $^{2}$} & \multicolumn{2}{|c|}{$\begin{array}{l}\text { Construcción } \\
\text { gramatical }^{2}\end{array}$} & \multirow[t]{2}{*}{ Observaciones } & \multirow[t]{2}{*}{ Sugerencias } \\
\hline & & Si & No & Si & No & $\mathrm{Si}$ & No & & \\
\hline 1 & El docente inicia la clase motivando a los estudiantes, mediante actividades que captan gu atención. & r & & $\bar{r}$ & & r & & & \\
\hline 2 & $\begin{array}{l}\text { Establece contacto con los estudiantes relacionando el tema de clase a través de una anécdota o vivencia } \\
\text { del dia. }\end{array}$ & $\checkmark$ & & $\checkmark$ & & $\bar{r}$ & & & \\
\hline 3 & $\begin{array}{l}\text { Utiliza ejemplos, testimonios, o casos para que los estudiantes identifiquen la problemática de su práctica } \\
\text { profesional. }\end{array}$ & $\checkmark$ & & $\checkmark$ & & $\bar{r}$ & & & \\
\hline 4 & El estudiante se siente incentivado en su proceso de aprendizaje. & $\checkmark$ & & 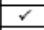 & & $\bar{r}$ & & & \\
\hline 5 & $\begin{array}{l}\text { El docente utiliza estrategias adecuadas para modelar propuestas de autorregulación del aprendizaje que } \\
\text { tengan impacto en la práctica profesional de sus estudiantes. }\end{array}$ & r & & r & & $\bar{r}$ & & & \\
\hline 6 & $\begin{array}{l}\text { El docente propone estrategias metodológicas que permiten a los estudiantes explorar su realidad en } \\
\text { relación al aprendizaje autorregulado. }\end{array}$ & $\checkmark$ & & r & & $\bar{r}$ & & & \\
\hline 7 & El docente utiliza las fuentes correctas para demostrar la estrategia didáctica que aplica. & $\checkmark$ & & $\checkmark$ & & $\checkmark$ & & & \\
\hline 8 & El estudiante demuestra conocer estrateggas metodológicas para autorregular su aprendizaje. & $\checkmark$ & & $r$ & & $\checkmark$ & & & \\
\hline 9 & El docente determina las estrategias metodológicas que se aprenderán en clase. & $\checkmark$ & & $r$ & & $\checkmark$ & & & \\
\hline 10 & El docente identifica los problemas y fortalezas de sus estudiantes en su aprendizaje autorregulado. & 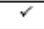 & & $\bar{r}$ & & $\bar{r}$ & & & \\
\hline 11 & El docente emplea los instrumentos de apoyo, herramientas y ayudas didácticas & $\checkmark$ & & $\checkmark$ & & $\checkmark$ & & & \\
\hline 12 & El docente utiliza indicadores apropiados para reconocer los avances de los estudiantes. & $\checkmark$ & & $r$ & & $\checkmark$ & & & \\
\hline 13 & $\begin{array}{l}\text { Los estudiantes demuestran que saben utilizar las estrategias metodológicas para autorregular su } \\
\text { aprendizaje. }\end{array}$ & r & & 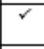 & & $\bar{r}$ & & & \\
\hline 14 & Los estudiantes conocen los logros que tendrán al aplicar las estrategias metodológicas. & r & & $\bar{r}$ & & $\bar{v}$ & & & \\
\hline 15 & $\begin{array}{l}\text { El docente evalúa los avances de los estudiantes en relación a la aplicación de las estrategias } \\
\text { metodelogicas an su anrendizaie autorrequlado. }\end{array}$ & $\checkmark$ & & $\checkmark$ & & $\checkmark$ & & & \\
\hline
\end{tabular}

\section{OPINIÓN DE APLICABILIDAD DE LA OBSERVACIÓN:}

Observaciones (precisar si hay suficiencia):

Opinión de aplicabilidad: Aplicable [ X ] Aplicable después de corregir [ ] No aplicable [ ]

\begin{tabular}{|c|c|c|c|}
\hline Nombres y Apellidos & Mana Teresa Atemera Monitya & DNI N & 25600207 \\
\hline Direoción domicliaria & 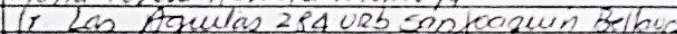 & Juelefono / Celular & $3622483=7$ \\
\hline $\begin{array}{l}\text { Titulo profesional/ } \\
\text { Especialidad }\end{array}$ & Lie Educauoin. & \multirow[t]{2}{*}{ Firma } & $7110 \mathrm{ND}$ \\
\hline Grado Académico & ma tsicopedogegia. & & \\
\hline Metodólogo/ temático & 30,0 or & Lugar y fecha & 20 Molina 25 enero 20 ?2 \\
\hline $\begin{array}{l}\text { Pertinencia: El item corresp } \\
\text { * Relevancia: El item es apror } \\
\text { 'Claridad: Se entiende sin di }\end{array}$ & $\begin{array}{l}\text { i concepto tećrico formulado. } \\
\text { para representar al componente o dimensión especifica del constructo } \\
\text { I alguna et enunciado del item, es conciso, exacto y directo }\end{array}$ & & \\
\hline
\end{tabular}




\begin{tabular}{|c|c|c|c|c|c|c|c|c|c|}
\hline \multirow[t]{2}{*}{$\mathbf{N}^{*}$} & \multirow[t]{2}{*}{ Formulación del ítem } & \multicolumn{2}{|c|}{ Pertinencia $^{1}$} & \multicolumn{2}{|c|}{ Relevancia $^{2}$} & \multicolumn{2}{|c|}{$\begin{array}{c}\text { Construcción } \\
\text { gramatical }\end{array}$} & \multirow[t]{2}{*}{ Observaciones } & \multirow[t]{2}{*}{ Sugerencias } \\
\hline & & $\mathrm{Si}$ & No & Si & No & $\mathrm{Si}$ & No & & \\
\hline 1 & $\begin{array}{l}\text { ¿Usted demuestra capacidad en el procesamiento de información del tema que desarrolla en la sesión de } \\
\text { clase? }\end{array}$ & $\frac{\mathrm{a}}{\mathrm{r}}$ & & $\checkmark$ & & $\checkmark$ & & & \\
\hline 2 & ¿El docente le permite esclarecer las eatrategias de repaso, la elaboración y organización? & $\bar{r}$ & & $\bar{r}$ & & $\checkmark$ & & & \\
\hline 3 & $\begin{array}{l}\text { ¿Usted acostumbra adoptar metas en relación con los propósitos para implicarte en las tareas y actividades } \\
\text { académicas? }\end{array}$ & $\mathrm{r}$ & & $\checkmark$ & & $\frac{1}{r}$ & & & \\
\hline 4 & $\begin{array}{l}\text { ¿Usted considera que el docente contribuye en el desarrollo de sus creencias motixacionales, como la } \\
\text { autoeficacia, interés personal y valor de las tareas? }\end{array}$ & r & & $\checkmark$ & & $\checkmark$ & & & \\
\hline 5 & $\begin{array}{l}\text { ¿Usted aprecia que el docente, en las sesiones de clase, emplea estrategias que permiten a los estudiantes } \\
\text { cumplir las normas del aula y de ese modo propiciar un clima emocional adecuado? }\end{array}$ & $\bar{r}$ & & $\checkmark$ & & $\checkmark$ & & & \\
\hline 6 & $\begin{array}{l}\text { ¿Cómo valora usted el ambiente fisico de aprendizaje? Por ejemplo, iluminación, ventilación, limpieza, } \\
\text { etc. }\end{array}$ & r & & $\checkmark$ & & $\checkmark$ & & & \\
\hline 7 & $\begin{array}{l}\text { ¿Cómo valora usted el nivel de exigencia de las tareas, las características de las evaluaciones y demandas } \\
\text { del profesor? }\end{array}$ & $\checkmark$ & & $\checkmark$ & & $\checkmark$ & & & \\
\hline 8 & $\begin{array}{l}\text { ¿Usted percibe que el docente plantea procesos anticipados, sistemáticos y generalizados para concretar } \\
\text { los planes de desarrollo en el aula de clases? }\end{array}$ & $\bar{r}$ & & $\checkmark$ & & $\checkmark$ & & & \\
\hline 9 & $\begin{array}{l}\text { ¿Considera usted que el docente determina acciones tendientes al desarrollo equilibrado y coherente de los } \\
\text { procesos de enseñanza aprendizaje? }\end{array}$ & 2 & & $\checkmark$ & & 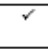 & & & \\
\hline 10 & $\begin{array}{l}\text { ¿Usted observa que el docente, al iniciar cada sesión de clase, precisa propósito, objetivos y estrategias } \\
\text { rectoras, que guien a los estudiantes y regpondan a gus demandas y necesidades? }\end{array}$ & $\bar{r}$ & & $\checkmark$ & & $\checkmark$ & & & \\
\hline 11 & $\begin{array}{l}\text { ¿Usted percibe que el docente desarrolla los contenidos de manera adecuada y de una forma comprensible } \\
\text { en las sesiones de clase? }\end{array}$ & $\bar{r}$ & & $\bar{r}$ & & r & & & \\
\hline 12 & $\begin{array}{l}\text { ¿Considera usted que el docente orienta desde el punto de vista integral, preocupándose del estudiante, del } \\
\text { medio de las dificultades de aprendizaje y los posibles problemas que se poodrian enfrentar en } \\
\text { determinadas situaciones? }\end{array}$ & 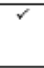 & & $\checkmark$ & & $r$ & & & \\
\hline 13 & $\begin{array}{l}\text { ¿Usted aprecia que el docente selecciona los instrumentos de apoyo, herramientas y ayudas didícticas con } \\
\text { el fin de tener mayor acercamiento a los estudiantes, al conocimiento y a la construcción de los conceptos } \\
\text { para facilitar de esta manera el aprendizaje? }\end{array}$ & $r$ & & $\checkmark$ & & $r$ & & & \\
\hline 14 & $\begin{array}{l}\text { ¿Usted observa que el docente emplea los instrumentos de apoyo, herramientas y ayudas didácticas } \\
\text { pertinentes en las sesiones de clase (guás, libros, materiales impresos y no impresos, esquemas, videos, } \\
\text { diapositivas, imágenes, herramientas digitales, etc.)? }\end{array}$ & $r$ & & $\checkmark$ & & $r$ & & & \\
\hline
\end{tabular}

OPINIÓN DE APLICABILIDAD DEL CUESTIONARIO:

Observaciones (precisar si hay suficiencia):

Opinión de aplicabilidad: Aplicable [ $\mathrm{X}$ ]

Aplicable después de corregir [ ]

No aplicable [ ]

\begin{tabular}{|c|c|c|c|}
\hline Nombres y Apellidos & Mana Terexa Hemeia Montola & DNIN ${ }^{\circ}$ & 25000207 \\
\hline Drección domicliana & 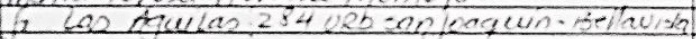 & Teléfono/Celutar & 360948837 \\
\hline $\begin{array}{l}\text { Titulo protesional/ } \\
\text { Especialidad }\end{array}$ & Le Educación & Firma & 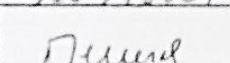 \\
\hline Grado Acadernico & Ma Psicepedogonia & & \\
\hline Metodólogo lemático & 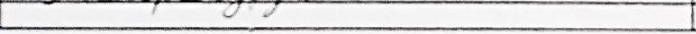 & Lugar y fecta & La kneune \\
\hline
\end{tabular}

Pertinencia. $\Theta$ item corresponde al concspio tecirico formulado.

PRelevancia: Ei item es aprociado para representar al component 0 dimensión espocifica del constructo

sClaridad: Se ertiende sin dficaltad algina ef enunciado det item, es conciso, exacto y directo

Nota Suficiencia, se dose sfficiencia cuando loa lisms plarteados son suficientes para medir la dimensión 
CERTIFICADO DE VALIDEZ DE CONTENDO DE LA ENTREVISTA A DOCENTES

\begin{tabular}{|c|c|c|c|c|c|c|c|c|c|}
\hline \multirow[t]{2}{*}{$\mathrm{N}^{*}$} & \multirow[t]{2}{*}{ Formulación del ítem } & \multicolumn{2}{|c|}{ Pertinencia ${ }^{1}$} & \multicolumn{2}{|c|}{ Relevancia $^{2}$} & \multicolumn{2}{|c|}{$\begin{array}{c}\text { Construcción } \\
\text { gramatical }\end{array}$} & \multirow[t]{2}{*}{ Observaciones } & \multirow[t]{2}{*}{ Sugerencias } \\
\hline & & $\mathrm{Si}$ & No & $\mathrm{Si}$ & No & $\mathrm{Si}$ & No & & \\
\hline 1 & $\begin{array}{l}\text { ¿Usted qué estrategias emplea con los estudiantes para el procesamiento de información, repaso, } \\
\text { elaboración y organización? ¿Cómo las aplica? }\end{array}$ & $\checkmark$ & & $\bar{r}$ & & $\bar{r}$ & & & \\
\hline 2 & $\begin{array}{l}\text { Usted considera importante que el estudiante adopte metas en relación con los propósitos para implicarse } \\
\text { en las tareas } \mathrm{y} \text { actividades académicas? ; Por qué? }\end{array}$ & $\checkmark$ & & $\bar{r}$ & & $\bar{r}$ & & & \\
\hline 3 & ¿De qué forma motiva a los estudiantes en las tareas y actividades académicas? & $\frac{2}{r}$ & & $\frac{2}{2}$ & & $\frac{2}{r}$ & & & \\
\hline 4 & $\begin{array}{l}\text { ¿De qué forma logra que los estudiantes puedan identificar y valorar las características de la clase? (Incluyen } \\
\text { la percepción de las normas en el aula, el clima emocional, las caracteristicas del ambiente físico de } \\
\text { aprendizaje y los métodos de enseñanza aplicados) }\end{array}$ & $\checkmark$ & & 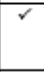 & & $\checkmark$ & & & \\
\hline 5 & $\begin{array}{l}\text { Cómo desarrolla en los estudiantes la valoración de las tareas, las características de las evaluaciones y sus } \\
\text { demandas como profesor? }\end{array}$ & $\bar{r}$ & & $\bar{r}$ & & $\bar{r}$ & & & \\
\hline 6 & $\begin{array}{l}\text { ¿Cuáles son los procesos anticipados, gistemáticos y generalizados que plantea para concretar los planes } \\
\text { de desarrollo en las sesiones de clases? ¿Cómo los aplicas? }\end{array}$ & $\frac{1}{2}$ & & $\bar{r}$ & & $\bar{r}$ & & & \\
\hline 7 & $\begin{array}{l}\text { ¿Cuáles son las acciones tendientes que determina para el desarrollo equilibrado y coherente de los } \\
\text { procesos de enseñanza - aprendizaje? ¿Cómo las aplicas? }\end{array}$ & $r$ & & $\bar{r}$ & & $r$ & & & \\
\hline 8 & $\begin{array}{l}\text { De qué manera establece propósito, objetivos y estrategias rectoras, que guien a los estudiantes y les } \\
\text { respondan a gus demandas y necesidades? }\end{array}$ & $\bar{r}$ & & $\checkmark$ & & 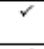 & & & \\
\hline 9 & $\begin{array}{l}\text { Cómo logra desarrollar los contenidos de manera adecuada y de una forma comprensible en las sesiones } \\
\text { de clase? }\end{array}$ & $\frac{\gamma}{r}$ & & $\bar{r}$ & & $v^{2}$ & & & \\
\hline 10 & $\begin{array}{l}\text { ¿Qué estrategias emplea para orientar y ayudar a los estudiantes en sus problemas de aprendizaje? ¿Cómo } \\
\text { las aplica? }\end{array}$ & $\bar{r}$ & & $\checkmark$ & & 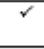 & & & \\
\hline 11 & $\begin{array}{l}\text { ¿Qué recursos materiales y digitales selecciona y diseña para lograr los aprendizajes significativos en los } \\
\text { estudiantes? Cómo los emplea? }\end{array}$ & $\frac{1}{r}$ & & $\checkmark$ & & 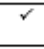 & & & \\
\hline
\end{tabular}

\section{OPINION DE APLICABILIDAD DE LA ENTREVISTA:}

Observaciones (precisar si hay suficiencia):

Opinión de aplicabilidad: Aplicable [X] Aplicable después de corregir [ ] No aplicable [ ]

\begin{tabular}{|c|c|c|c|}
\hline Nombres y Apellidos & HERNA'O FloReS VALDIUE2O & $\mathrm{DNIN}^{\circ}$ & 06055101 \\
\hline Dirección domiciliaria & Jos CApULies 159(201) Salamanor & Teléfono / Celular & 999461104 \\
\hline $\begin{array}{l}\text { Titulo profesional/ } \\
\text { Especialidad }\end{array}$ & Sociol logo & Firma & \\
\hline Grado Académico & MAOISTER & & \\
\hline Metodólogo/ temático & Metodilojo & Lugar y fecha & $\angle M$ HethA $/ 23 / 10 \mathrm{~V} \cdot / 19$ \\
\hline
\end{tabular}

'Pertinencia: El item corresponde al concepto teórico formulado.

2Relevancia: El item es apropiado para representar al componente o dimensión especifica del constructo

"Claridad: Se entiende sin dficultad alguna el enunciado del item, es conciso, exacto y directo

Nota: Suficiencia, se dice suficiencia cuando los items planteados son suficientes para medir la dimensión

CERTIFICADO DE VALIDEZ DE CONTENDO DE LA OBSERVACIÓN DE CLASE

\begin{tabular}{|c|c|c|c|c|c|c|c|c|c|}
\hline \multirow[t]{2}{*}{$\mathrm{N}^{\mathrm{O}}$} & \multirow[t]{2}{*}{ Formulación del item } & \multicolumn{2}{|c|}{ Pertinencia $^{1}$} & \multicolumn{2}{|c|}{ Relevancia $^{2}$} & \multicolumn{2}{|c|}{ Construcción } & \multirow[t]{2}{*}{ Observaciones } & \multirow[t]{2}{*}{ Sugerencias } \\
\hline & & $\mathrm{Si}$ & No & $\mathrm{Si}$ & No & $\frac{\mathrm{grat}}{\mathrm{Si}}$ & No & & \\
\hline 1 & El docente inicia la clase motivando a los estudiantes, mediante actividades que captan su atención & r & & 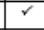 & & $\checkmark$ & & & \\
\hline 2 & $\begin{array}{l}\text { Egtablece contacto con los estudiantes relacionando el tema de clase a través de una anécdota o vivencia } \\
\text { del dia }\end{array}$ & 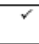 & & 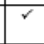 & & $\checkmark$ & & & \\
\hline 3 & $\begin{array}{l}\text { Utiliza ejemplos, teastimonios, o casos para que los estudiantes identifiquen la problemática de su práctica } \\
\text { profesional. }\end{array}$ & $\bar{r}$ & & r & & י & & & \\
\hline 4 & \begin{tabular}{|l} 
El estudiante se siente incentivado en su proceso de aprendizaje. \\
\end{tabular} & 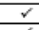 & & 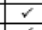 & & r & & & \\
\hline 5 & $\begin{array}{l}\text { El docente utiliza estrategias adecuadas para modelar propuestas de autorregulación del aprendizaje que } \\
\text { tengan impacto en la práctica profesional de sus estudiantes. }\end{array}$ & 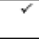 & & 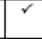 & & r & & & \\
\hline 6 & $\begin{array}{l}\text { El docente propone estrategias metodológicas que permiten a los estudiantes explorar su realidad en } \\
\text { relación al aprendizaje autore evulado. }\end{array}$ & 2 & & 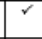 & & r & & & \\
\hline 7 & El docente utiliza las fuentes correctas para demostrar la estrategia didáctica que aplica. & 2 & & r & & r & & & \\
\hline 8 & El estudiante demuestra conocer estrategias metodológicas para autorregular su aprendizaje. & 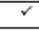 & & 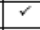 & & r & & & \\
\hline 9 & El docente detemina las estrategias metodológicas que se aprenderán en clase. & 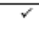 & & 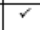 & & r & & & \\
\hline 10 & El docente identifica los problemas y fortalezas de sus estudiantes en su aprendizaje autorregulado. & 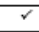 & & 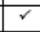 & & $\mathrm{r}$ & & & \\
\hline 11 & El docente emplea los instrumentos de apoyo, herramientas y ayudas didacticas & 2 & & 2 & & 2 & & & \\
\hline 12 & El docente utiliza indicadores apropiados para reconocer los avances de los estudiantes. & $\checkmark$ & & $\checkmark$ & & $\checkmark$ & & & \\
\hline 13 & $\begin{array}{l}\text { Los estudiantes demuestran que saben utilizar las estrategias metodológicas para autorregular su } \\
\text { arrendizase }\end{array}$ & r & & $\bar{r}$ & & r & & & \\
\hline 14 & \begin{tabular}{|l} 
Los estudiantes conocen los loggos que tendrán al aplicar las estrategias metodológicas. \\
\end{tabular} & 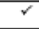 & & 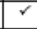 & & 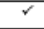 & & & \\
\hline 15 & $\begin{array}{l}\text { El docente evalúa los avances de los estudiantes en relación a la aplicación de las estrategias } \\
\text { metodologicas en an anrendizaie sutorrezulado. }\end{array}$ & 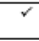 & & 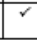 & & י & & & \\
\hline
\end{tabular}

OPINION DE APLICABILIDAD DE LA OBSERVACIÓN:

Observaciones (precisar si hay suficiencia):

Opinión de aplicabilidad: Aplicable $\left[X_{\text {J }} \quad\right.$ Aplicable después de corregir [ ] No aplicable [ ]

\begin{tabular}{|c|c|c|c|}
\hline Nombres y Apellidos & HEDNAN Fleres ka CDIULE 20 & $\mathrm{DNIN}^{\circ}$ & 06055101 \\
\hline Dirección domiciliaria & LOS CAPULES 159 (201) Salcureala & Teléfono / Celular & 994461104 \\
\hline $\begin{array}{l}\text { Titulo profesional/ } \\
\text { Especialidad }\end{array}$ & Soadlogo & Firma & \\
\hline Grado Académico & MAGISPER & & \\
\hline Metodólogo/ temático & nyetidolopo & Lugar y fecha & $\angle . A$. \\
\hline
\end{tabular}

Pertinencia: El item corresponde al concepto teórico formulado.

2Relevancia: El item es apropiado para representar al componente o dimensión especifica del constructo

${ }^{3}$ Claridad: Se entiende sin dificultad alguna el enunciado del ítem, es conciso, exacto y directo

Nota: Suficiencia, se dice suficiencia cuando los ítems planteados son suficientes para medir la dimensión 
CERTIFICADO DE VALIDEZ DE CONTENDO DEL CUESTIONARIO TOMADO A ESTUDIANTES

\begin{tabular}{|c|c|c|c|c|c|c|c|c|c|}
\hline \multirow[t]{2}{*}{$\mathrm{N}^{\circ}$} & \multirow[t]{2}{*}{ Formulación del ítem } & \multicolumn{2}{|c|}{ Pertinencia $^{1}$} & \multicolumn{2}{|c|}{ Relevancia $^{2}$} & \multicolumn{2}{|c|}{$\begin{array}{c}\text { Construcción } \\
\text { gramatical }^{2}\end{array}$} & \multirow[t]{2}{*}{ Observaciones } & \multirow[t]{2}{*}{ Sugerencias } \\
\hline & & Si & No & $\mathrm{Si}$ & No & & No & & \\
\hline 2 & ¿El docente le permite esclarecer las estrategias de repaso, la elaboración y organización? & $\mathrm{r}$ & & $\mathrm{r}$ & & 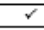 & & & \\
\hline 4 & $\begin{array}{l}\text { ¿Usted considera que el docente contribuye en el desarrollo de sus creencias motivacionales, como la } \\
\text { autoeficacia, interés personal y valor de las tareas? }\end{array}$ & r & & $\mathrm{r}$ & & $\bar{r}$ & & & \\
\hline 5 & $\begin{array}{l}\text { USted aprecia que el docente, en las sesiones de clase, emplea estrategias que permiten a los estudiantes } \\
\text { cumplir las normas del aula y de ese modo propiciar un clima emocional adecuado? }\end{array}$ & r & & r & & $\checkmark$ & & & \\
\hline 8 & $\begin{array}{l}\text { ¿Usted percibe que el docente plantea procesos anticipados, sistemáticos y generalizados para concretar } \\
\text { los planes de deaarnollo en el aula de clases? }\end{array}$ & $\mathrm{r}$ & & י & & $\bar{r}$ & & & \\
\hline 9 & $\begin{array}{l}\text { ¿Considera usted que el docente determina acciones tendientes al desarrollo equilibrado y coherente de los } \\
\text { procesos de enseñanza aprendizaje? }\end{array}$ & r & & $\bar{r}$ & & $\bar{r}$ & & & \\
\hline 10 & $\begin{array}{l}\text { ¿Usted observa que el docente, al iniciar cada sesión de clase, precisa propósito, objetivos y estrategias } \\
\text { rectoras, cue guien a los estudiantes y reapondan a sus demandas y necesidades? }\end{array}$ & 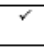 & & $\bar{r}$ & & $\checkmark$ & & & \\
\hline 11 & $\begin{array}{l}\text { ¿Usted percibe que el docente desarrolla los contenidos de manera adecuada y de una forma comprensible } \\
\text { en las sesiones de clase? }\end{array}$ & $\bar{r}$ & & $\mathrm{r}$ & & $\bar{r}$ & & & \\
\hline 14 & $\begin{array}{l}\text { ¿Usted obserra que el docente emplea los instrumentos de apoyo, herramientas y ayudas didácticas } \\
\text { pertinentes en las sesiones de clase (uuas, libros, materiales impresos y no impresos, esquemas, videos, } \\
\text { diapositivas, imágenes, herramientas digitales, etc.)? }\end{array}$ & r & & $\checkmark$ & & $\bar{r}$ & & & \\
\hline
\end{tabular}

OPINIÓN DE APLICABILIDAD DEL CUESTIONARIO:

Observaciones (precisar si hay suficiencia):

\begin{tabular}{|c|c|c|c|}
\hline Nombres y Apellidos & IEKNAN FLORES VACDIUID & $\mathrm{DNIN}^{\circ}$ & 06055101 \\
\hline Dirección domiciliaria & os enputíes 15a (201) solauncuea & Teléfono / Celular & 994461104 \\
\hline $\begin{array}{l}\text { Titulo profesional/ } \\
\text { Especialidad }\end{array}$ & Soccótogo & \multirow[t]{2}{*}{ Firma } & \\
\hline Grado Académico & MAG'sTEN & & \\
\hline
\end{tabular}

1Pertinencia: El item corresponde al concepto teórico formulado.

2Relevancla El item espocifica del constructo

${ }^{3}$ Claridad: Se entiende sin dificultad alguna el enunciado del item, es conciso, exacto y directo

Nota: Suficiencia, se dice suficiencia cuando los ítems planteados son suficientes para medir la dimensión 
Ficha de validación de la propuesta metodológica

\section{Datos generales.}

Apellidos y nombres de especialista: Hernán Flores Valdiviezo Grado de estudios alcanzado: Magister

Eetodológica para desarrollar el aprendizaje autorregulado en los estudiantes del primer ciclo de la carrera de dministración de una universidad privada de Lima.

Autor del resultado científico: Mónica Maribel García Álvarez

Aspectos a observar

\section{Validación interna}

\begin{tabular}{|c|c|c|c|c|}
\hline indicadores & $\begin{array}{l}\text { Escala de } \\
\text { valoraion }\end{array}$ & Aspectos & & \\
\hline & & 5 Positivos & Negativos & Sugerendias \\
\hline Factibilidad de aplicación del resultado que se presenta. & & & & \\
\hline Posibilidad de la propuesta de extensión a otros & $\underline{x}$ & & & \\
\hline $\begin{array}{l}\text { Cortersposondenciaicicos las necesidades sociales } \mathrm{e} \\
\text { individuales actuales }\end{array}$ & & $\underline{x}$ & & \\
\hline $\begin{array}{l}\text { Congruencia entre el resultado propuesto y el objetivo } \\
\text { fijado. }\end{array}$ & $\underline{x}$ & & & \\
\hline Novedad en el uso de conceptos y procedimientos de la & $\underline{x}$ & & & \\
\hline $\begin{array}{l}\text { La modelacicín contiene propósitios basados en los } \\
\text { fundamentos eductivos. auriculares y pedagógicos, } \\
\text { detaladado, recisotis efectivo }\end{array}$ & $\underline{x}$ & & & \\
\hline $\begin{array}{l}\text { La propuesta está contextualizada a la realidad en } \\
\text { estudio }\end{array}$ & $\underline{x}$ & & & \\
\hline $\begin{array}{l}\text { Presenta objetivos claros, coherentes y posibles de } \\
\text { alcanzar. }\end{array}$ & $\underline{x}$ & & & \\
\hline Entien & & & & \\
\hline
\end{tabular}

Ficha de validación externa (forma)

\begin{tabular}{|c|c|c|c|c|c|}
\hline \multirow[t]{2}{*}{ Indicadores } & & \multirow{2}{*}{$\begin{array}{l}\text { Escala de } \\
\text { valoración }\end{array}$} & \multicolumn{3}{|l|}{ Aspectos } \\
\hline & & & Positivos & Negativos & Sugerencias \\
\hline Clanidad & $\begin{array}{l}\text { Es formulado con lenguaje } \\
\text { apropiado }\end{array}$ & $\underline{x}$ & & & \\
\hline Objetividad & $\begin{array}{l}\text { Está expresado en conductas } \\
\text { observables }\end{array}$ & $\underline{x}$ & & & \\
\hline Acturalidad & $\begin{array}{l}\text { Adecuado ol avance de la } \\
\text { ciencia nedánica }\end{array}$ & & & & \\
\hline Organización & 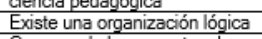 & & & & \\
\hline Suficiencia & $\begin{array}{l}\text { Comprenne los aspectos de } \\
\text { cantididad y calidad }\end{array}$ & $\underline{x}$ & & & \\
\hline Intencionalidad & $\begin{array}{l}\text { Adecuado para valorar los } \\
\text { aspectos de las cateogrias. }\end{array}$ & $\underline{x}$ & & & \\
\hline Consistencia & $\begin{array}{l}\text { Basado en aspectos teóricos } \\
\text { cientificos de la educación }\end{array}$ & $\underline{x}$ & & & \\
\hline Coherencia & $\begin{array}{l}\text { Entre el propósito, diseño y la } \\
\text { implementación de la propuesta }\end{array}$ & $\underline{x}$ & & & \\
\hline Metodologia & $\begin{array}{l}\text { La estrtategia responde al } \\
\text { propónito de la investianción }\end{array}$ & $\underline{x}$ & & & \\
\hline Pertinencia & $\begin{array}{l}\text { Es útill y adecuado para la } \\
\text { investifacíó }\end{array}$ & $\underline{x}$ & & & \\
\hline
\end{tabular}

\section{Aportes o sugerencias para el perfeccionamiento del resultado científico:}

Opinión de aplicabilidad:

Resultados

Promedio de valoración $=\frac{\text { Valoración interna+valoración externa }}{2}$

Resultado de valoración: $\frac{44+42}{2}=43$

Escala de valoración

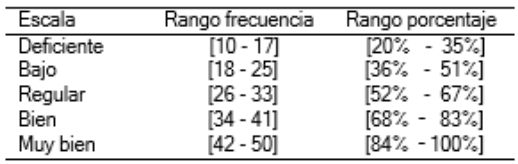

Opinión de aplicabilidad:

a) Deficiente ( ) b) Bajo ( ) c) Regular ( ) d) Bien ( ) e) Muy Bien (X

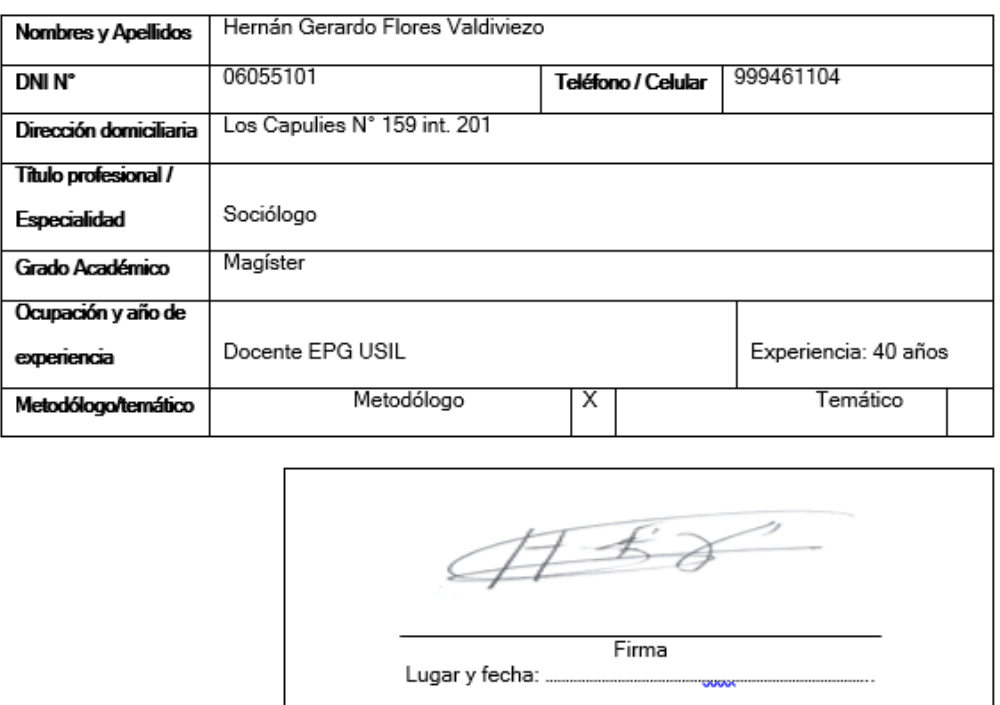


Apellidos y nombres de especialista: Muñoz Salazar José Manuel

Grado de estudios alcanzado: Doctor en Ciencias de la Educación

Resultado cientifico en valoración: Estrategia metodológica para desarrollar el aprendizaje

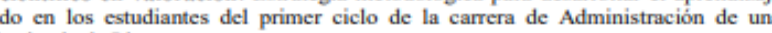

Autor del resultado cientifico: Bachiller García Álvarez Mónica Maribel

\section{Aspectos a observar}

\section{Validación interna}

\begin{tabular}{|c|c|c|c|c|c|c|}
\hline \multirow{3}{*}{\begin{tabular}{|l|} 
mollowsonom \\
$\begin{array}{l}\text { Factibilidad de aplicación del resultado que se } \\
\text { presenta. }\end{array}$
\end{tabular}} & \multirow{2}{*}{\multicolumn{3}{|c|}{ 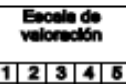 }} & \multicolumn{3}{|c|}{ Alopectosen } \\
\hline & & & & Poefitivos & Neopativon & Sugarencere \\
\hline & & & $x$ & & & \\
\hline $\begin{array}{l}\begin{array}{l}\text { Claridad de la propuesta para ser aplicado por } \\
\text { otros }\end{array} \\
\text {. }\end{array}$ & & $\mathrm{x}$ & & & & \\
\hline \begin{tabular}{|l|}
$\begin{array}{l}\text { Posibilidad de la propuesta de extension a otros } \\
\text { contextos semejantes }\end{array}$
\end{tabular} & & $\mathrm{x}$ & & & & \\
\hline 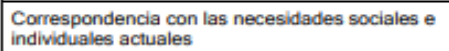 & & & $x$ & & & \\
\hline 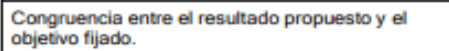 & & & $x$ & & & \\
\hline $\begin{array}{l}\text { Novedad en el uso de conoeptos y procedimientos } \\
\text { de la propuesta. }\end{array}$ & & $\mathrm{x}$ & & & & \\
\hline $\begin{array}{l}\text { La modelación contiene propósitos basados en los } \\
\text { fundamentos educativos, curriculares y } \\
\text { pedagégioos, detallado, preciso y efectivo }\end{array}$ & & & $x$ & & & \\
\hline $\begin{array}{l}\text { La propuesta está contextualizada a la realidad en } \\
\text { estudio. }\end{array}$ & & $\mathrm{x}$ & & & & \\
\hline $\begin{array}{l}\text { Presenta objetivos claros, coherentes y posibles } \\
\text { de alcanzar. }\end{array}$ & & & $\mathrm{x}$ & & & \\
\hline \begin{tabular}{|l}
$\begin{array}{l}\text { Contiene un plan de acción de lo general a lo } \\
\text { particular. }\end{array}$ \\
.
\end{tabular} & & & $|x|$ & & & \\
\hline
\end{tabular}

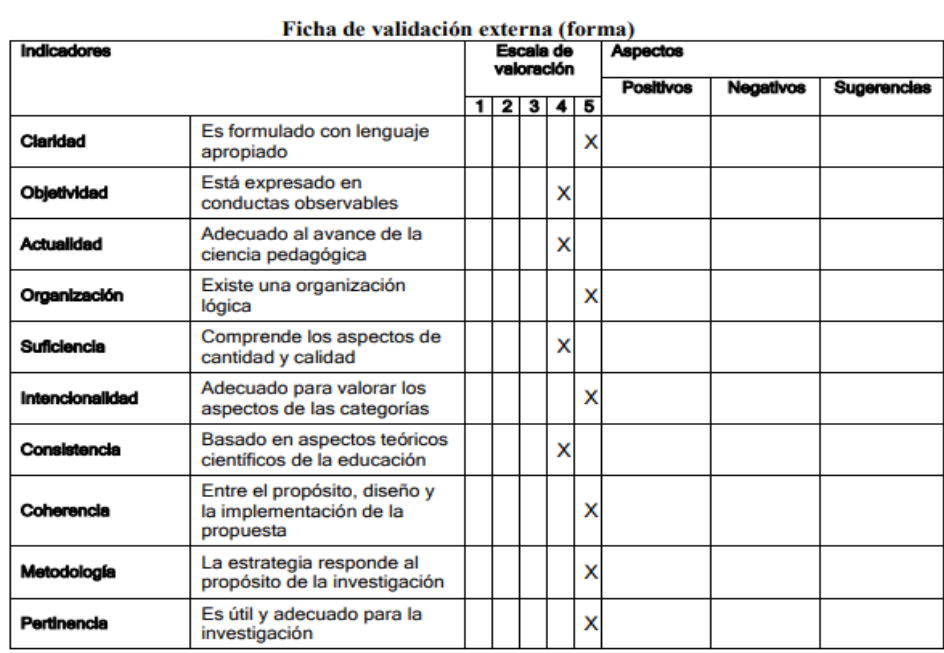

Opinión de aplicabilidad.

La propuesta de modelamiento es aplicable

$\underline{\text { Resultados }}$

romedio de valoración $=\underline{\text { Valoración interna }+ \text { valoración externa }}$

Resultado de valoración: $\frac{46+46}{2}=46$

Escala de valoración

\begin{tabular}{lcc}
\hline Escala & Rango frecuencia & Rango porcentaje \\
\hline Deficiente & {$[10-17]$} & {$[20 \%-35 \%]$} \\
Bajo & {$[18-25]$} & {$[36 \%-51 \%]$} \\
Regular & {$[26-33]$} & {$[52 \%-67 \%]$} \\
Bien & {$[34-41]$} & {$[68 \%-83 \%]$} \\
Muy bien & {$[42-50]$} & {$[84 \%-100 \%]$} \\
\hline
\end{tabular}

Opinión de aplicabilidad:

a) Deficiente ( ) b) Bajo ( ) c) Regular ( ) d) Bien ( ) Muy bien (X)

\begin{tabular}{|c|c|c|c|}
\hline \begin{tabular}{|l|} 
Nombres y Apellldos \\
\end{tabular} & José Manuel Muñoz Salazar & DNIN N & 09536793 \\
\hline \begin{tabular}{|l|} 
Direcclón domlclllarla \\
\end{tabular} & & Teleffono/Colular & \\
\hline \begin{tabular}{|l|} 
Thulo profoslonal/ \\
Eapeclalldad
\end{tabular} & Ingeniero Electrónico & & \\
\hline Grado Académlco & Doctor en Ciencias de la Educación & & \\
\hline \begin{tabular}{|l}
$\begin{array}{l}\text { Ocupeclón y a afo de } \\
\text { experiencla }\end{array}$ \\
\end{tabular} & Docente 35 años de experiencia & & \\
\hline Metodólogo/temético & Metodólogo & & \\
\hline
\end{tabular}

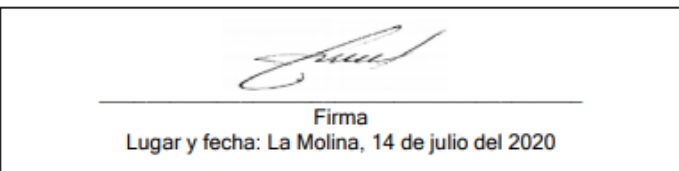


Datos generales.

Apellidos y nombres de especialista: María Teresa Herrera Montoya

Grado de estudios alcanzado: Magister

Resultado científico en valoración: Estrategia metodológica para desarrollar el

aprendizaje autorregulado en los estudiantes del primer ciclo de la carrera de

dministracion de una universidad privada de Lima.

Autor del resultado científico: Mónica Maribel García Álvarez

Aspectos a observar

\section{Validación interna}

\begin{tabular}{|c|c|c|c|c|c|c|}
\hline \multirow{2}{*}{ indicadores } & \multirow{2}{*}{\multicolumn{3}{|c|}{$\begin{array}{l}\text { Escala de } \\
\text { valoración } \\
1|2| 3 \mid\end{array}$}} & \multirow{2}{*}{$\begin{array}{l}\text { Aspectos } \\
\text { Positivos }\end{array}$} & \multirow[b]{2}{*}{ Negativos } & \multirow[b]{2}{*}{ Sugerencias } \\
\hline & & & & & & \\
\hline & & $\underline{x}$ & & & & $\begin{array}{l}\text { Sensibilización a } \\
\text { doestes }\end{array}$ \\
\hline Claridad de la propuesta para ser aplicado por otros & & & $\underline{x}$ & & & \\
\hline $\begin{array}{l}\text { Posibilidad de la propuesta de extensión a otros } \\
\text { contextos semeiantes }\end{array}$ & & & $\underline{\underline{x}}$ & & & \\
\hline $\begin{array}{l}\text { Correspondencia con las necesidades sociales e } \\
\text { individuales actuales }\end{array}$ & & & $\underline{x}$ & & & \\
\hline $\begin{array}{l}\text { Congruencia entre el resultado propuesto y el objetivo } \\
\text { fijado. }\end{array}$ & & & $\underline{x}$ & & & \\
\hline $\begin{array}{l}\text { Novedad en el uso de conceptos y procedimientos de la } \\
\text { propuesta. }\end{array}$ & & $\underline{x}$ & & & & \\
\hline $\begin{array}{l}\text { La modedelacićn contiene propósitos basados en los } \\
\text { fundamentos eductativos, uursiculares y pedagógicos. } \\
\text { detallado, preciso y efectivo }\end{array}$ & & & $\underline{x}$ & & & \\
\hline $\begin{array}{l}\text { La propuesta está contextualizada a la realidad en } \\
\text { estudio. }\end{array}$ & & & $\underline{x}$ & & & \\
\hline $\begin{array}{l}\text { Presenta objetivos claros, coherentes y posibles de } \\
\text { alcanzar. }\end{array}$ & & & $\underline{x}$ & & & \\
\hline
\end{tabular}

Ficha de validación externa (forma)

\begin{tabular}{|c|c|c|c|c|c|}
\hline \multicolumn{2}{|l|}{ Indicadores } & \multirow{2}{*}{$\begin{array}{l}\text { Escala de } \\
\text { valoración }\end{array}$} & \multicolumn{3}{|l|}{ Aspectos } \\
\hline & & & Positivos & Negativos & Sugerencias \\
\hline Clanidad & $\begin{array}{l}\text { Es formulado con lenguaje } \\
\text { apropiado }\end{array}$ & & $\underline{\underline{x}}$ & & \\
\hline Objetividad & $\begin{array}{l}\text { Está expresado en conductas } \\
\text { observables }\end{array}$ & & $\underline{\underline{x}}$ & & \\
\hline Actualidad & $\begin{array}{l}\text { Adecuado al avance de la } \\
\text { ciencia pedagógica }\end{array}$ & & $\underline{x}$ & & \\
\hline \begin{tabular}{|l} 
Organización \\
\end{tabular} & \begin{tabular}{|l} 
Existe una organización lógica \\
\end{tabular} & & $\underline{x}$ & & \\
\hline \begin{tabular}{|l|} 
Suficiencia \\
\end{tabular} & $\begin{array}{l}\text { Comprende los aspectos de } \\
\text { cantidad y calidad }\end{array}$ & & $\underline{\underline{x}}$ & & \\
\hline Intencionalidad & \begin{tabular}{|l|} 
Adecuado para valorar los \\
aspectos de las categorías
\end{tabular} & & $\underline{x}$ & & \\
\hline Consistencia & \begin{tabular}{|l} 
Basado en aspectos teóricos \\
científicos de la educación
\end{tabular} & & $\underline{x}$ & & \\
\hline \begin{tabular}{|l|} 
Coherencia \\
\end{tabular} & $\begin{array}{l}\text { Entre el propósito, diseño y la } \\
\text { implementación de la propuesta }\end{array}$ & & $\underline{\underline{x}}$ & & \\
\hline Metodologia & $\begin{array}{l}\text { La estrategiair responde al } \\
\text { propósito de la investigación }\end{array}$ & & $\underline{x}$ & & \\
\hline Pertinencia & $\begin{array}{l}\text { Es útily y adecuado para la } \\
\text { investigación }\end{array}$ & & $\underline{x}$ & & \\
\hline
\end{tabular}

Aportes o sugerencias para el perfeccionamiento del resultado científico:

Considerar que la coyuntura nos llevó al mundo digital a docentes y estudiantes, y según opiniones de expertos, después de esta situación, nada será igual en ningún contexto, incluyendo el educativo, por tal, en la conclusión del estudio debe quedar abierta la posibilidad de que la propuesta podrá ajustarse al dictado de clases de forma sincrónica y retroalimentación asincrónica.

Opinión de aplicabilidad: En modalidad presencial sensibilizando, docentes propuesta es factible de ser aplicada, requiere de cambios de actitudes docentes para que en el dictado de clases tengan una mirada diferente al estudiante.

\section{Resultados}

Promedio de valoración $=\frac{\text { Valoración internatvaloración externa }}{2}$

Resultado de valoración: $48+50 / 2=49$

Escala de valoración

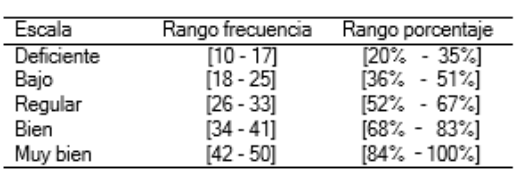

\section{Opinión de aplicabilidad:}

a) Deficiente ( ) b) Bajo ( ) c) Regular ( ) d) Bien ( ) e) Muy Bien (X)

\begin{tabular}{|c|c|c|c|}
\hline Nombres y Apellidos & María Teresa Herrera Montoya & DNI N ${ }^{\circ}$ & 25600207 \\
\hline Dirección domiciliaria & $\begin{array}{l}\text { Jr. Las Aguilas } 284 \text { San Joaquín } \\
\text { Bellavista Callao. }\end{array}$ & Teléfono/Celular & 966948837 \\
\hline $\begin{array}{l}\text { Thulo profesional/ } \\
\text { Especialidad }\end{array}$ & \multicolumn{3}{|l|}{ Licenciada en Ciencias de la Educación } \\
\hline Grado Académico & \multicolumn{3}{|l|}{ Maestra en Psicopedagogía } \\
\hline $\begin{array}{l}\text { Ocupación y año de } \\
\text { experiencia }\end{array}$ & Docente & \multicolumn{2}{|c|}{ Experiencia: 33 años } \\
\hline Metodólogoftemático & Metodólogo & Temático & $x$ \\
\hline
\end{tabular}

$\frac{\text { Tumers }}{\frac{\text { Firma }}{\text { Lugar y fecha: bellavista } 19 \text { de julio } 2020}}$




\section{Anexo 6 - Documentos del trabajo de campo}

\section{Entrevistas a los docentes}

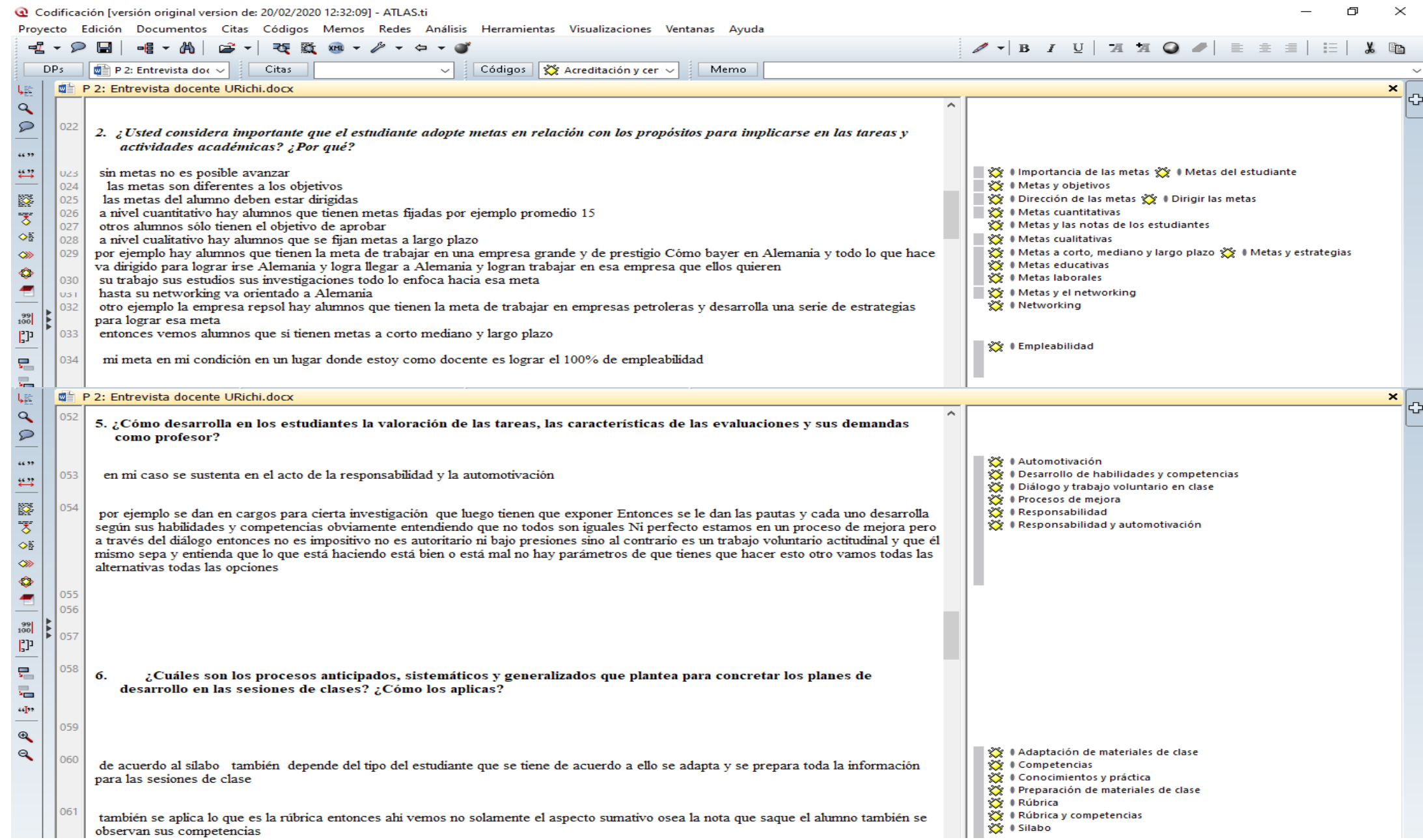




\section{Observación de clases}

A Codificación [versión original version de: 20/02/2020 12:32:09] - ATLAS.t

mientas Visualizaciones ventanas Ayuda

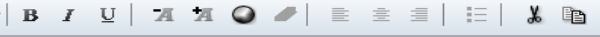

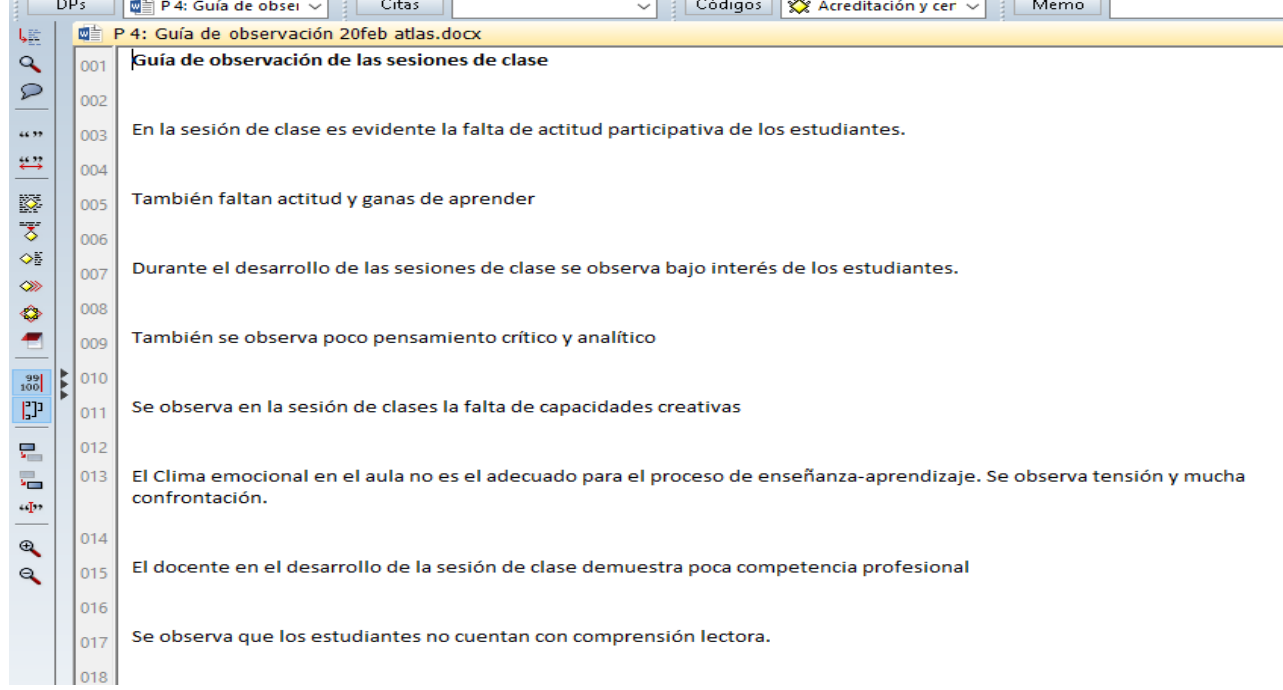


¿Usted demuestra capacidad en el procesamiento de información del tema que desarrolla en la sesión de clase?

— Pocas veces nunca Casi siempre

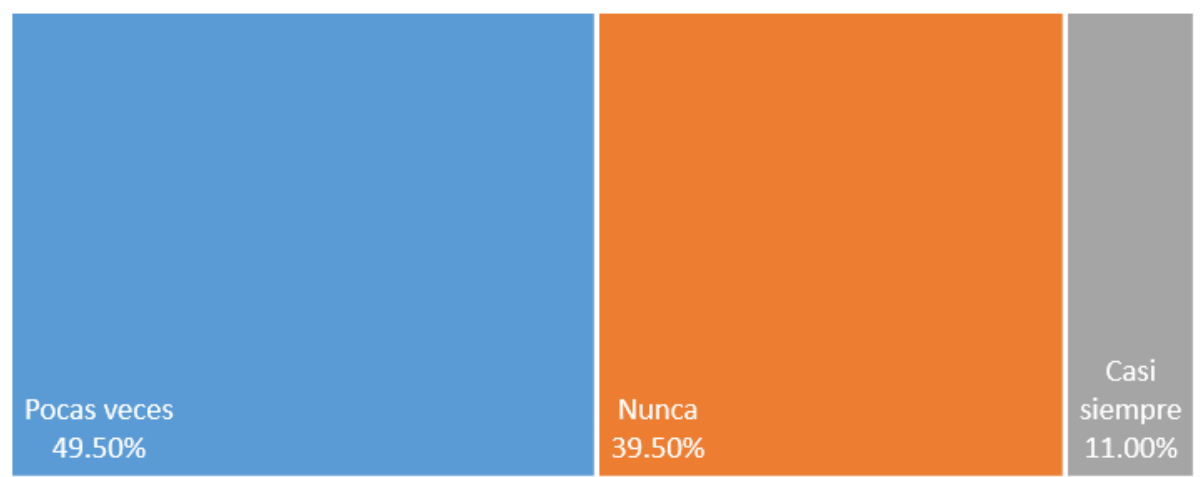

¿El docente permite esclarecer las estrategias de repaso, elaboración y organización?

Pocas veces $\quad$ Nunca $\quad$ Casi siempre

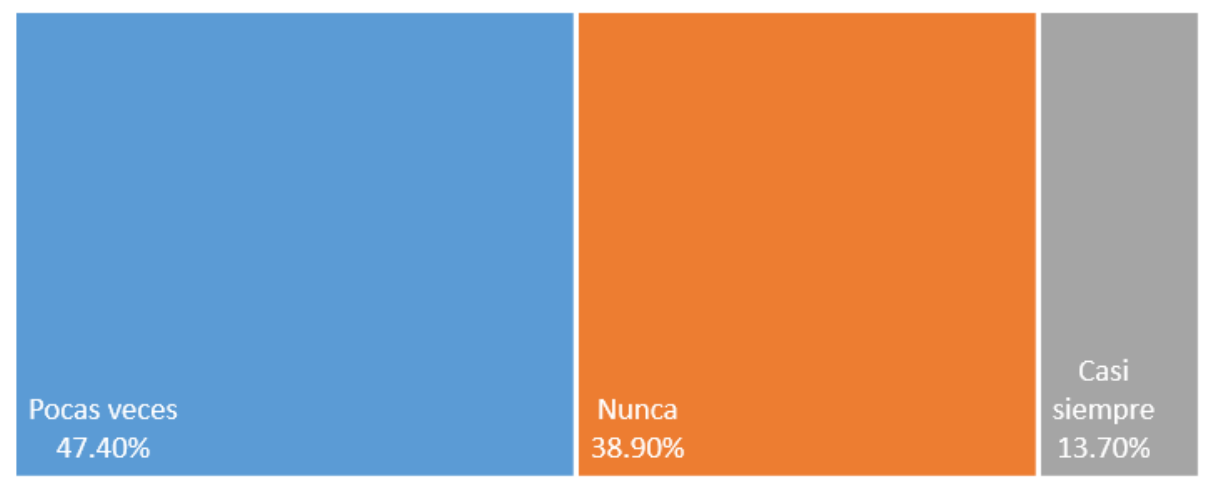

¿Usted acostumbra adoptar metas en relación con los propósitos para implicarse en las tareas y actividades académicas?

Pocas veces nunca Casi siempre

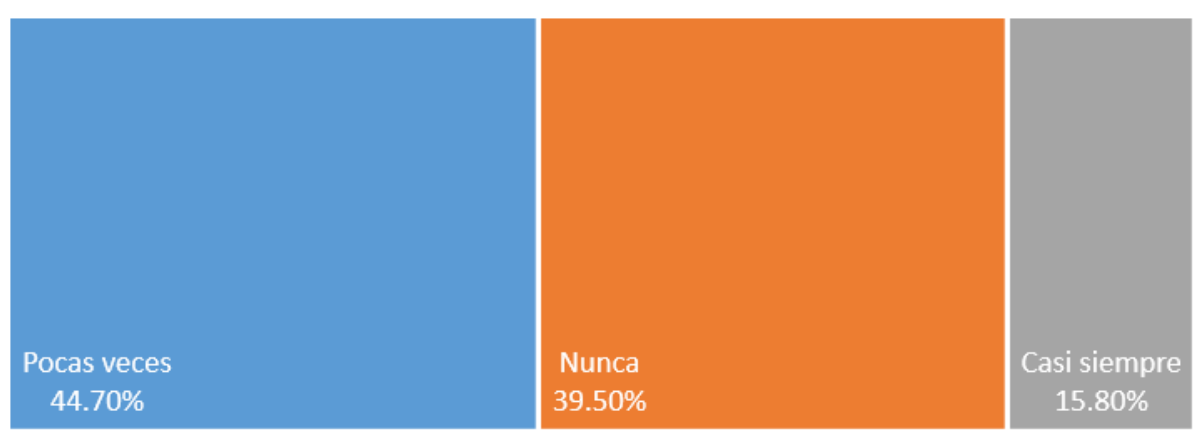




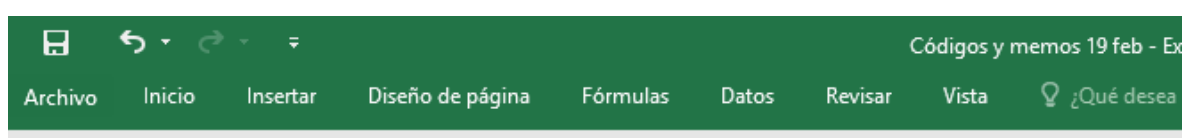

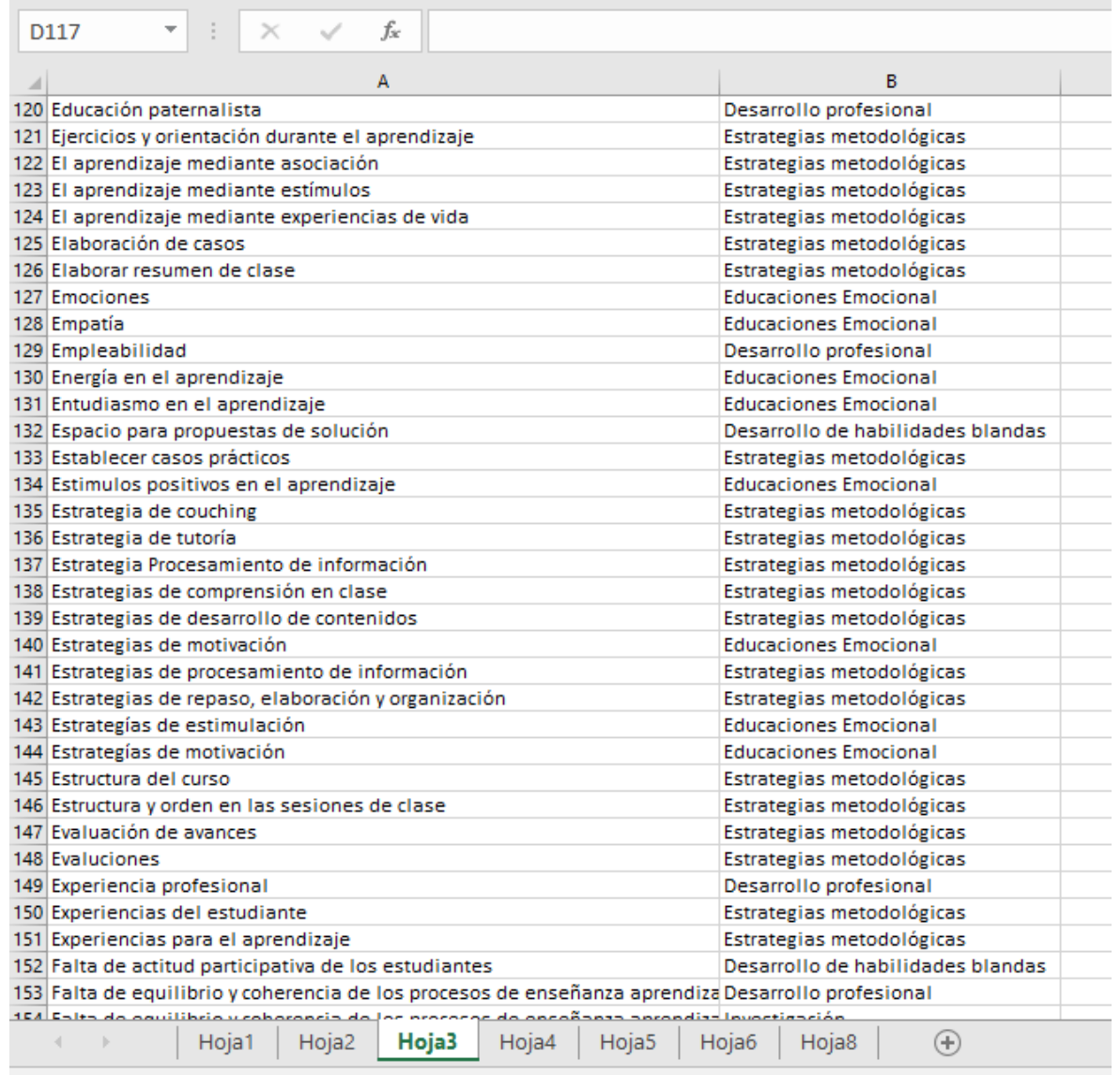

\# Escribe aquí para buscar

㟔 (6)

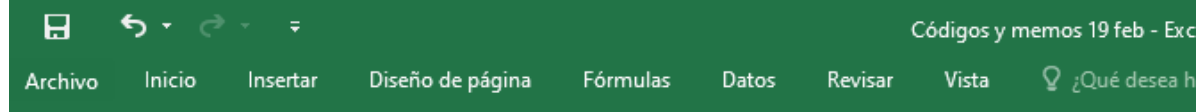

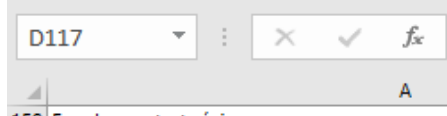

159 Fundamento teórico

160 Fundamento teórico
161 Habilidades comunicativas

162 Habilidades sociales

164 importancia del diálogo

165 Investigación

165

167 Investigación formativa

168 Investigacón

169 Lectura rigurosa y comprensiva.

170 Liderazgo

171 Los docentes y la motivación de los estudiantes

172 Los estudiantes y sus autoridades

173 Manejo de emociones

174 Materiales didácticos

175 Materiales fisicos y digitales

176 Mecanismos de soporte de actualidad

177 Metas a corto, mediano y largo plazo

178 Metas cualitativas

179 Metas cuantitativas

180 Metas da sentido

181 Metas del estudiante

182 Metas dotan motiva

184 Metas establecen rumbo

185 Metas laborales

186 Metas yel networkin

188 Metas y las notas de los estudiantes

189 Metas y objetivos

190 Metodología experiencial y dialógica

191 Metodología psicológica

192 Método casuística

B

Investigación

ensamiento crítico $y$ analítico Desarrollo de habilidades blandas Aprendizaje autorregulado

Desarrollo de habilidades blandas

Investigación

Investigación

Investigación
Investigación

Estrategias metodológicas

Desarrollo de habilidades blandas

Educaciones Emocional

Aprendizaje autorregulado

Educaciones Emocional

Estrategias metodológicas

Estrategias metodológicas

Estrategias metodológicas

Aprendizaje autorregulado

Aprendizaje autorregulado

Aprendizaje autorregulado

Aprendizaje autorregulado

Aprendizaje autorregulado

Aprendizaje autorregulado

Aprendizaje autorregulado

Aprendizaje autorregulado

Aprendizaje autorregulado

Aprendizaje autorregulado

Aprendizaje autorregulado

Aprendizaje autorregulado

Estrategias metodológicas

Estrategias metodológicas

Estrategias metodológicas

Hoja6 | Hoja8 | 


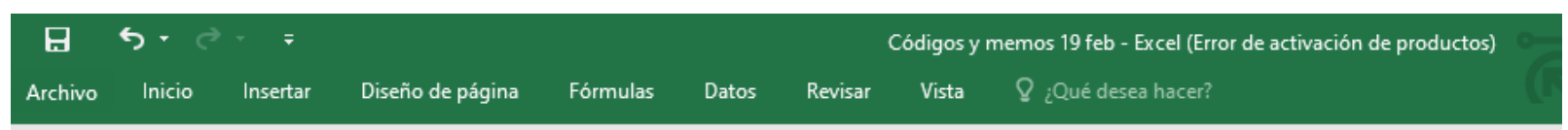

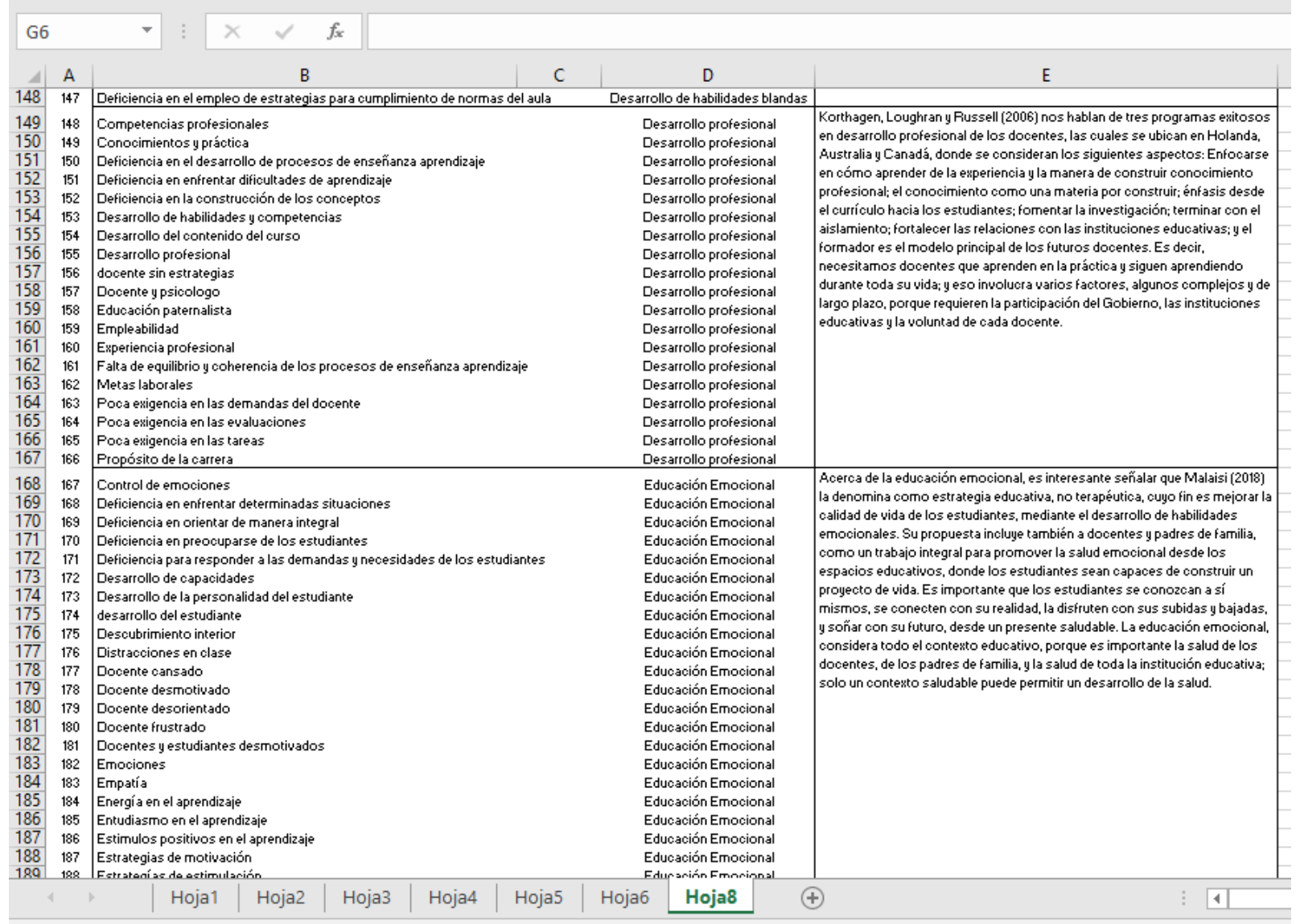

Listo

Escribe aquí para buscar

㟔 (日) 


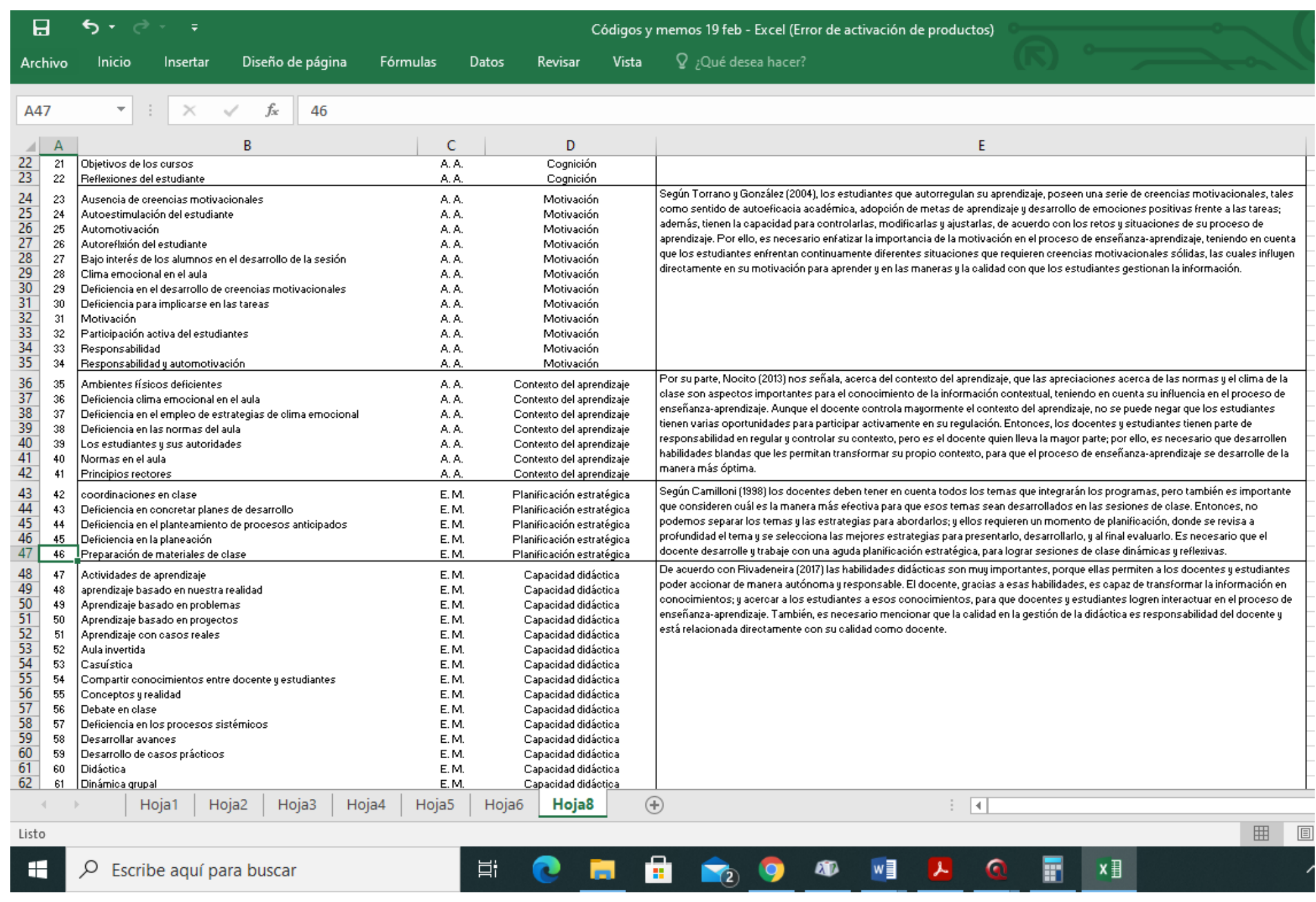

